NBER WORKING PAPER SERIES

\title{
IMMIGRATION, INNOVATION, AND GROWTH
}

\author{
Konrad B. Burchardi \\ Thomas Chaney \\ Tarek Alexander Hassan \\ Lisa Tarquinio \\ Stephen J. Terry \\ Working Paper 27075 \\ http://www.nber.org/papers/w27075 \\ NATIONAL BUREAU OF ECONOMIC RESEARCH \\ 1050 Massachusetts Avenue \\ Cambridge, MA 02138 \\ May 2020, Revised November 2021
}

We are grateful to Ran Abramitzky, Daron Acemoglu, David Autor, David Atkin, Murat Celik, William Kerr, Klaus Desmet, Ray Fisman, Lisa Kahn, Kevin Lang, Ethan Lewis, Ömer Özak, Michael Peters, Chris Tonetti, and Pascual Restrepo for helpful comments. We also thank seminar participants at AEA Annual Meeting, the University of California San Diego, University of Toronto, Imperial College London, the Federal Reserve banks of Boston, Philadelphia, and Richmond, Southern Methodist University, University of Toronto, Goethe University Frankfurt, Duke, Princeton, the University of Chicago, the University of Southern California, London Business School, the Wharton Conference on Migration, and the NBER EFG, EFEG, and PRMP group meetings. Chaney is grateful for financial support from ERC grant $\mathrm{N}^{\circ} 337272$-FiNet. All remaining mistakes are our own. This paper is dedicated to the memory of Dr. Sherif A. Hassan. The views expressed herein are those of the authors and do not necessarily reflect the views of the National Bureau of Economic Research.

NBER working papers are circulated for discussion and comment purposes. They have not been peer-reviewed or been subject to the review by the NBER Board of Directors that accompanies official NBER publications.

(C) 2020 by Konrad B. Burchardi, Thomas Chaney, Tarek Alexander Hassan, Lisa Tarquinio, and Stephen J. Terry. All rights reserved. Short sections of text, not to exceed two paragraphs, may be quoted without explicit permission provided that full credit, including $(\mathbb{C}$ notice, is given to the source. 
Immigration, Innovation, and Growth

Konrad B. Burchardi, Thomas Chaney, Tarek Alexander Hassan, Lisa Tarquinio, and Stephen

J. Terry

NBER Working Paper No. 27075

May 2020, Revised November 2021

JEL No. J61,O31,O40

\section{ABSTRACT}

We show a causal impact of immigration on innovation and growth in US counties. To identify the causal impact of immigration, we use 130 years of detailed data on migrations from foreign countries to US counties to isolate quasi-random variation in the ancestry composition of US counties; interacting this plausibly exogenous variation in ancestry composition with the recent inflows of migrants from different origins, we predict the total number of migrants flowing into each US county in recent decades. We show immigration has a positive causal impact on innovation, measured as patenting of local firms, and on economic growth, measured as real income growth for native workers. We interpret those results through the lens of a quantitative model of endogenous growth and migrations. A structural estimation of this model targeting the well identified causal impact of migration on innovation suggests the large inflow of foreign migrants into the US since 1965 may have contributed to an additional 8\% growth in innovation and $5 \%$ growth in wages.

Konrad B. Burchardi

Institute for International Economic Studies

Stockholm University

SE-106 91 Stockholm

Sweden

konrad.burchardi@iies.su.se

Thomas Chaney

Sciences Po

28 rue des Saints Peres

75005 Paris

France

thomas.chaney@gmail.com

Tarek Alexander Hassan

Department of Economics

Boston University

270 Bay State Road

Boston, MA 02215

and NBER

thassan@bu.edu
Lisa Tarquinio

Department of Economics

University of Western Ontario

London, Onta

Canada

LTarqui@uwo.ca

Stephen J. Terry

Department of Economics

Boston University

270 Bay State Road

Boston, MA 02215

and NBER

stephenjamesterry@gmail.com 


\section{Introduction}

Does immigration cause more or less innovation and growth? In this paper, we answer this question in the context of international migration to the US over the last three decades. We find a positive causal impact of immigration on both innovation and growth at the local level (US counties) over a short horizon (five-year periods) and interpret these findings through the lens of a model of endogenous growth and migrations.

Canonical theories of economic growth suggest a role for immigrants in driving local economic outcomes. When immigrants bring ideas, skills, and effort into the research process, or stimulate demand for new inventions, they also stimulate growth according to the logic of a range of endogenous growth models (Romer, 1990; Jones, 1995). In the presence of frictions on mobility, trade, or idea flows, another set of models of regional economic development suggest immigrants should have local, not just aggregate, effects on innovation and wages (Desmet et al., 2018; Peters, forthcoming). In contrast to these predictions, fierce political controversies surround the economic contribution of migrants: are the new arrivals draining resources of their host communities and stifling innovation?

A rigorous quantification of the causal impact of immigration on innovation and growth has often proven difficult. The reason is that migrants do not allocate randomly across space, but instead are likely to choose destinations that offer the best prospects for them and their families. Migrants arriving in the US might therefore select into more innovative regions, creating a spurious correlation between local immigration, innovation, and economic growth.

We make three main contributions to the literature on immigration and growth. First, we propose a formal identification strategy allowing us to estimate the causal impact of migrations on local innovation and economic growth at a highly granular level. To do so, we build upon the seminal contribution of Card (2001) but add one key innovation: instead of using the realized pre-existing distribution of foreign origins to predict new migrations, we construct a granular set of instruments for this distribution, using 130 years of country-county-level migration data. Second, using our newly constructed panel dataset of exogenous county-level immigration shocks, we show that immigration causes a large and significant increase in local innovation. Third, we combine this credibly identified disaggregated evidence with a quantitative regional model of endogenous innovation and migrations to structurally estimate the local elasticity of innovation to research labor. This key elasticity determines both the size of local scale effects (and thus the distribution of idea production across space) and the aggregate response to large-scale immigration shocks. We also use our model to clarify the impact of immigration 
shocks on wages and reveal why our empirical identification strategy is less likely to suffer from endogeneity concerns than existing methods.

We now turn to a more detailed description of our three main contributions. Our first contribution is a granular identification strategy able to isolate quasi-random immigration shocks for each US county in each five-year period starting in 1975. As in the canonical shift-share approach, we rely on the tendency of newly arriving migrants to settle in US counties with large pre-existing communities of the same origin. But instead of using past realized immigration (Card, 2001) or ancestry shares (Tabellini, 2019) to measure the pre-existing distribution of foreign origins, we instrument for the pre-existing ancestry distribution (Burchardi et al., 2019). Doing so, we guard against the potential concern that where migrants settle within the US, both in recent decades (the distribution of immigrants) and in the more distant past (the distribution of ancestry), may be correlated with unobserved factors that also affect local innovation and growth. ${ }^{1}$

To isolate quasi random immigration shocks, we proceed in two steps. In a first step, we follow the method in Burchardi et al. (2019) to construct a set of instruments for the pre-existing distribution of foreign ancestry in 1975. This method leverages granular variation in relative historical migrations that are exclusively attributable to the historical coincidence between the timing of migrations from different foreign countries and the timing of the relative attractiveness of different US counties. For each period starting in 1880, we predict the number of migrants from a given origin country to a given destination county by interacting the total number of migrants arriving in the US from that country with the share of foreign migrants from other origins who settle in that US county. In particular, because our focus is on immigration to the US after 1975, primarily originating from non-European countries, we use the historical location choices of European migrants to predict where non-European migrants settled in each period prior to 1975. Iterating this procedure over 100 years, we isolate quasi-random variation in the distribution of ancestry across US counties in 1975.

In a second step, we follow the canonical shift-share approach: for each period starting in 1975, we estimate migration into a county from a foreign origin country using only the interaction of predicted pre-1975 ancestry and the contemporaneous inflow of migrants from that

\footnotetext{
${ }^{1}$ David Card himself notes that past immigration shares may be endogenous (Card, 2001, p. 43), and a large literature has since highlighted inference and consistency issues arising from this core issue (e.g. Adão et al., 2019; Borusyak et al., 2021; Goldsmith-Pinkham et al., 2020; Jaeger et al., 2018). David Card further states "[o]ne could potentially overcome this problem by finding a set of instruments that explain the location choices of earlier immigrants from different source countries and using predicted settlement patterns of the earlier cohort to construct the supply push indexes." This is precisely the task we undertake in this paper.
} 
origin. For example, we predict a US county on the West Coast will receive a large immigration shock post-1975 if that US county attracted a large number of European migrants in a pre-1975 period when a relatively large number of Indians were arriving in the US, excluding that county and the surrounding West Coast region, controlling for country $\times$ region and county $\times$ continent interacted fixed effects (large predicted pre-1975 Indian ancestry relative to other Asian countries, and relative to other West Coast counties), and many Indians arrive in the US post-1975. Summing over all countries, we predict the total number of migrants flowing into each US county at each point in time post 1975 (our panel of immigration shocks).

To further guard against any lingering concerns about identification, all of our specifications estimate the impact of immigration shocks on changes in local innovation and growth, not on levels. In many specifications, we are even able to include county fixed effects, thus controlling for any county-specific trend in innovation.

Our second contribution is to quantify the causal impact of immigration on innovation and growth in reduced form. We find a positive and significant causal impact of local immigration on the number of local patents filed per person: on average, the arrival of 10,000 additional immigrants in a county (close to one standard deviation) increases the flow of patents over a five-year period by 1.15 patents per 100,000 residents, an increase of $21 \%$ relative to its mean (5.53 new patents per 100,000 residents). ${ }^{2}$ Immigration also causes a significant increase in local real income growth, with 10,000 additional adult immigrants adding an extra $\$ 290$ to wages (in 2010 dollars), a 15\% higher annual wage growth for local workers on average.

This positive effect of immigration on innovation and growth diffuses over space. If more migrants settle in counties near $d$, innovation in $d$ increases significantly. This spatial diffusion dies out quickly with distance. Compared to the direct effect of immigration in a county, the indirect effect is $27 \%$ smaller for immigration within $100 \mathrm{~km}$ (60 miles), $81 \%$ smaller between $100 \mathrm{~km}$ and $250 \mathrm{~km}$ (150 miles), and statistically indistinguishable from zero beyond.

The effect of immigration on innovation and growth is also stronger for more educated migrants: low education migrants (bottom third of the distribution of schooling among migrants) have no detectable impact on local innovation, the impact of medium educated migrants (middle third) is about half of that for the average migrant, and the impact of high education migrants (top third) is an order of magnitude larger than for the average migrant. To reach

\footnotetext{
${ }^{2}$ We show that while a conventional instrument using the realized composition of foreign origins (Card, 2001) suffers from over-rejection typical of shift-share designs (Adão et al., 2019), our method instrumenting for preexisting foreign origins does not. We also show that contemporaneous immigration shocks have no impact on past innovation, only on future innovation, with a cumulative effect that plateaus after 15 years.
} 
that conclusion, we use our identification strategy to construct separate instruments for migrations from each foreign country to each US county at each point in time, leveraging the fact that migrants' education varies between countries and over time.

Our third contribution is to construct a structural model of endogenous growth and migrations, which we use to estimate the elasticity of local innovation to research labor and to illustrate the challenges to reduced-form identification that arise in this context. In the model, migrants endogenously choose where to settle within the US, preferring destinations with higher wages and larger pre-existing communities of the same origin. Workers in local labor markets innovate and produce goods. An immigration shock, a positive labor supply shock, depresses local wages initially but also induces more innovation, which in turn increases the productivity of local labor and wages over time.

We structurally estimate our model, targeting the well identified reduced form effect of immigration on local innovation. We estimate an elasticity of local research output with respect to local research labor equal to 0.86 . In addition to governing the distribution of idea production across regions, this elasticity also crucially disciplines the magnitude of the aggregate response to immigration shocks. To illustrate this response, we conduct a counterfactual experiment, removing the large rise in immigration to the US after the 1965 Immigration National Act (an increase of approximately $1 / 6$ of total population growth in the data). This exercise shows that immigration to the US from 1965 to 2010 may have driven a gradual increase in per capita patenting of $8 \%$ and in wages and output per worker of $5 \%$.

Because migrations are endogenous in our model, we can also use our simulated model's data to explicitly show that the identification restriction for a simple shift-share instrument for immigration as used by Card (2001), as well as variations of this approach developed in the more recent literature, are violated: a positive productivity shock increases wages and attracts migrants; because local productivity shocks are persistent, the pre-existing distribution of foreign origins strongly correlates with contemporaneous productivity shocks for long periods of time. In contrast, within our model, our identification strategy generates instruments that are orthogonal to such shocks and even guard against more subtle, county-country specific confounds to identification.

Related Literature. Our paper contributes to several strands of the literature.

First, macroeconomic theories of endogenous growth predict strong positive impacts of overall population growth on economic growth and innovation (Romer, 1990), with the nature of 
these scale effects depending upon the technology for producing ideas and the horizon of analysis (Jones, 1995, 1999; Peretto, 1998; Young, 1998; Laincz and Peretto, 2006; Bloom et al., 2020). Our empirical work can be thought of as a reduced-form test and a structural quantification of these predictions, in the sense that immigration constitutes a large part of regional population growth in the US. However, we also differ from this literature because of our initial empirical focus on the local, rather than the aggregate, response of innovation to research labor. In this sense, our evidence relates to a burgeoning set of theories of the spatial distribution of economic growth which also tend to predict a positive impact of immigration on local innovation and economic dynamism. ${ }^{3}$ The exact nature of the local effects of immigration differ in such models based on the type and extent of frictions on mobility, trade, and idea diffusion. Some theories emphasize limits to labor mobility and local market size (Desmet et al., 2018), others tease out subtle distinctions between the long-run and short-run effects of migration (Peters, forthcoming), some link migration frictions to traditional gravity relationships across regions (Monte et al., 2018), and still others emphasize inequality across regions (Giannone, 2019). However, the quantitative predictions of these models for the mean and distribution of local growth uniformly rely on the size of the local scale effect in innovation. Instead of disciplining this object by matching moments of income growth, the usual approach, we instead structurally estimate its value based on our direct empirical estimates of the link between labor supply and local innovation outcomes. A notable recent exception is Arkolakis et al. (2020), who estimate the impact of European immigration on US innovation 1880-1920, using our exogenous immigration shocks, and calibrate a model of endogenous growth. Our aggregate counterfactual exercises also show that local scale effects in innovation govern the aggregate response of growth for the economy as a whole to immigration shocks. In this sense, our use of credibly identified disaggregated empirical variation to discipline not only local but also aggregate magnitudes in an equilibrium model links to a growing literature in macroeconomics focused on the use and interpretation of regional evidence (Nakamura and Steinsson, 2014; Guren et al., 2021).

Second, we contribute to a growing empirical literature on the link between immigration,

\footnotetext{
${ }^{3}$ Note that although our empirical and theoretical focus is mostly on net innovation outcomes such as patenting and wage changes, a rich class of Schumpeterian growth models would link such net innovation measures directly to churn, gross flows, and dynamism through creative destruction mechanisms (Aghion and Howitt, 1992; Grossman and Helpman, 1991; Klette and Kortum, 2004). Recent empirical evidence suggests that US dynamism has declined (Decker et al., 2014; Hathaway and Litan, 2014; Alon et al., 2018), with multiple causal mechanisms explored in recent papers (Akcigit and Ates, 2021; Aghion et al., 2019; Gordon, 2012; Karahan et al., 2019; Hopenhayn et al., 2018; Walsh, 2019; Peters and Walsh, 2021). Consistent with this view, our estimates in Appendix Table 1 imply that a one standard deviation local immigration shock increases gross county-level job creation and destruction rates by around 2 percentage points.
} 
innovation, and technology adoption. Different branches of this literature have documented large contributions of high-skilled immigrants to innovation in the US (Kerr and Lincoln, 2010; Hunt and Gauthier-Loiselle, 2010; Stuen et al., 2012; Akcigit et al., 2017; Arkolakis et al., 2020), spillovers from the arrival of high-skilled scientists and inventors on the productivity of their American peers (Borjas and Doran, 2012; Moser et al., 2014; Bernstein et al., 2018), and the contribution of migrants to the diffusion of knowledge across borders (Kerr, 2008). ${ }^{4}$ Our results show the positive impact of immigration on innovation is not solely driven by the most educated migrants. Lewis (2011) and Lafortune et al. (2019) study the effect of immigration on local technology adoption, whereas Tabellini (2019) shows positive effects of immigration on output and employment. Khanna and Lee (2018) show a positive association between highskilled migration and firm-level measures of dynamism. Many of these studies use variants of the canonical shift-share instrument (Card, 2001) that takes pre-existing foreign-origin shares as given. Consistent with our structural model linking local innovation to local productivity shocks and to the endogenous presence of particular ethnicities, this approach has recently been shown to lead to bias and over-rejection in a number of different contexts (Borusyak et al., 2021; Goldsmith-Pinkham et al., 2020; Adão et al., 2019). We contribute to this literature by isolating exogenous variation in the pre-existing spatial distribution of ancestry and using this variation to construct plausibly exogenous immigration shocks to US counties in recent decades.

Closely related to our own work, Sequeira et al. (2020) develop an alternative to the canonical shift-share approach using the gradual expansion of US railroads 1850-1920 for identification. Complementary to our finding of a positive impact of immigration on growth in the short-run (over 5 or 10 years), they document positive long-term effects of European immigration to the US between 1850-1920 on local economic development that persists to the present day.

The remainder of this paper is structured as follows. Section 2 introduces our data. Section 3 lays out our strategy for identification and isolates quasi-random immigration shocks to US counties. Section 4 estimates the causal effect of immigration on innovation and growth. Section 5 tests for geographic spillovers in the effect of immigration on innovation and disentangles the impact of high- versus low-skilled migration. Section 6 builds and structurally estimates a quantitative regional model of endogenous innovation and migrations. Section 7 concludes.

\footnotetext{
${ }^{4}$ Hanson (2009, 2010) and Lewis (2013) provide early surveys. Lewis and Peri (2015) and Abramitzky and Boustan (2017) give an overview of the broader literature on the effect of immigration on regional economies.
} 


\section{Data}

We collect detailed data on migration, ancestry, the education level of migrants, patents issued, and measures of dynamism of local firms and local labor markets. Throughout the paper, we use the subscripts $o$ for foreign origin country, $d$ for US domestic destination county, $t$ for the end year of a 5 -year interval, and $t-1$ for the end year of the previous 5-year interval. Further details on the construction and sources of the data are given in Appendix A.

Immigration and Ancestry. Following Burchardi et al. (2019), our immigration and ancestry data are constructed from the individual files of the Integrated Public Use Microdata Series (IPUMS) samples of the 1880, 1900, 1910, 1920, 1930, 1970, 1980, 1990, and 2000 waves of the US census, and the 2006-2010 five-year sample of the American Community Survey. We weigh observations using the personal weights provided by these data sources. $I_{\text {odt }}$ is the number of respondents who immigrated from $o$ to $d$ between $t-1$ and $t$. $A_{o d t}$ is the number of respondents in $d$ who claim ancestry from $o$ at $t$. Our dyadic dataset covers 3,141 US counties, 195 foreign countries, and 10 census waves. Appendix A.1 gives additional details.

Innovation. To measure innovation we use patent microdata provided by the US Patent and Trademark Office (USPTO) from 1975 until 2010. We match the patent assignee locations provided by the USPTO in coordinate form to 2010 US counties, tabulating the number of corporate utility patents granted to assignees in each county in each year of the sample, and then use area weights to transition to 1990 US counties. ${ }^{5}$ The patent flow in county $d$ at $t$ is the sum of patents in each year form $t-1$ to $t$. We normalize by the 1970 county population. The change in the flow of patents per capita from period $t-1$ to $t$ in $d$ is our primary outcome of interest. Appendices A.2 and A.3 give additional details.

Wages. We compute from 1975 to 2010 the local average annual wages deflated using the Personal Consumption Expenditure price index from the Quarterly Census of Wages (QCEW) dataset provided by the US Bureau of Labor Statistics. The change in real wages per capita over a 5-year period is our primary outcome of interest. We also compute the change in the average annual wages, CPI-deflated, for US-born working individuals (natives) and the subset of natives who have lived in their county of residence for the past five years (native non-movers)

\footnotetext{
${ }^{5}$ We use the location of assignees rather than innovators as the majority of recent patents are assigned to corporations, unlike in earlier periods (Akcigit et al., 2017). For robustness, we also replicate our results using alternative assignments, and various weights to control for quality (Hall et al., 2001)
} 
using data from IPUMS USA. This measure is only available at a 10-year frequency. Appendix A.4 gives additional details.

Economic Dynamism. We supplement our analysis with data on local economic dynamism. From the US Census Business Dynamism Statistics (BDS) database, we compute over 19772015 the job creation and job destruction rates, after mapping Metropolitan Statistical Areas to 1990 US counties using population weights. ${ }^{6}$ From the US Census County Business Patterns (CBP) dataset, we compute over 1985-2010 the five-year change in the skewness of the employment growth across 4-digit industries, a measure of the change in economic dynamism (Decker et al., 2014). Appendix A.5 gives additional details.

Summary Statistics. Table 1 reports summary statistics. The series are observed at the county by five-year-window level. The table reveals sensible patterns. Counties, on average, received around 1,400 non-European immigrants in each five-year period between 1975 and 2010, a meaningful contribution to overall average population growth of around 4,000. Innovation (per-capita patenting) increased on average over the period, with substantial heterogeneity across counties. Wages per capita grew on average, as expected. The statistics on the remaining variables, reflecting the variation in subsets of our data and in several constructed instruments, will become useful in our discussion below.

\section{Constructing a Valid Instrument for Immigration}

Our aim is to estimate the causal impact of immigration on innovation and local economic growth, which can inform a structural model of endogenous migrations and growth. To do so, we estimate the following equation:

$$
\Delta Y_{d}^{t}=\delta_{t}+\delta_{s(d)}+\beta \cdot \text { Immigration }_{d}^{t}+\epsilon_{d}^{t}
$$

where Immigration ${ }_{d}^{t}$ measures the number of migrants flowing into destination county $d$ between $t-1$ and $t . \Delta Y_{d}^{t}$ is a change from $t-1$ to $t$ in the outcome of interest, usually the change in the number of patents filed per capita in the county. This specification in changes ensures any long-lasting differences between counties that are on average more or less innovative are

\footnotetext{
${ }^{6}$ Job creation and destruction rates are gross flows representing the ratio of the number of jobs created or destroyed as a fraction of total average employment in the current and past year. See Davis and Haltiwanger (1999) for an overview of gross labor market flows. Apportionment is necessary because the BDS statistics are available only at the local level for MSAs rather than for the universe of individual counties. Creating equivalent county measures would require use of the underlying confidential Census LBD microdata.
} 
controlled for. $\delta_{t}$ and $\delta_{s(d)}$ are time and state fixed effects, respectively. Our most conservative specifications also include a county fixed effect, $\delta_{d}$, which controls for any county-specific trend in $Y_{d}^{t}$, so that we exploit only variation in the growth rate of per-capita patenting over time within a given county.

The main concern with a simple OLS estimate of $\beta$ is that unobserved factors may affect both immigration and innovation, even though we estimate (1) in differences, and even with fixed effects that absorb state- or county-specific trends. We spell out two leading identification concerns explicitly, and propose a solution. The first is simple reverse causality concern: local wages are likely correlated with local productivity shocks and innovation, and foreign migrants are in part attracted by higher wages. This induces a spurious correlation between immigration and innovation, where counties that become more innovative attract more migrants over time because they pay higher wages. The second is a county-country specific omitted factors concern: for example, workers from a specific country (say India) may disproportionately have specific skills (say engineering) well-suited for specific sectors (say telegraph, aeronautics, and software development) that are concentrated in a specific county (say Silicon Valley). Any time a positive shock to productivity and innovation occurs in that sector (e.g. a shock to the telegraph industry in the 1900's, to aeronautics the 1960's, or to software development in the 2000's), workers from that country (India) will be drawn to this county (Silicon Valley) - resulting in spurious correlations between local innovation and immigration, past and present. ${ }^{7}$

We propose an identification strategy plausibly immune to both concerns. Drawing on the seminal work of Card (2001), we leverage the tendency of incoming migrants to settle in US counties with large pre-existing communities from the same origin. However, we depart from Card (2001) and the subsequent literature employing the the canonical shift-share approach by using only plausibly exogenous variation in pre-existing ancestry patterns when interacting the ancestry pattern with contemporaneous immigration.

Step 1: Predicting ancestry. To predict the number of residents with ancestry from $O$ who reside in $d$ at $t, A_{o, d, t}$, we directly apply the method developed in Burchardi et al. (2019). We only give a brief summary here. Burchardi et al. (2019) show that a simple reduced form model of migrations driven by 'push' and 'pull' shocks, combined with a rigorous leave-out strategy, allows to identify variations in $A_{o, d, t}$ that are plausibly exogenous not only to local factors, $d$-specific, but also to bilateral factors, $(o, d)$-specific. We later develop a structural

\footnotetext{
${ }^{7}$ A conventional shift-share design would wrongly assume that pre-existing immigration or ancestry shares (say Indians in Silicon Valley) are orthogonal to future innovation shocks.
} 
model explicitly featuring those two forces, see Section 6 .

The identification strategy is best described by a stylized example. We predict a relatively large inflow of migrants from $o$ (say Indians relative to other Asians) to $d$ (say Fresno in the Central Valley of California relative to other destinations on the West Coast) at a point in history $\tau$ (say 1900) if the following happens: in 1900, many Indians migrate to the United States including towards regions outside the West Coast (1900 corresponds to the first historical Indian migration wave to the US) and Fresno county is attractive to foreign migrants from any origin, including from Europe (1900 corresponds to the beginning of oil exploitation in Fresno, and an increase in agricultural production following the construction of irrigation canals in the late 19th Century). This early settlement of Indian migrants in Fresno partly explains the large community of Indian ancestry in Fresno after 1975. ${ }^{8}$ Our identification strategy applies this logic for all time periods starting in 1880, all origin countries, and all destination counties. We generate granular variation in the ancestry composition of US counties that emanates solely from the coincidence of migrants being 'pushed' from their origin country and 'pulled' into destination counties.

Formally, we estimate

$$
A_{o, d, t}=\delta_{o, r(d), t}+\delta_{c(o), d, t}+X_{o, d}^{\prime} \zeta+\sum_{\tau=1880}^{t} a_{r(d), \tau} I_{o,-r(d), \tau} \frac{I_{\text {Europe }, d, \tau}}{I_{\text {Europe }, \tau}}+v_{o, d, t},
$$

where $I_{o,-r(d), \tau}$ is the total number of migrants arriving from $o$ at $\tau$ who settle in counties outside of the region where $d$ is located, ${ }^{9} \delta_{o, r(d), t}$ and $\delta_{c(o), d, t}$ are a series of origin country $\times$ destination region and continent of origin $\times$ destination county interacted fixed effects, whereas $X_{o, d}$ contains a series of time-invariant controls for $\{o, d\}$ characteristics. We estimate (2) separately for each $t=1980,1985,1990,1995,2000,2005,2010$ using all non-European countries in our sample. From this estimation, we derive predicted ancestry

$$
\hat{A}_{o, d, t}=\sum_{\tau=1880}^{t} \hat{a}_{r(d), \tau}\left(I_{o,-r(d), \tau} \frac{I_{\text {Europe }, d \tau}}{I_{\text {Europe }, \tau}}\right)^{\perp}
$$

where $\hat{a}_{r(d), \tau}$ are the coefficients estimated from (2) and $\perp$ indicates that the interaction of push and pull factors has been residualized with respect to all of the controls in (2).

\footnotetext{
${ }^{8}$ Appendix Figure 1 shows how the timing of migrations varies between foreign origins; one can notice the early (small) spike in Indian migration in 1900. Appendix Figure 2 shows that US counties are attractive to foreign (European) migrants at different points in time; one can notice that Fresno in 1900 was attractive to all migrants, including Europeans.

${ }^{9}$ The term 'region' refers to the nine US census divisions - groupings of, on average, 5 adjacent states (see Appendix Table 2).
} 
This reduced form regression captures the intuition above: we expect a large community of ancestry from India living in Fresno in 1980 if many Indian migrants in 1900 settled outside the West Coast (I India,-r(Fresno),1900 large) and Fresno in 1900 was attracting a large share of

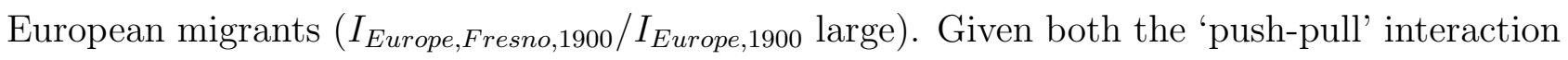
and the restrictive leave-out strategy (we exclude the West Coast from India's push, and exclude all non-European migrants from Fresno's pull), we ensure that predicted ancestry from (2) does not suffer from the endogeneity concerns above. For instance, we leave-out Indian migrants with specific skills who may have endogenously chosen where to settle. Had we used realized ancestry instead, we may have included 1980 descendants of 1960 Indian migrants with engineering skills who endogenously settled in Silicon Valley at the time of the early development of aeronautics. This would have induced a spurious correlation between contemporaneous Indian ancestry and productivity and innovation shocks in Silicon Valley, such as software development in 2000.

Going beyond the procedure in Burchardi et al. (2019), note that (3) also residualizes this predicted ancestry with respect to all of the controls and fixed effects included in (2). Doing so ensures that $\hat{A}_{o, d, t}$ relies exclusively on local variations in relative predicted ancestry. For example, the $\delta_{c(o), d, t}$ interacted fixed effects ensure that $\hat{A}_{o, d, t}$ contains no information about which destinations were on average historically more or less attractive for the average migrant $\left(\sum_{o} \hat{A}_{o, d, t}=0\right)$, or even migrants from a given origin continent $\left(\sum_{o \in c} \hat{A}_{o, d, t}=0\right)$. Instead, for a given destination, $\hat{A}_{o, d, t}$ varies only across ethnicities from the same origin continent (e.g. Indians vs other Asians in Silicon Valley). Similarly, $\hat{A}_{o, d, t}$ removes differences between large and small countries $\left(\sum_{d} \hat{A}_{o, d, t}=0\right)$ and, for a given country, varies only across counties within a given US census region $\left(\sum_{d \in r} \hat{A}_{o, d, t}=0\right)$. We show below this orthogonalization is effective in removing any remaining confounding variation between large and small counties that could result from long-lasting productivity shocks (the reverse causality concern outlined above).

Step 2: Predicting immigration. Having predicted pre-existing ancestry, we can now simply apply the canonical shift-share approach to isolate exogenous immigration shocks by interacting predicted pre-existing ancestry in a given county with contemporaneous (US-wide) immigration from that origin,

$$
I_{o, d, t}=\delta_{o, r(d)}+\delta_{c(o), d}+\delta_{t}+X_{o, d}^{\prime} \theta+b_{t} \cdot\left[\hat{A}_{o, d, t-1} \times \tilde{I}_{o,-r(d), t}\right]+u_{o, d, t},
$$

where again the $\delta$ 's are time, country $\times$ region, and continent $\times$ county fixed effects, $X_{o, d}^{\prime}$ observable controls, $\hat{A}_{o, d}^{t-1}$ is predicted ancestry from (3), and $\tilde{I}_{o,-r(d), t}=I_{o,-r(d), t}\left(I_{\text {Europe }, r(d), t} / I_{\text {Europe, }, r(d), t}\right)$ is the scaled push factor from $o$. (Because we leave out from $I_{o,-r(d), t}$ all migrants from $o$ who 
settle in d's region, the scaling factor $I_{\text {Europe }, r(d)}^{t} / I_{\text {Europe },-r(d), t}$ corrects for differences in region sizes.) Simply adding up across foreign origins, we derive our main instrument for the total number of migrants settling in county $d$ in period $t$, Immigration $_{d, t}$ in (1),

$$
\hat{I}_{d, t}=\sum_{o} \hat{b}_{t} \cdot\left[\hat{A}_{o, d, t-1} \times \tilde{I}_{o,-r(d), t}\right]
$$

This instrument predicts a large immigration shock to Fresno county in 2000 if $(i)$ many Indians migrate to the US in 2000 (excluding the West Coast), and (ii) we predict a large pre-existing community of Indian ancestry in Fresno because (iii) Fresno was an attractive destination for all migrants in 1900 (proxied by European migrants choices), precisely at a time of relatively large Indian migrations to the US (excluding the West Coast). The key innovation relative to Card (2001) is thus to rely on predicted foreign ancestry using historical migration shocks, instead of realized immigration or ancestry.

Identifying assumption. A sufficient condition for the validity of this instrument is that predicted ancestry, $\hat{A}_{o, d, t-1}$, is exogenous in equation (1). With our baseline regional and continental leave-outs, we can write this condition as

$$
I_{o,-r(d), \tau} \frac{I_{\text {Europe }, d, \tau}}{I_{\text {Europe }, \tau}} \perp \epsilon_{d, t} \forall o, \tau \leq t
$$

It requires that any confounding factors that drive temporary increases in a given US county's innovation post-1975 $\left(\epsilon_{d, t}\right)$ do not systematically correlate with pre-1975 immigration from that origin to other regions within the US $\left(I_{o,-r(d), \tau}\right)$ interacted with the simultaneous settlement of European migrants in that US destination $\left(I_{\text {Europe }, d, \tau} / I_{\text {Europe }, \tau}\right)$. If this condition is satisfied, the ancestry used to predict immigration in Step 2 is exogenous. ${ }^{10}$

We believe this assumption is plausible: consider a productivity shock to software development in Silicon Valley $\left(\epsilon_{\text {Santa Clara }, t}\right)$ that attracts Indian software engineers $\left(I_{\text {India,SantaClara }, t}\right)$. This confounding shock, and any other origin-destination specific factor that drives migration and might affect the destination's capacity for future innovation generally has no effect on $\hat{A}_{\text {India,Santa Clara }, t-1}$ : the fact that Indians might on average excel at programming has no effect on how the historical destination choices of Europeans $\left(I_{\text {Europe,Santa Clara, } \tau} / I_{\text {Europe,-SantaClara }, \tau}\right)$ coincide with the number of Indians arriving in US destinations outside of the West Coast

\footnotetext{
${ }^{10}$ Exogeneity of ancestry is a sufficient, but generally not a necessary, condition for the validity of the canonical shift-share approach (Goldsmith-Pinkham et al., 2020). For work identifying necessary and sufficient conditions for the validity of the shift-share instrument as proposed by Card (2001) and Bartik (1991), see Borusyak, Hull, and Jaravel (2021).
} 
$\left(I_{\text {India },-r(\text { Santa Clara }), \tau}\right)$. To violate $(6)$, the confounding shock $\left(\epsilon_{\text {Santa Clara }, t}\right)$ would have to systematically affect the destination choices of many Europeans, say French software engineers (a shock to $I_{\text {France,Santa Clara, } \tau}$ large enough to affect $\left.I_{\text {Europe,Santa Clara }, \tau} / I_{\text {Europe,-SantaClara }, \tau}\right)$, while also attracting a large number of Indians to US counties outside the West Coast, say to Route 128 in Massachusetts (a shock to $I_{\text {India,Middlesex }, \tau}$ large enough to affect $I_{\text {India },-r(\text { Santa Clara }), \tau}$ ). We address this remaining (if unlikely-sounding) concern below by varying how we construct the leave-out categories in our estimation, and within an explicit model of endogenous migrations. ${ }^{11}$

Performance of the instrument. Table 2 shows that our method is able to predict contemporaneous immigration accurately. It shows the results from estimating various specifications of (4), i.e. explaining bilateral $o \times d$ immigration flows post-1975 $\left(I_{o, d, t}\right)$ using predicted $o \times d$ ancestry $\left(\hat{A}_{o, d, t}\right)$ interacted with national immigration shocks $\left(\tilde{I}_{o,-r(d), t}\right) .{ }^{12}$ The interaction of predicted ancestry and national immigration predicts bilateral immigration flows well: the $R^{2}$ in column 1 without any controls is $65.6 \%$.

More importantly, the coefficients on the interaction between predicted ancestry and national immigration are virtually unchanged as we add more controls: controlling for distance, latitude distance, country and county fixed effects in column 2, and adding 14,031 country $\times$ census division and county $\times$ continent interacted fixed effects in column 3. Remarkably, the coefficients also remain unchanged when we control for the (endogenous) total flow of European migrants to the same county in column 4 , or when we control directly for contemporaneous economic forces shaping migration by including economic push-pull interactions for each period post $1975 .{ }^{13}$ This latter pattern in particular is strongly indicative that our instrumentation strategy effectively removes any confounding migrations caused by local economic expansions. We conclude our instruments for origin-destination-specific migration are orthogonal to a wide range of observables, and therefore plausibly predict exogenous variation in immigration.

Figure 1 presents a series of maps displaying these exogenous "immigration shocks" for each five-year period from 1975 to $2010, \hat{I}_{d, t}$ in (5). To highlight the variation in this shock, we

\footnotetext{
${ }^{11}$ Note this scenario implies a series of non-zero correlations, pairwise between $\epsilon_{\text {Santa Clara, },}, \epsilon_{\text {Middlesex }, t}$, $I_{\text {India,Santa Clara }, t}, I_{\text {India,Middlesex }, t}$ and $I_{\text {France,Santa Clara }, \tau}$. We explicitly explore this possibility empirically in Section 4.2, and quantitatively in Section 6.4.

${ }^{12}$ We know from Burchardi et al. (2019) that the interaction of historical push and pull factors is a good predictor of contemporaneous ancestry. This is confirmed in Appendix Figure 3, which shows a binned scatter plot of predicted ancestry $\left(\hat{A}_{o, d, 2010}\right)$ against actual ancestry $\left(A_{o, d, 2010}\right)$ : both variables are tightly aligned along the 45-degree line.

${ }^{13}$ Because this specification is saturated with controls, the incremental increase in $R^{2}$ from adding this variable appears small. However, if we allow for flexible coefficients at the census region level as in (2), the $R^{2}$ increases by about six percentage points.
} 
remove county and year fixed effects. Our immigration shock instrument picks up substantial variation both over time and between counties.

\section{The Impact of Immigration on Innovation and Growth}

In this section, we exploit our quasi-random immigration shocks to test and quantify the causal impact of immigration on innovation and growth. We then probe the robustness of our results in detail.

\subsection{Immigration and Innovation}

Table 3 shows our main results, a test of the hypothesis that immigration causes an increase in innovation at the local level (US county), in the short run (five-year period). Our baseline estimate for coefficient $\beta$ in (1) is in panel B column 1. It measures the impact of an exogenous inflow of immigrants to county $d$ (in 1,000's) on the change in the number of patents per 100,000 residents filed over five years, where we instrument for immigration using our immigration shocks (5). The estimated effect is positive and statistically significant $(0.115$, s.e. $=0.040)$. It implies the inflow of 10,000 additional immigrants to a county increases the flow of patents filed locally over a five-year period by 1.15 patent per 100,000 people. This effect is substantial: a one standard deviation increase in immigration - 12,000 immigrants - causes 1.4 more patents per 100,000 people, an increase of $25 \%$ relative to the mean - 5.53 patents per 100,000 people.

Panel A shows OLS estimates, panel B our IV estimates, and panel C estimates of the first stage of our IV. Across specifications, our IV estimates are lower than OLS estimates (though not statistically significantly different), suggesting that migrants endogenously sort into destinations that experience an increase in innovation. Consistent with the presence of reverse causality or country-county specific confounding factors, the OLS estimates are unstable as we add more controls, state $\times$ time fixed effects in column 2, and county fixed effects in column 3. By contrast, the IV estimates remain stable across specifications, even when controlling for county fixed effects, so exploiting solely variation in the growth rate of innovation within-county over time. This stability bolsters our confidence that our exogenous immigration shocks are orthogonal to persistent confounding factors at the county-level. Our first stage has a strong F-statistic (above 85) and Anderson-Rubin Wald F-test (p-value below 1.6\%).

We interpret this large positive impact of immigration on the flow of patenting through the lens of a regional endogenous growth model in Section 6, and we quantify this model using the 
well identified reduced form parameters presented here.

\subsection{Robustness}

Below, we show our results are robust to a large array of alternative specifications and relate our approach to ongoing debates on the merits of the shift-share approach to identification.

Alternative Instruments. Table 4 panel A column 1 addresses the potential threat to identification spelled out in Section 3: if pre-1975 periods of IT innovation attracted Indian as well as French software engineers to Silicon Valley as well as to Route 128, and post-1975 periods of IT innovation repeatedly have the same effect on a large enough number of migrants to sway averages, then our instrument (which uses pre-1975 European migration to Silicon Valley, including French migrants, interacted with post-1975 inflows of Indian migrants outside of the West Coast, including Route 128) may pick up endogenous migrations correlated with innovation. To address this concern, we use an alternative leave-out strategy in the construction of our instrument: when predicting relative immigration from $o$ (say India) to $d$ (say Silicon Valley), instead of excluding o's migrants who settle in the same census division as $d$ (Pacific), we leave out migrants from $o$ who settle in counties with migrations that are serially correlated with those to $d$ (we leave out Route 128 in the example above). ${ }^{14}$ Our estimated $\beta$ coefficient remains virtually unchanged $(0.102$, s.e. $=0.041$ instead of 0.115 , s.e. $=0.041)$, suggesting our baseline estimates are not confounded by county-country specific omitted variables.

Table 4 panel A columns 2-4 show further variations in the construction of our instrument. Column 2 replaces the pull factor in (2), the share of European migrants who settle in county $d$, with the share of migrants from a continent different than o's who settle in $d$. Column 3 freezes predicted ancestry at its 1975 level in the construction of our instrument in (5), instead of updating predicted ancestry each period. Column 4 uses non-European immigration until 1960 only to predict pre-existing ancestry. This ensures our instrument does not contain any information from the more recent large non-European migration waves post-1960. Our estimate for $\beta$ varies little across specifications, except for column 4 where it drops by about one third relative to our baseline specification (perhaps not surprisingly our first stage has less power in that case). Importantly, however, all coefficients of interest remain statistically significant at the $1 \%$ level and our first-stage remains strong, with large F-statistics, and Anderson-Rubin

\footnotetext{
${ }^{14}$ For each pair of counties, we compute the correlation coefficient over time of total immigration (from all origin countries) and exclude from the push factor at $t$ for county $d$ all migrations to counties $d^{\prime}$ if their correlation with $d$ is positive and statistically significant at the $5 \%$ level.
} 
Wald F-statistics below 1\%, even when using only pre-1960 migrations.

Panel B compares the performance of our instrument to two alternative instruments for immigration used in the recent literature. Sequeira et al. (2020) interact the connection of a US county to the railroad network between 1850 and 1920 with the inflow of immigrants over that period to build an instrument for the size of the immigrant population during the age of mass migration. This instrument varies only across counties, not over time. Hunt and Gauthier-Loiselle (2010) use a method similar to Card (2001). They interact immigration shares in 1940 with the inflow of migrants in recent decades as an instrument for recent immigration. This instrument varies only across states and time (10-year periods), not across counties. We estimate the impact of immigration on patenting, controlling for the instrument in Sequeira et al. (2020) (columns 1 and 3) and the instrument in Hunt and Gauthier-Loiselle (2010) (columns 2-4). Across specifications, our baseline estimate remains stable as we control for those alternative instruments. The purely cross-sectional variation in Sequeira et al. (2020) has a significant impact on local innovation, consistent with their finding that these inflows around the turn of the last century had a persistent impact on local economic performance. The state-level variation in Hunt and Gauthier-Loiselle (2010) on the other hand has no differential explanatory power once we control for our more granular local immigration shock.

Randomization tests. Table 5 implements a randomization test developed by Adão et al. (2019) to gauge whether our instrument suffers from an over-rejection problem typical of shiftshare designs. ${ }^{15}$ This over-rejection problem arises because two US counties with similar preexisting ancestry composition may also have similar exposure to other (unobservable) economic forces, which may lead to a dependency across regression residuals that is not accounted for by conventional clustered standard errors. Following the procedure in Adão et al. (2019), we randomly generate immigration shocks (for each $\{o, r, t\}$ country-region-time triplet), and construct placebo instruments by interacting these random shocks with our predicted ancestry shares in column $1 .^{16}$ We then run 1,000 placebo regressions of actual immigration on our

\footnotetext{
${ }^{15}$ To clarify the comparison, the shifts are industry shocks in Adão et al. (2019) versus immigration shocks in our case, whereas the shares are employment shares in Adão et al. (2019) versus ancestry shares in our case; the variation is at the sector-commuting zone level in Adão et al. (2019), versus country-county in our case.

${ }^{16}$ To implement the procedure as in Adão et al. (2019), we replace ancestry in levels with ancestry shares. Formally, using predicted ancestry $\hat{A}_{o, d, t-1}$ from (2), equation (4) becomes

$$
I_{o, d, t}=\delta_{o, r(d)}+\delta_{c(o), d}+\delta_{t}+X_{o, d}^{\prime} \theta+b_{t} \cdot\left[\frac{\tilde{A}_{o, d, t-1}}{\sum_{d^{\prime}} \tilde{A}_{o, d^{\prime}, t-1}} \times \tilde{I}_{o,-r(d), t}\right]+u_{o, d, t},
$$

where the normaliztion $\tilde{A}_{o, d, t-1}=\hat{A}_{o, d, t-1}-\min \left[0, \min _{\delta}\left[\hat{A}_{o, \delta, t-1}\right]\right]$ ensures predicted shares are in $[0,1]$.
} 
randomly generated instrument, and report the fraction for which we reject the null hypothesis of no effect at the $5 \%$ statistical significance threshold. We find a false rejection rate of $3.8 \%-$ close to the theoretical asymptotic $5 \%$ level, again bolstering our confidence that our immigration shocks are indeed orthogonal to any confounding economic forces, and that our inferences based on conventional clustered standard errors are valid.

The remaining columns show that using predicted rather than realized ancestry in the construction of our instruments is key to this result. In column 2 we repeat the same procedure but rely on realized past immigration shares as in Card (2001). In this case, the false rejection rate is close to 27\%, a sign of unreliable inference as argued by Adão et al. (2019). The remaining columns show the same problematic result using realized ancestry shares (instead of immigration shares, column 3) and realized ancestry shares interacted with push factors that leaving out migrants who settle in the same census division (column 4). ${ }^{17}$ We conclude conventional shift-share instruments for immigration, including the classical version of Card (2001), suffer from over-rejection while our instrument using predicted ancestry does not.

Despite this confounded inference, note that the point estimates in columns 2-4 are all positive. These alternative approaches thus yield similar economic conclusions, although standard errors are considerably too narrow. We show in Section 6 that within a structural model of endogenous growth and innovation, these alternative approaches are confounded specifically due to persistent productivity shocks and country-county specific omitted variables.

Placebo and dynamic effects. Table 6 shows the dynamic effects of a one-time exogenous inflow of migrants. First and reassuringly, we show in column 1 that contemporaneous migrations have no effect on past innovation. This finding further strengthens our confidence in our identification strategy. ${ }^{18}$ Column 2 replicates our baseline results, the contemporaneous effect of immigration on innovation over a five-year period, as in Table 3, panel B, column 3. Columns 3 and 4 consider the impact of immigration on patenting over a 10- and 15-year period. We find the effect of immigration on innovation gradually increases, and stabilizes after about 10 years. In other words, the effect more than doubles from 5 to 10 years, and remains constant beyond. This gradual increase in innovation following an immigration shock is also consistent with our structural model of endogenous migrations and innovation in Section 6.

\footnotetext{
${ }^{17}$ Appendix Table 3 presents additional statistics from the randomization test in Adão et al. (2019).

${ }^{18}$ The fact that we find no impact on past innovation suggests our instrument is immune to the critique in Jaeger et al. (2018) that serial correlation leads to incorrect inference on the short run impact of immigration. This pattern is also consistent with our finding in Section 6 that our immigration shocks are not confounded by persistent productivity shocks.
} 
Additional robustness checks. Appendix Table 4 shows our results are robust to using alternative measures of patenting, using the location of the patent assignee or inventor, and weighting by the citation counts of patents, to account for differences in patent quality. Appendix Table 5 shows a permutation test, randomly reassigning the baseline instrument within various sets of observations. Across all permutation tests, we find no effect of this permuted instrument on immigration, no reduced-form impact of this permuted instrument on innovation, and the right hand side rejection rate is small (generally below 5\%). Appendix Table 6 shows results similar to our baseline specification for the impact of population growth on innovation, using our immigration shocks in (5) as an instrument for population growth. Appendix Table 7 shows our coefficient is stable to including 'bad controls': population density in 1970, patents per capita in 1975, and the share of high school or college education in 1970. Appendix Table 8 shows our results are not driven by individual origin countries. In panel $\mathrm{A}$ we repeat the exercise in Table 3 removing one country at a time (for the 5 largest origin countries, Mexico, China, India, the Philippines, and Vietnam). In panel B, we use only migrants from each one of those 5 countries. The estimate for the impact of immigration on innovation varies very little across samples.

Economic dynamism. Finally, Appendix Table 1 shows immigration also has a positive impact on various measures of economic dynamism (a natural proxy for innovation): the job creation rate, the job destruction rate, and the skewness of the job growth rate across sectors. This finding is consistent with endogenous growth theories which feature Schumpeterian creative destruction linked to innovation (Aghion and Howitt, 1992; Grossman and Helpman, 1991; Klette and Kortum, 2004).

\subsection{Immigration and Income Growth}

Table 7 tests the hypothesis that immigration causes an increase in local wages. Even if immigration has a positive impact on innovation as documented above, the impact on wages is theoretically ambiguous, as we show formally in our model in Section 6. An inflow of immigrants increases the local supply of labor, which depresses local wages. At the same time, it also induces a rise in local innovation, which increases the marginal product of labor and pushes wages up. ${ }^{19}$ The net effect of immigration on local wages in the short run thus remains an empirical question.

\footnotetext{
${ }^{19}$ This ambiguous prediction may explain the seemingly contradictory effect of immigration on wages found in the labor literature (Borjas, 2003; Cortes, 2008; Ottaviano and Peri, 2012; Foged and Peri, 2016; Dustmann et al., 2017; Monras, 2020; Jaeger et al., 2018; Bratsberg et al., 2019).
} 
Columns 1 and 2 show that immigration has a positive impact on local wages over a 5-year horizon at the county level. This is true both when controlling for state fixed effects (column 1) and county fixed effects (column 2). Our estimates imply that a one standard deviation increase in adult immigration (7,000 more adult migrants in a county) increases wages per capita by around $6 \%$ relative to the mean increase in wages in our sample. ${ }^{2021}$ Column 3 shows this effect is not mechanically driven by high-earning migrants: immigration induces an increase in the wages of native (US-born) residents. Column 4 shows this effect is not driven by a composition effect either, where low-earner natives may leave in response to the arrival of immigrants: immigration induces an increase in the wages of natives, even when restricting to native non-movers. ${ }^{22}$

Interestingly, we also show in Appendix Table 9 that an exogenous immigration shock to county $d$ causes an inflow of natives (both whites and non-whites). A possible explanation is that natives endogenously respond to the anticipated positive impact of immigration on innovation and wages. While this agglomeration force is beyond the scope of our model, it suggests subtle complementarities between external and internal migrations that warrant further study.

\section{Spillovers and Education}

The local positive impact of immigration on innovation and wages that we document naturally brings to mind two questions: First, if ideas and goods flow across regions, to what extent does the impact of immigration spill over to neighboring counties? Second, if more skilled workers bring more effective inputs for innovation or production, to what extent does the impact of immigration on innovation vary with the education level of migrants? We find positive spatial spillovers and a higher impact of more educated migrants on local innovation.

\footnotetext{
${ }^{20}$ For ease of interpretation, we use adult immigration (aged 25+) as the endogenous variable in all of our regressions regarding wages and education.

${ }^{21}$ Potentially interesting for the interpretation of our results in the context of structural spatial growth models, we find this effect of immigration on wages is higher in services (non-traded sector), with a coefficient of 0.429 (s.e. 0.135), than in manufacturing (traded sector), with a coefficient of 0.215 (s.e. 0.049).

${ }^{22}$ In columns 3 and 4 we use a different time horizon, and data from the US census instead of QCEW wage data. As a consequence, the effect of immigration on wages appears smaller than in columns 1 and 3. Nevertheless, both sets of estimates imply similar relative effects: the arrival of 7,000 additional migrants (half of a standard deviation in 10-year adult immigration) leads to an increase in the average wage of natives and native non-movers of $5.7 \%$ and $4.2 \%$, respectively.
} 


\section{$5.1 \quad$ Spatial Spillovers}

We consider three geographic spillover concepts in Table 8. First, we consider within-state spillovers, constructing for each destination county $d$ at each time $t$ a measure of immigration to all counties other than $d$ in the same state. To construct a separate instrument for statelevel immigration flows, we simply add up the immigration shocks for all other counties within the same state as $d$. Second, we consider a specification allowing spillovers from neighboring counties to vary smoothly by distance. For county $d$ at time $t$, we construct the sum of all immigration to other counties, inversely weighted by the distance to county $d .^{23}$ Finally, we also consider a non-parametric estimate for the diffusion of the effect of immigration, with separate instruments for immigration within 100km (60 miles), excluding county $d$ itself, immigration between $100 \mathrm{~km}$ and $250 \mathrm{~km}$ (150 miles), between $250 \mathrm{~km}$ and $500 \mathrm{~km}$ (300 miles), and beyond $500 \mathrm{~km}$. We explore the spatial spillovers of immigration on both innovation (panel A), and on local wages (panel B).

Innovation Spillovers. In panel A column 1, we first report an instrumental-variable (IV) estimate of the effect of own-county immigration on innovation using census division instead of state fixed effects. The coefficient of interest is similar to those in Table $3(0.149$, s.e. $=0.050)$. Column 2 shows that immigration within county $d$ 's state, excluding $d$, has a positive impact on local innovation in $d$. The direct and indirect effects have a similar magnitude: a one standard deviation increase in immigration to $d$ (12,000 migrants) on average increases local patenting per capita by $26 \%$ relative to mean, while a one standard deviation increase in immigration in the surrounding counties within the state (1.4 million migrants) on average increases local patenting per capita by $51 \%$ relative to mean. Column 3 shows immigration to neighboring counties has a positive impact on local innovation, where we discount distant counties inversely with distance. Column 4 shows a one standard deviation increase in immigration within 100km of county $d$ on average increases innovation in $d$ by $77 \%$ relative to the mean; this effect falls to $41 \%$ between $100 \mathrm{~km}$ and $250 \mathrm{~km}$; and becomes indistinguishable from zero beyond $250 \mathrm{~km}$.

Appendix Table 10 displays the corresponding first-stage regression results, showcasing the strength of our identification strategy. ${ }^{24}$ We are able to successfully identify independent variations in each of the separate endogenous variables. For instance, in the non-parametric specifi-

\footnotetext{
${ }^{23}$ The distance measures reflect a matrix of great circle distances computed from county centroids using the census mapping files for county geographies. The inverse weighted average of immigration is akin to a measure of market potential in international trade.

${ }^{24}$ For all specifications involving multiple endogenous variables, we use the Angrist and Pischke (2009, p. 217-218) first-stage $F$-statistic, separately testing for each regressor the null of weak identification.
} 
cation, where we use four separate instruments, each instrument predicts significant first-stage variation in the corresponding endogenous variable. This ability to simultaneously identify exogenous variations in immigration for different levels of aggregation is one of the strengths of our identification method.

Wage Growth Spillovers. The spatial spillovers of the effect of immigration on wage growth in panel B are similar to those on innovation, although they appear more local than the innovation spillovers: while we do not find a significant effect of immigration to other counties within the state on local wages (column 2), we do find such a significant spill-over from immigration to nearby counties (column 3). Consistent with this pattern, immigration within $100 \mathrm{~km}$ significantly affects local wage growth, with a one standard deviation increase in adult immigration on average leading to around a $22 \%$ increase in wage growth relative to mean, but again the effect becomes insignificant beyond $100 \mathrm{~km}$ (column 4). ${ }^{25}$

\subsection{Education of Immigrants}

We now explore whether more educated immigrants have a detectable differential impact on local innovation and wages. First, to measure educational attainment for individuals who might reasonably have had the time to complete their schooling, we limit ourselves to the analysis of immigrants age 25 or older, constructing the endogenous measure of immigration at the county level for this subset of immigrants. We then interact this overall adult immigration flow with the average schooling levels of adult migrants arriving in a given county at a given time (which we again construct from IPUMS), adding a second endogenous variable to our baseline specification. $^{26}$

To separately instrument for the total immigration flow and for the interaction of immigration and education, we exploit the fact that different origin countries send migrants with different levels of education to the US at different times. For example, Japanese immigrants, on average, have about twice the number of years of schooling as those from Guatemala, whereas the education levels of Mexican arrivals increased by about $30 \%$ during our sample period.

\footnotetext{
${ }^{25}$ The fast geographic decay of spatial spillovers may suggest that the effect of immigration shocks on local innovation and wage growth are disproportionately driven by the supply side - more immigrants bring in more ideas, rather than by the demand side - more immigrants bring more demand which induces firms to innovate. If the demand side were the main driver, given the patterns of within-US trade, we would expect a slower spatial decay. This however is only indirect evidence, and our data does not allow us to definitively confirm one mechanism against another.

${ }^{26}$ IPUMS lists information on the number of years of schooling and the number of years of college education each respondent has received. See Appendix A.1 for details.
} 
Recall from (5) that our identification strategy allows us to construct a separate instrument for each origin-destination pair and each time period, $\hat{I}_{o, d}^{t}=\hat{\beta}_{t} \cdot \hat{A}_{o, d}^{t-1} \times \tilde{I}_{o,-r(d)}^{t}$. We disaggregate our baseline instrument to this level, using the predicted immigration shocks for each of the top 25 origin countries (those that send the most migrants) as a joint set of instruments for both total immigration and immigration interacted with education. ${ }^{27}$ The first stage for this additional endogenous variable is

$$
\text { Average Years Education }{ }_{d}^{t} \times \text { Immigration }_{d}^{t}=\delta_{s}+\delta_{t}+\sum_{o=1}^{25} \kappa_{o} \hat{I}_{o, d}^{t}+\nu_{d}^{t} \text {. }
$$

Because migrants arriving from different countries at different times have different schooling levels and emigrate to different counties, we are able to isolate exogenous variation in the level of education of migrants arriving in a given destination at a given point in time. For example, other things equal, an exogenous increase of Japanese migrants to a given destination implies a relative increase in the average education level of local immigrants at that point in time.

Innovation and Education. Table 9 panel A examines heterogeneity in the impact of immigrants on innovation by education level. Column 1 replicates our standard specification for the age 25+ immigration sample, with a positive - now slightly stronger than baseline - impact of immigration on the growth of patenting per capita. ${ }^{28}$ Column 2 adds the interaction of immigration with (demeaned) average years of schooling, and shows that more educated immigrants cause a larger increase in innovation. 10,000 migrants of average education (about 11 years) cause 2.6 more local patents per 100,000 residents $(10 \times 0.257)$, while 10,000 migrants with one standard deviation higher education (3.7 more years of schooling) cause 11 more local patents $(10 \times(0.257+3.7 \times 0.235))$. Those effects are similar or stronger when controlling for county fixed effects (column 3), or when measuring years of college instead of total years of education (column 4). Column 5 uses a nonparametric measure: while the (positive) impact of migrants in the bottom tercile of education on innovation is insignificant, the impact of those

\footnotetext{
${ }^{27}$ We prefer working with this limited number of origin countries whose migrants are numerous enough to plausibly induce variation in the local average education level of arriving migrants.

${ }^{28}$ In column 1 of Table 9 (both panels), we consider a specification with a single endogenous regressor and multiple instruments, and therefore report the first-stage F-statistic developed in Montiel Olea and Pflueger (2013). The remaining columns in this table report results for specifications with multiple endogenous variables and multiple instruments and, to our knowledge, there is no comparable effective F-statistic in this case (Isaiah et al., 2018). To nevertheless gauge our ability to identify differential exogenous variation in the separate endogenous variables, the table shows the F-Statistics from Montiel Olea and Pflueger (2013) after applying the orthogonalization procedure in Angrist and Pischke (2009) to each endogenous variable. In Column 2 of both panel $\mathrm{A}$ and $\mathrm{B}$ those $\mathrm{F}$-statistics exceed the critical values for a $10 \%$ bias. In further columns the F-statistics do not always exceed the critical values, indicating possibly weak instruments.
} 
in the top tercile is one order-of-magnitude larger than for immigrants with average education. The effect for the middle tercile of education, while lower than that for the average migrants -about half- is significant. Our results are thus consistent with a large literature on the special role of educated migrants (Kerr and Lincoln, 2010; Hunt and Gauthier-Loiselle, 2010; Akcigit et al., 2017; Borjas and Doran, 2012; Moser et al., 2014; Bernstein et al., 2018), although it does appear that the positive effect of immigration on local innovation and income is not exclusively attributable to the this elite group.

Wage Growth and Education. Table 9 panel B shows similar results for wage growth. A county receiving 10,000 migrants with average schooling would see wages per capita increase by $\$ 269$ (in 2010 dollars) over five years $(10 \times 0.269 \times \$ 100)$, while receiving 10,000 migrants with one standard deviation extra years of education increases wages per capita increase by $\$ 1,005$ over five years $(10 \times(0.269+3.7 \times 0.199) \times \$ 100)$. The effect for the top tercile of education is also one order-of-magnitude larger than for migrants with average education.

\section{Structural Model and Estimation}

We now interpret our main finding that immigration shocks have a positive causal effect on local innovation and wages at the 5-year horizon through the lens of a quantitative regional equilibrium model of endogenous growth and migrations. This model features a local innovation decision similar to Desmet and Rossi-Hansberg (2014) and Peters (forthcoming), but also endogenizes the local distribution of immigration and ancestry from distinct origins. The model serves two main purposes. First, it enables us to quantify the equilibrium effect of migration. By matching the credibly identified reduced form response of innovation to immigration shocks, we can structurally estimate a key theoretical parameter: the local elasticity of innovation to research labor. This elasticity governs local innovation, the distribution of economic activity across space, and the aggregate response to immigration shocks in a wide range of endogenous growth models. Second, the model allows us to explicitly model threats to our identification strategy. We replicate various potential identification threats within the model and confirm our identification strategy is immune to those threats, while conventional instruments are not.

\subsection{Model}

There are $o=1, \cdots, O$ foreign origin countries and $d=1, \cdots, D$ destination US counties. Upon arriving in the US, migrants endogenously select a destination within the US to maximize their 
utility. Time $t$ is discrete, and corresponds to the five-year intervals in our data. Each county produces a nationally traded final good $(Y)$ and patents/ideas $(Q)$.

Goods production. The final good $Y_{d, t}$, with price normalized to 1 , is produced by a representative firm in $d$ at time $t$ with technology

$$
Y_{d, t}=Z_{d, t} Q_{d, t} L_{Y, d, t}^{\alpha},
$$

where $Q_{d, t}$ is the number (stock) of ideas used in production, $L_{Y, d, t}$ is labor used for production, and $0<\alpha<1$ is the elasticity of output to production labor. $Z_{d, t}$ is a stationary exogenous total factor productivity shock and evolves according to $\ln Z_{d, t}=\rho \ln Z_{d, t-1}+\epsilon_{d, t}$, with autocorrelation $0<\rho<1$ and normally distributed innovations $\epsilon_{d, t} \sim \mathcal{N}\left(0, \sigma_{\epsilon}^{2}\right)$.

Ideas production. The stock of patents/ideas in $d$ evolves cumulatively, $Q_{d, t}=Q_{d, t-1}+$ $M_{d, t}$, where $M_{d, t}$ new patents are produced by combining research labor and existing patents,

$$
M_{d, t}=L_{M, d, t}^{\gamma} Q_{d, t-1}^{1-\gamma}
$$

$L_{M, d, t}$ is labor used for research, and $0<\gamma<1$ is our key parameter: the elasticity of innovation to research labor. $M_{d, t}$, the flow of new ideas, corresponds to the total number of patents issued in $d$ at $t$. The structure of the innovation production function in equation (8) is carefully chosen to place our model within the class of semi-endogenous growth models (Jones, 1995). In these models generally, and in our model in particular (as we derive in Appendix B), diminishing returns to past ideas in innovation require that the supply of researchers increases over time to generate sustained growth in ideas. In other words, the supply of researchers, which can shift through immigration supply shocks, is the key driver of innovation in this class of models.

In the main text, we assume ideas accumulate locally based on a county's own idea stock $Q_{d, t-1}$, with no spillovers to other locations. Motivated by our empirical evidence for geographic spillovers in innovation, in Appendix B we relax this assumption and allow for idea spillovers across regions. We obtain similar quantitative results and discuss these in Section 6.5.

Firms. Both the goods market and the market for patents are competitive, with price taking firms. The final goods firm in $d$ optimally chooses the mass of ideas and production labor as inputs and maximizes profits,

$$
\max _{M, L_{Y}} Z_{d, t}\left(M+Q_{d, t-1}\right) L_{Y}^{\alpha}-W_{d, t} L_{Y}-p_{d, t} M,
$$


while the research firm optimally chooses research labor inputs to maximize

$$
\max _{L_{M}} p_{d, t} L_{M}^{\gamma} Q_{d, t-1}^{1-\gamma}-W_{d, t} L_{M}
$$

The local wage $W_{d, t}$ and the price of a local patent $p_{d, t}$, determined in equilibrium, are taken as given by both types of firms. Note the research firm gains ownership of the patents it produces for a single period. In the next period, patents expire and become a public good for other firms in the county. This simplifying assumption ensures the research firm makes only static decisions, increasing tractability despite the rich underlying semi-endogenous growth dynamics.

Population and immigration. In each county $d$, a mass $L_{d, t}$ of current residents each supplies one unit of labor to their local labor market alone. The local labor force grows solely from the inflow of foreign migrants, $L_{d, t+1}=L_{d, t}+\sum_{o=1}^{O} I_{o, d, t}$, where $I_{o, d, t}$ is the number of migrants from country $o$ who settle in county $d$ at time $t$. Note the one-period "time to migrate" lag, which mimics the way we construct our data. The total number of migrants from origin $o$ to the US, $I_{o, t}=\sum_{d=1}^{D} I_{o, d, t}$, grows at a rate $n, I_{o, t}=(1+n)^{t} \exp \left(\nu_{o, t}\right)$, subject to log-normally distributed exogenous shocks, $\nu_{o, t} \sim \mathcal{N}\left(0, \sigma_{\nu}\right)$. These shocks correspond to the origin-specific 'push' shocks in our empirical analysis.

Upon her arrival from $o$ at $t$, an individual migrant $i$ endogenously decides where to settle within the US, choosing the destination $d$ where she derives the highest utility,

$$
d=\arg \max _{k}\left(W_{k, t}\right)^{\lambda}\left(\frac{A_{o, k, t}}{A_{o, t}}\right)^{1-\lambda} \exp \left(-\tau_{o, k, t}\right) \eta_{i, k, t},
$$

where $W_{k, t}$ is the wage in destination $k, A_{o, k, t} / A_{o, t}$ is the pre-existing ancestry share from origin $o$ who reside in $k\left(A_{o, t}=\sum_{d=1}^{D} A_{o, d, t}\right), \eta_{i, k, t}$ are i.i.d. extreme-value distributed shocks across individual migrants with dispersion parameter $\theta,{ }^{29}$ and $\tau_{o, k t,} \sim \mathcal{N}\left(0, \sigma_{\tau}^{2}\right)$ are i.i.d. normal shocks to bilateral migration costs from $o$ to $k$.

Other things equal, a migrant is thus more likely to choose destination $d$ if she earns a high real wage there $\left(W_{d, t}\right),{ }^{30}$ if $d$ hosts a large pre-existing community of common ancestry $\left(A_{o, d, t} / A_{o, t}\right)$, if the bilateral migration cost is low $\left(\tau_{o, d, t}\right)$, and if she draws a high idiosyncratic taste shock $\left(\eta_{i, d, t}\right)$. The relative weight on economic versus social factors in utility is governed by the parameter $\lambda$ satisfying $0<\lambda<1$. Note she decides where to settle at $t$ using information

\footnotetext{
${ }^{29}$ The idiosyncratic taste shocks are distributed Frechet, with $\operatorname{Pr}\left[\eta_{i, k, t} \leq \eta\right]=\exp \left(-\eta^{-\theta}\right), \forall i, k, t$.

${ }^{30}$ Given that goods are freely traded on a national US market, wages in units of the numeraire are real wages, and directly comparable across locations.
} 
on the prevailing wage $W_{d, t}$, but due to the "time to migrate" lag, she enters $d$ 's labor market only at time $t+1$. This timing assumption ensures that migration decisions are static. ${ }^{31}$

Assuming a continuum of migrants, we can solve for the share of migrants from $o$ who chose destination $d$ as

$$
\frac{I_{o, d, t}}{I_{o, t}}=\frac{\left(W_{d, t}\right)^{\lambda \theta}\left(\frac{A_{o, d, t}}{A_{o, t}}\right)^{(1-\lambda) \theta} \exp \left(-\theta \tau_{o, d, t}\right)}{\sum_{k=1}^{D}\left(W_{k, t}\right)^{\lambda \theta}\left(\frac{A_{o, k, t}}{A_{o, t}}\right)^{(1-\lambda) \theta} \exp \left(-\theta \tau_{o, k, t}\right)} .
$$

This expression intuitively links to our reduced-form migration model in Section 3. There is a large inflow of migrants from $o$ to $d$ if $(i)$ many migrants from $o$ arrive in the US, $I_{o, t}$ large (a 'push' factor), (ii) $d$ offers a high wage, $W_{d, t}$ high, ( $\left.i i i\right)$ the migration cost from $o$ to $d$ is low, $\tau_{o, d, t}$ low ('economic pull' factors, potentially giving rise to the reverse causality and countycountry omitted factors concerns described above), and (iv) there is a large pre-existing group with ancestry from $o$ in $d, A_{o, d, t} / A_{o, t}$ large (a 'social pull' factor).

Ancestry evolves cumulatively, $A_{o, d, t+1}=A_{o, d, t}+I_{o, d, t}$, and local labor is allocated to goods production and research, $L_{d, t}=L_{Y, d, t}+L_{M, d, t}$. Given the tractable timing assumptions we make for patent ownership and migrations, migrants and residents make no dynamic decisions, so we do not need to explicitly model household preferences further.

\subsection{Equilibrium and Estimation}

We characterize the deterministic balanced growth path equilibrium analytically and numerically solve for dynamics off the balanced growth path with each period equal to a 5-year span matching our reduced-form empirics. See Appendix B for more information on each step, together with a formal definition of the equilibrium. We then estimate the model's key parameters by matching the dynamics of immigration and innovation in our simulated model to those in the data. Importantly, we use indirect inference, implementing the same identification strategy for immigration shocks to match the causal response of innovation to immigration in simulated and real-world data. Before describing our estimation procedure and results, we discuss the equilibrium properties of our model.

Figure 2 displays impulse response functions to a temporary, exogenous, increase in the number of migrants arriving in a given destination (top-left panel). The endogenous responses reflect deviations from the balanced growth path. The local labor force increases mechanically due to the influx of migrants (top-right panel). Due to both the cumulative impact of immi-

\footnotetext{
${ }^{31}$ See for instance Caliendo et al. (2019) and Adda et al. (forthcoming) for models with dynamic migration decisions.
} 
gration, with past immigrant enclaves attracting more future migrants, as well as the sluggish nature of deterministic population growth in the long run, the resulting increase in the local labor force is persistent. The influx of additional workers allows the research sector to expand, and patenting increases for multiple periods (bottom-left panel). Immigration has two competing effects on wages (bottom-right panel): on the one hand, the increased abundance of local labor exerts a downward pressure on wages, a negative neo-classical labor-supply effect; on the other hand, higher local innovations increase the marginal product of labor, which drives wages up, a positive endogenous-growth channel. At our estimated parameters, the positive effect dominates at the 5-year horizon, so that the effect on wages is positive, consistent with our empirical results on wages above.

The key parameter governing the strength of the innovation and wage responses to immigration shocks is $\gamma$, the local elasticity of innovation to research labor. Figure 3 shows the response of patenting (left panel) and wages (right panel) to a one-period immigration shock for different values of $\gamma$ : the smaller the value of $\gamma$, the weaker the positive impact of immigration on innovation. This pattern motivates our choice to use the reduced-form causal impact of immigration on innovation to identify $\gamma$ via structural estimation.

Note also that for lower values of $\gamma$ (dash-dot line, right panel), wages initially decline due to the increased labor supply, but eventually increase as innovations accumulate. ${ }^{32}$ This simple intuition may explain the mixed results in the empirical labor literature on immigration and wages: an immigration shock has two competing effects on wages, a negative neo-classical laborsupply effect, and a positive endogenous-growth effect. ${ }^{33}$ In light of our model, it is therefore no surprise that this literature has found seemingly contradictory results, with the effect of immigration on natives' wages estimated to be positive in some settings and negative in others (Borjas, 2003; Cortes, 2008; Ottaviano and Peri, 2012; Foged and Peri, 2016; Dustmann et al., 2017; Monras, 2020; Jaeger et al., 2018; Bratsberg et al., 2019).

Estimation results. We use a simulated method of moments (or indirect inference strategy) to estimate the model. In addition to a range of conventional moments, including the volatility and persistence of immigration, output, and patent flows, we crucially target the IV regression

\footnotetext{
${ }^{32}$ In fact, through the lens of this endogenous growth model, all growth in wages in the long run is due to population growth for any $\gamma>0$.

${ }^{33}$ This intuition is complementary to Jaeger et al. (2018), where the gradual inflow of capital in response to a labor shock plays a role similar to endogenous innovation in our model. The qualitative difference is that capital accumulation induces a temporary rise in real income and a subsequent decrease, while the innovation response in our model yields permanent gains.
} 
coefficient of patenting on immigration, using the same identification strategy to construct an instrument for immigration in our simulated model as in the actual data. The only departure from our baseline specification in Table 3 column 2 is that we use a scale invariant specification to accommodate economic growth in our model. We estimate in simulated and actual data

$$
\text { IHS }\left(\text { Patents }_{d t}\right)=\delta_{t}+\delta_{s(d)}+\beta I H S\left(\text { Immigration }_{d t}\right)+\epsilon_{d}^{t}
$$

where we instrument for immigration using the same instrument (5) as in our baseline specification. The inverse hyperbolic sine function, IHS, approximates the logarithm function, so the coefficient $\beta$ approximates the elasticity of patenting to immigration. Consistent with our earlier results, we find a large and significant elasticity of patenting to immigration shocks, $\beta=1.723$ (s.e. $=0.111$ ) (see Appendix Table 11 for details). Our simulated method of moment estimation strategy matches this regression coefficient $\beta$ in our model and in the data. Comparative statics in Appendix Figure 4 show that in simulated data, this IV regression coefficient increases with the structural parameter $\gamma$, the local elasticity of patenting to research labor, further validating our structural identification strategy.

Table 10 presents results from our structural estimation, including point estimates, standard errors, and the model's fit. Further technical details on the estimation are in Appendix B. We are able to match our target moments well (panel A). In particular, the elasticity of innovation to immigration $\beta$ is close in our simulated model and in the data (1.734 versus 1.723). Our structural estimate for the local elasticity of patenting to research labor $(\gamma=0.859$, s.e. $=0.020$ in panel B) reveals a local elasticity at the upper end of the range of values typically used in calibrated models of aggregate endogenous growth and firm innovation (Acemoglu et al., 2018; Bloom et al., 2021; Akcigit et al., 2020; Blundell et al., 2002; Terry et al., 2020).

This relatively large elasticity explains the robust response of innovation to immigration shocks in our model and also generates the positive response of wages to immigration shocks, even though we do not target this response in our estimation. Table 10 also reports our estimates of other parameters, which are intuitive. We estimate highly persistent local productivity processes with an annual autocorrelation of $\rho^{1 / 5}=0.98$, matching the high persistence of GDP and patenting at the local level. Finally, we also estimate that innovations to countylevel productivity are less volatile $\left(\sigma_{\epsilon}=0.032\right)$ than shocks to origin-level immigration flows $\left(\sigma_{\nu}=0.594\right)$ or bilateral immigration $\operatorname{costs}\left(\sigma_{\tau}=0.552\right)$, matching the relative volatilties of immigration at the county, origin, and county-origin levels. 


\subsection{Quantification of the Aggregate Impact of Immigration}

Having estimated the structural parameters of our model, we compute a simple aggregate counterfactual to gain intuition for the magnitudes involved. To this end, we compute the trajectory the US economy would have followed if the Immigration and Nationality Act of 1965 (INA) had not been passed. This act lifted many restrictions on immigration into the US. By comparing a high realized migration path under the INA, versus this counterfactually lower migration path without the INA, we offer suggestive evidence on the quantitative impact of immigration on innovation and growth.

Using decadal Census aggregates from 1860-2010, calculations detailed in Appendix B reveal that the share of the foreign-born in population growth increased on average by about $16 \%$ of total population growth in the decades after the passage of the INA. To approximately simulate the dynamics of the economy without the post-INA increase in immigration, we therefore feed in a repeated series of negative immigration supply shocks leading to a reduction of aggregate immigration flows by the same $16 \%$ of total population growth each period.

The resulting cumulative deviations of macroeconomic aggregates from the balanced growth path are presented in Figure 4. Our estimates suggest this counterfactual reduction in immigration would have caused a sharp reduction in patenting per capita, reaching an 8\% drop by 1990 (top right panel), and a slower reduction of wages, reaching a 5\% drop by 2010 (bottom left panel). Interestingly, the impact on output per capita is close to zero until 1980, as the large stock of patents inherited from the pre-INA period, and the reallocation of labor away from innovation due to the reduction in immigration, allows for more goods production; eventually, as the stock of innovation falls, output per capita falls by $5 \%$ by 2010 (top left panel).

This simple counterfactual experiment suggests that the sustained immigration into the US following the passage of the Immigration and Nationality Act of 1965 has contributed to substantial, albeit gradual, gains in innovation (about $8 \%$ over 25 years), in wages (about $5 \%$ over 45 years), and in output per worker (about $5 \%$ over 45 years).

\subsection{Identification}

Importantly, our structural model allows us to shed light on our reduced-form identification strategy from Section 3. We can both analyze our IV approach and compare it to the seminal identification strategy proposed by Card (2001) which predicts contemporaneous immigration 
shocks by interacting contemporaneous immigration shifters with past immigration shares,

$$
\hat{I}_{d, t}^{C a r d}=\sum_{o=1}^{O} I_{o, t} \frac{I_{o, d, t-1}}{I_{o, t-1}} .
$$

Applying our endogenous migration model (12) at time $t-1$, we directly see that past immigration shares are proportional to past local wages, $I_{o, d, t-1} / I_{o, t-1} \propto\left(W_{d, t-1}\right)^{\lambda \theta}, \forall o$, so that predicted immigration shocks in $d$ are themselves proportional to past wages in $d, \hat{I}_{d, t}^{C a r d} \propto\left(W_{d, t-1}\right)^{\lambda \theta}$. A positive productivity shock, an increase in $Z_{d, t-1}$ in (7), increases wages $W_{d, t-1}$ which in turn attracts migrants to $d$. As productivity shocks are persistent, the 'Card' instrument in (14) thus picks up the (simple) reverse causality effect of technology on immigration mentioned above. ${ }^{34}$ Our identification strategy instead constructs a set of instruments for ancestry (5): $\hat{I}_{d, t}=\sum_{o=1}^{O} \hat{b}_{t}\left[\hat{A}_{o, d, t-1} \times \tilde{I}_{o, \text { leave-out }, t}\right]$ which isolate relative variation in predicted local ancestry composition that results exclusively from the coincidental timing of historical push and pull factors - purging the effect of persistent productivity shocks from our immigration shocks.

Figure 5 (left panel) explicitly shows the correlation structure between productivity shocks $\left(Z_{d, t}\right)$, realized immigration $\left(I_{d, t}\right)$, the 'Card' predicted immigration shock $\left(\hat{I}_{d, t}^{C a r d}\right)$, and our proposed predicted immigration shock $\left(\hat{I}_{d, t}\right)$. For reference, the figure also includes an intermediate 'Ancestry' version of our instrument $\hat{I}_{d, t}^{A n c}$ constructed by simply replacing predicted ancestry $\hat{A}_{o, d, t-1}$ with realized ancestry. As expected, because productivity is persistent, realized immigration is correlated with contemporaneous productivity shocks. The 'Card' instrument, because it relies on past immigration shares, themselves correlated with persistent past productivity shocks, is also correlated with contemporaneous productivity shocks. Simply leveraging realized ancestry data in the 'Ancestry' instrument, rather than recent immigration shares as in the Card approach, alleviates this correlation somewhat but not fully. Our predicted immigration shocks $\hat{I}_{d, t}$, which exploit only the historically predicted, relative component of ancestry and include a rich leave-out structure, are not correlated at all with local productivity shocks.

Figure 5 (right panel) shows our identification strategy is also immune to the more refined identification concern regarding county-country specific omitted factors. If specific migrants (say Indian engineers) have skills suited for certain industries and destinations (say IT in Silicon Valley), then any shock to the cost of migration correlated with TFP (say $\tau_{\text {India,SantaClara, } t}$ correlated with $Z_{\text {Santa Clara,t }}$ ) would induce a spurious correlation between innovation, immigration, and ancestry. Figure 5 (right panel) confirms that realized bilateral migration flows $\left(I_{o, d, t}\right)$,

\footnotetext{
${ }^{34}$ As noted earlier, David Card explicitly notes that past immigration shares may be correlated with persistent productivity shocks (Card, 2001, p. 43), potentially creating a spurious correlation with contemporaneous wages.
} 
'Card' predicted bilateral migration flows $\left(\hat{I}_{o, d, t}^{\text {Card }}\right)$, and a crude 'Ancestry' instruments' predicted migration flows $\left(\hat{I}_{o, d, t}^{A n c}\right)$ are all correlated with the model's underlying bilateral migration cost shock $\left(\tau_{o, d, t}\right)$, while our predicted migration flows $\left(\hat{I}_{o, d, t}\right)$ are not.

To summarize, within a quantitative model of endogenous growth and migration, our proposed instrument for immigration shocks is orthogonal to two key variables that would raise natural endogeneity concerns (persistent productivity and bilateral migration costs). This set of results makes us confident our identification strategy is well-suited to identify the causal impact of immigration on innovation and growth.

\subsection{Extensions}

The Appendix contains additional variations of the model that incorporate and allow for some of our additional empirical results.

Idea Spillovers. In our baseline model, local innovations are assumed to depend on local research labor and the local stock of ideas only, while we show evidence of spatial diffusion in Section 5. In Appendix B, with an extended model allowing for the effective stock of ideas in one region to depend upon a flexible weighted average of idea stocks in all regions, we show that this assumption is quantitatively inconsequential for our estimation. If we assume full spillovers of idea stocks instead, and repeat our structural estimation, we find a local innovation elasticity $\gamma$ similar to our baseline $(\gamma=0.837$, s.e. $=0.029$ in panel B in Appendix Table 12 versus $\gamma=0.859$ in our baseline). Intuitively, our structural estimates of $\gamma$ are similar in the two cases because we match the short-run response of local innovation to immigration shocks which shift local research inputs ( $L_{M, d, t}$ in (8) above). By contrast, spillovers do not meaningfully affect this short-run response because they operate through a slower-moving local idea stock $\left(Q_{d, t-1}\right.$ in (8) above) which does not vary meaningfully in our five-year estimation window. Similarly, our assumptions on spatial spillovers do not meaningfully affect our quantification of the aggregate response to a symmetric, country-wide immigration shock. Instead, alternative assumptions on the spillovers of innovations only affect the distribution of innovation and income growth across regions in response to asymmetric shocks, which we do not explicitly study here.

Educational Heterogeneity and Efficiency Units. Labor inputs for both goods and idea production in our model can easily be interpreted as corresponding to efficiency units of labor. We specify and analyze this extension in Appendix B, building a structure where the effectiveness of researchers in innovation increases when their average education level is higher. 
We then link the quantitative magnitude of the returns to education in the model extension to our empirical results on the differential impacts of high versus low education migrants from Section 5. We then compare the baseline quantitative impact of a one standard deviation immigration shock on a region's patenting and wages to two alternative extreme cases in which immigration flows by themselves cause (i) an increase or (ii) a decline in the local research labor force's average schooling level by a full year. Since the flow of immigrants is small relative to the existing stock of local researchers, shifts in average education levels by a full year in either direction as we consider would only result from dramatically skewed immigrant educational attainment. Appendix Figure 5 shows that even across the full range of these extreme assumptions the positive impacts of immigration on a region's patenting $(1.3-1.8 \%$ relative to the balanced growth path) and wages (0.19 - 0.27\% relative to the balanced growth path) remain meaningful. Since the quantitative impact of immigration on innovation varies only moderately across this wide range of experiments, we conclude that our results are robust to reasonable extensions with educational heterogeneity.

\section{Conclusion}

The economic, social, political, and cultural changes immigrants bring to their host communities are often the subject of fierce political controversy. Is immigration an asset or a liability for the receiving communities? Informing this debate with data has often proven difficult, not only because different migrants may affect their host societies in many different and highly heterogeneous ways, but also due to an identification problem: immigrants do not randomly allocate across space, but likely select into host communities that offer the best prospects. This selection generates endogenous correlation between past and present immigration, ancestry composition, and local economic outcomes, making it difficult to isolate the causal effects of immigration on these outcomes.

In this paper, we introduce a novel solution to this identification problem that allows for the construction of local immigration shocks - instruments for the total number of migrants arriving in each US county for each five-year period since 1975. Importantly, these immigration shocks remain valid even if migrations prior to 1975, and thus the county's pre-existing ancestry composition, are endogenous to local economic activity, and can be flexibly disaggregated to obtain different instruments for migrations from each of the origin countries to each destination county at each point in time.

We use these instruments to document three main empirical findings. First, we show that, 
on average, immigration to the US between 1975 and 2010 had a positive causal effect on local innovation, local economic dynamism, and average wages of natives, where, for example, a $1 \%$ increase in immigration to a given county on average increased the number of patents filed by local residents by $1.7 \%$ over a five-year period. Second, we find positive spillovers of these positive local effects, where, for example, an increase in a given US county's immigration significantly increases the patenting rate in surrounding areas up to a distance of $250 \mathrm{~km}$ (150 miles). Third, we find the effect of immigration on innovation and local wages is not uniform, with more educated migrants inducing more local innovation and higher local wages than migrants with little or no education.

We interpret those empirical results through the lens of a structural model of endogenous migrations and innovation. To quantify this structural model, we target the reduced form impact of immigration on innovation. This quantification exercise suggests that the elasticity of innovation with respect to research labor, 0.859, is relatively large, implying that labor supply shocks such as those brought by international migrations have strong scale effects on local innovation. This model also explicitly shows that while immigration unambiguously increases innovation, its effect on local wages varies over time: in the very short run, its is possible for a labor supply shock to depress wages, while the positive impact of higher innovation and labor productivity on wages gradually builds over time and becomes dominant.

Beyond our application to immigration and innovation, we believe our approach linking pre-existing (ancestry) shares to the interaction of historical push and economic pull factors may prove useful in other applications of the canonical shift-share instrument. For example, the cumulative forces that lead to the establishment of migrants of a given ethnicity in a given location over time may be similar to the historical forces that generate variation in pre-existing shares of industries, occupations, and other specializations in a given location. Our procedure for isolating quasi-random variation in pre-existing shares may thus prove useful in other settings that have studied the local effects of import competition, the local fiscal multiplier, local supply elasticities, and other important subjects. 


\section{References}

Abramitzky, R. and L. Boustan (2017): "Immigration in American economic history," Journal of Economic Literature, 55, 1311-45.

Acemoglu, D., U. Akcigit, H. Alp, N. Bloom, And W. Kerr (2018): "Innovation, reallocation, and growth," American Economic Review, 108, 3450-91.

AdÃo, R., M. Kolesár, And E. Morales (2019): "Shift-share designs: Theory and inference," The Quarterly Journal of Economics, 134, 1949-2010.

Adda, J., C. Dustmann, and J.-S. GöRlach (forthcoming): "The dynamics of return migration, human capital accumulation, and wage assimilation," The Review of Economic Studies.

Aghion, P., A. Bergeaud, T. Boppart, P. J. Klenow, and H. Li (2019): "A theory of falling growth and rising rents," NBER Working Paper 26448.

Aghion, P. And P. Howitt (1992): "A model of growth through creative destruction," Econometrica (1986-1998), 60, 323.

Akcigit, U. And S. T. Ates (2021): "Ten facts on declining business dynamism and lessons from endogenous growth theory," American Economic Journal: Macroeconomics, 13, 257-98.

Akcigit, U., J. Grigsby, And T. Nicholas (2017): "The rise of American ingenuity: Innovation and inventors of the Golden Age," NBER Working Paper 23047.

Akcigit, U., J. G. Pearce, and M. Prato (2020): "Tapping into talent: Coupling education and innovation policies for economic growth," NBER Working Paper 27862.

Alon, T., D. Berger, R. Dent, And B. Pugsley (2018): "Older and slower: The startup deficit's lasting effects on aggregate productivity growth," Journal of Monetary Economics, 93, 68-85.

Angrist, J. D. And J.-S. Pischke (2009): Mostly harmless econometrics: An empiricist's companion, Princeton university press.

Arkolakis, C., M. Peters, And S. K. Lee (2020): "European Immigrants and the United States' Rise to the Technological Frontier," Working Paper. 
BARTIK, T. (1991): Who benefits from state and local economic development policies?, W.E. Upjohn Institute.

Bernstein, S., R. Diamond, T. McQuade, And B. Pousada (2018): "The contribution of high-skilled immigrants to innovation in the United States," Working paper.

Bloom, N., C. I. Jones, J. Van Reenen, And M. Webb (2020): "Are ideas getting harder to find?" American Economic Review, 110, 1104-44.

Bloom, N., P. Romer, S. J. Terry, and J. Van Reenen (2021): "Trapped factors and China's impact on global growth," The Economic Journal, 131, 156-191.

Blundell, R., R. Griffith, And F. Windmeijer (2002): "Individual effects and dynamics in count data models," Journal of Econometrics, 108, 113-131.

BorJas, G. J. (2003): "The labor demand curve is downward sloping: Reexamining the impact of immigration on the labor market," The Quarterly Journal of Economics, 118, 1335-1374.

BorJas, G. J. And K. B. Doran (2012): "The collapse of the Soviet Union and the productivity of American mathematicians," The Quarterly Journal of Economics, 127, 1143-1203.

Borusyak, K., P. Hull, And X. Jaravel (2021): "Quasi-experimental shift-share research designs," The Review of Economic Studies.

Bratsberg, B., A. Moxnes, O. RaAum, K.-H. Ulltveit-Moe, et Al. (2019): "Opening the floodgates: Industry and occupation adjustments to labor immigration," CEPR Discussion Paper No. 13670.

Burchardi, K. B., T. Chaney, And T. A. Hassan (2019): "Migrants, Ancestors, and Foreign Investments," The Review of Economic Studies, 86, 1448-86.

Caliendo, L., M. Dvorkin, And F. Parro (2019): "Trade and labor market dynamics: General equilibrium analysis of the china trade shock," Econometrica, 87, 741-835.

CARD, D. (2001): "Immigrant Inflows, Native outflows, and the Local Labor Market Impacts of Higher Immigration," Journal of Labor Economics, 19, 22-64.

Cortes, P. (2008): "The Effect of Low-Skilled Immigration on U.S. Prices: Evidence from CPI Data," Journal of Political Economy, 116, 381-422. 
Davis, S. J. And J. Haltiwanger (1999): "Gross job flows," Handbook of Labor Economics, 3, 2711-2805.

Decker, R., J. Haltiwanger, R. Jarmin, and J. Miranda (2014): "The secular decline in business dynamism in the US," Working paper.

Desmet, K., D. K. Nagy, and E. Rossi-Hansberg (2018): "The geography of development," Journal of Political Economy, 126, 903-983.

Desmet, K. And E. Rossi-Hansberg (2014): "Spatial development," American Economic Review, 104, 1211-43.

Dustmann, C., U. Schönberg, And J. Stuhler (2017): "Labor supply shocks, native wages, and the adjustment of local employment," The Quarterly Journal of Economics, 132, 435-483.

Foged, M. And G. PERI (2016): “Immigrants' effect on native workers: New analysis on longitudinal data," American Economic Journal: Applied Economics, 8, 1-34.

Giannone, E. (2019): "Skill-biased technical change and regional convergence," Working paper.

Goldsmith-Pinkham, P., I. Sorkin, And H. Swift (2020): "Bartik instruments: What, when, why, and how," .

Gordon, R. J. (2012): "Is US economic growth over? Faltering innovation confronts the six headwinds," NBER Working Paper 18315.

Grossman, G. M. And E. Helpman (1991): "Quality ladders in the theory of growth," The Review of Economic Studies, 58, 43-61.

Guren, A., A. McKay, E. Nakamura, and J. Steinsson (2021): "What Do We Learn from Cross-Regional Empirical Estimates in Macroeconomics?" NBER Macroeconomics Annual, 35, 175-223.

Hall, B. H., A. B. Jaffe, And M. Trajtenberg (2001): "The NBER Patent Citaitons Data File: Lessons, Insights, and Methodological Tools," NBER Working Paper 8498.

Hall, R. E. And C. I. Jones (1999): "Why do some countries produce so much more output per worker than others?" The Quarterly Journal of Economics, 114, 83-116. 
Hanson, G. H. (2009): "The economic consequences of the international migration of labor," Annual Review of Economics, 1, 179-208.

(2010): "Future Directions for Research on Immigration," American Economic Association, Ten Years and Beyond: Economists Answer NSF's Call for Long-Term Research Agendas.

Hathaway, I. And R. E. Litan (2014): "Declining business dynamism in the United States: A look at states and metros," Brookings Institution, 2.

Hopenhayn, H., J. Neira, and R. Singhania (2018): "From Population Growth to Firm Demographics: Implications for Concentration, Entrepreneurship and the Labor Share," NBER Working Paper 25382.

Hunt, J. And M. Gauthier-Loiselle (2010): "How Much Does Immigration Boost Innovation?" American Economic Journal: Macroeconomics, 2, 31-56.

Isaiah, A., S. James, S. LiYang, ET AL. (2018): "Weak Instruments in IV Regression: Theory and Practice," Annual Review of Economics.

Jaeger, D. A., J. Ruist, And J. Stuhler (2018): "Shift-share instruments and the impact of immigration," NBER Working Paper 24285.

Jones, C. I. (1995): "R\&D-Based Models of Economic Growth," Journal of Political Economy, 103.

(1999): "Growth: with or without scale effects?" American Economic Review, 89, $139-144$.

Karahan, F., B. Pugsley, And A. Sahin (2019): "Demographic origins of the startup deficit," NBER Working Paper 25874.

KERR, W. R. (2008): "Ethnic scientific communities and international technology diffusion," The Review of Economics and Statistics, 90, 518-537.

KerR, W. R. And W. F. Lincoln (2010): "The Supply Side of Innovation: H1B Visa Reforms and U.S. Ethnic Invention," Journal of Labor Economics, 28, 473-508.

Khanna, G. And M. LeE (2018): "High-skill Immigration, Innovation, and Creative Destruction," NBER Working Paper 24824. 
Klette, T. J. And S. Kortum (2004): "Innovating firms and aggregate innovation," Journal of Political Economy, 112, 986-1018.

Koop, G., M. H. Pesaran, And S. M. Potter (1996): "Impulse response analysis in nonlinear multivariate models," Journal of Econometrics, 74, 119-147.

Lafortune, J., E. Lewis, And T. José (2019): "People and Machines: A Look at the Evolving Relationships Between Capital and Skill in Manufacturing 1860-1930 Using Immigration Shocks," The Review of Economics and Statistics, 101, 30-43.

Laincz, C. A. And P. F. Peretto (2006): "Scale effects in endogenous growth theory: An error of aggregation not specification," Journal of Economic Growth, 11, 263-288.

LEwis, E. (2011): "Immigration, Skill Mix, and Capital Skill Complementarity," The Quarterly Journal of Economics, 126, 1029-1069.

(2013): "Immigration and production technology," Annual Review of Economics, 5, $165-191$.

Lewis, E. AND G. Peri (2015): "Immigration and the Economy of Cities and Regions," in Handbook of regional and urban economics, Elsevier, vol. 5, 625-685.

Monras, J. (2020): "Immigration and Wage Dynamics: Evidence from the Mexican Peso Crisis," Journal of Political Economy, 128, 3017-3089.

Monte, F., S. J. Redding, and E. Rossi-Hansberg (2018): "Commuting, migration, and local employment elasticities," American Economic Review, 108, 3855-90.

Montiel Olea, J. L. And C. Pflueger (2013): “A Robust Test for Weak Instruments," Journal of Business \& Economic Statistics, 31, 358-369.

Moser, P., A. Voena, And F. Waldinger (2014): "German Jewish émigrés and US invention," American Economic Review, 104, 3222-55.

Nakamura, E. And J. Steinsson (2014): "Fiscal stimulus in a monetary union: Evidence from US regions," American Economic Review, 104, 753-92.

Ottaviano, G. I. And G. Peri (2012): "Rethinking the effect of immigration on wages," Journal of the European Economic Association, 10, 152-197. 
Peretto, P. F. (1998): "Technological change and population growth," Journal of Economic Growth, 3, 283-311.

Peters, M. (forthcoming): "Market Size and Spatial Growth - Evidence from Germany's Post-War Population Expulsions," Econometrica.

Peters, M. And C. Walsh (2021): "Population Growth and Firm Dynamics," Working Paper 29424, National Bureau of Economic Research.

Romer, P. M. (1990): "Endogenous technological change," Journal of Political Economy, 98, S71-S102.

SEqueira, S., N. Nunn, And N. Quian (2020): "Immigrants and the making of America," The Review of Economic Studies, 382-419.

Stuen, E. T., A. M. Mobarak, And K. E. Maskus (2012): "Skilled Immigration and Innovation: Evidence from Enrolment Fluctuations in US Doctoral Programmes," The Economic Journal, 122, 1143-1176.

Tabellini, M. (2019): "Gifts of the Immigrants, Woes of the Natives: Lessons from the Age of Mass Migration," The Review of Economic Studies, 87, 454-486.

Terry, S. J., T. M. Whited, And A. Zakolyukina (2020): "Information versus Investment," Working paper.

US Census Bureau (2014): "The "Second Great Wave" of Immigration: Growth of the Foreign-Born Population Since 1970," Web posting.

Walsh, C. (2019): "Firm Creation and Local Growth," Working paper.

Young, A. (1998): "Growth without scale effects," Journal of Political Economy, 106, 41-63. 
Table 1: Summary Statistics by County-Year

\begin{tabular}{|c|c|c|c|c|}
\hline & $\mathrm{N}$ & mean & sd & iqr \\
\hline \multicolumn{5}{|l|}{ Immigration Flows and Population Change } \\
\hline Immigration $_{d}^{t}$ & 21,987 & 1.42 & 12.21 & 0.22 \\
\hline$\Delta$ Population ${ }_{d}^{t}$ & 21,986 & 4.03 & 19.63 & 2.55 \\
\hline Immigration Shock $\left(\hat{I}_{d}^{t}\right)$ & 21,987 & 0.00 & 4.99 & 0.24 \\
\hline \multicolumn{5}{|l|}{ Patents } \\
\hline Patenting per 100,000 people & 21,987 & 38.34 & 110.65 & 24.36 \\
\hline 5-Year Difference in in Patenting per 100,000 People & 18,846 & 5.53 & 56.54 & 7.53 \\
\hline 5-Year Difference in in Patenting per 100,000 People (Inventors) & 18,846 & 23.96 & 113.27 & 47.59 \\
\hline 5-Year Difference in in Patenting per 100,000 People (Citation Weighted) & 18,846 & 6.60 & 78.45 & 7.06 \\
\hline \multicolumn{5}{|l|}{ Dynamism and Wages } \\
\hline 5-Year Difference in Job Creation Rate & $6,600.00$ & -32.47 & 209.90 & 50.00 \\
\hline 5-Year Difference in Job Destruction Rate & $6,600.00$ & -17.37 & 199.58 & 38.46 \\
\hline 5-Year Difference in Job Growth Rate Skewness & $12,564.00$ & -6.82 & 48.91 & 51.87 \\
\hline 5-Year Difference in Average Annual Wage & 21,978 & 19.02 & 56.65 & 25.81 \\
\hline 10-Year Difference in Average Annual Wage of Natives & 12,546 & 10.75 & 25.80 & 32.20 \\
\hline 10-Year Difference in Average Annual Wage of Native Non-Movers & 6,274 & 16.85 & 27.19 & 33.08 \\
\hline \multicolumn{5}{|l|}{ Immigration and Education } \\
\hline Immigration $_{d}^{t}($ Age $25+)$ & 21,987 & 0.80 & 6.91 & 0.11 \\
\hline Average Years College ${ }_{d}^{t}$ (Age 25+) & 21,987 & 1.50 & 1.41 & 1.82 \\
\hline Average Years Education ${ }_{d}^{t}$ (Age $25+$ ) & 21,987 & 10.88 & 3.65 & 4.59 \\
\hline \multicolumn{5}{|l|}{ Spillovers } \\
\hline Immigration $_{\text {State }}^{t}$ & 21,987 & 808.00 & $1,438.90$ & 557.47 \\
\hline Neighbors' Immigration ${ }_{d}^{t}$ (Inverse Distance Weight) & 21,987 & 1.15 & 0.78 & 0.65 \\
\hline Immigration $^{t}$ within $100 \mathrm{~km}$ & 21,987 & 18.58 & 64.65 & 9.21 \\
\hline Immigration $^{t}$ within $250 \mathrm{~km}$ & 21,987 & 74.96 & 133.50 & 67.60 \\
\hline Immigration $^{t}$ within $500 \mathrm{~km}$ & 21,987 & 123.10 & 149.52 & 143.69 \\
\hline
\end{tabular}

Notes: This table displays the number of observations, mean, standard deviation, and interquartile range for all outcome variables considered, as well as the variables for immigration and the immigration instrument. The first section of the table contains summary statistics for immigration (here we focus only on non-European migration) and population growth in 1000s of people. The second section lists summary statistics for patenting and differences in patenting per 100,000 people. The third section reports summary statistics for dynamism and wages $(\$ 100)$. Finally, the fourth and fifth section provide summary statistics on the immigration variables used in the education and spillovers analyses, respectively. Variables for immigration, population growth, and education are all for fiveyear periods, as are the differenced outcomes except in the case of differences in average annual wage for natives and native non-movers, which are over 10-year periods. 
Table 2: Regressions of Immigration on Push-Pull Instruments at the Country-County Level

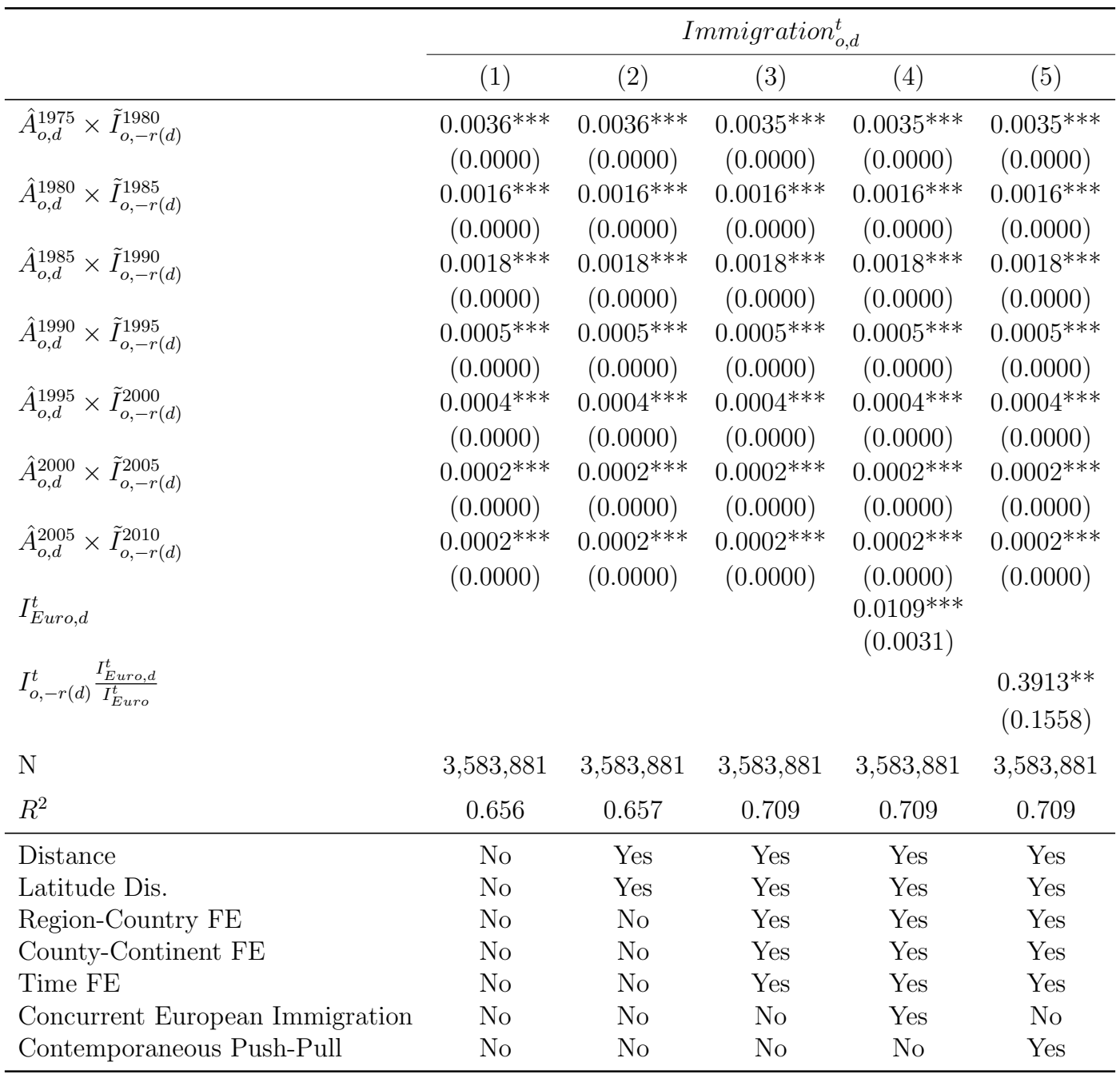

Notes: This table reports coefficient estimates for step 2 of our instrument construction, shown in equation (4), at the country-county level. Moving from column 1 to column 3 we introduce controls for distance and latitude distance and then fixed effects into the regression specification. Column 4 adds contemporaneous European migration as a control while column 5 instead introduces the contemporaneous push-economic pull factor for non-European migration. Standard errors are clustered by country for all specifications and $*, * *$, and $* * *$ denote statistical significance at the $10 \%, 5 \%$, and $1 \%$ levels, respectively. 
Table 3: County-Level Panel Regressions of Difference in Patenting on Immigration

\begin{tabular}{|c|c|c|c|}
\hline & \multicolumn{3}{|c|}{$\begin{array}{l}\text { 5-Year Difference in Patenting } \\
\text { per 100,000 People Post } 1980\end{array}$} \\
\hline & (1) & $(2)$ & $(3)$ \\
\hline \multicolumn{4}{|l|}{ Panel A: OLS } \\
\hline $\operatorname{Immigration}_{d}^{t}$ & $\begin{array}{l}0.196^{* *} \\
(0.097)\end{array}$ & $\begin{array}{l}0.186^{*} \\
(0.093)\end{array}$ & $\begin{array}{c}0.342 \\
(0.225)\end{array}$ \\
\hline $\mathrm{N}$ & 18,846 & 18,840 & 18,846 \\
\hline$R^{2}$ & 0.023 & 0.044 & 0.155 \\
\hline \multicolumn{4}{|l|}{ Panel B: IV } \\
\hline $\operatorname{Immigration}_{d}^{t}$ & $\begin{array}{c}0.115^{* * *} \\
(0.040)\end{array}$ & $\begin{array}{c}0.111^{* * *} \\
(0.041)\end{array}$ & $\begin{array}{c}0.116^{* * *} \\
(0.026)\end{array}$ \\
\hline $\mathrm{N}$ & 18,846 & 18,840 & 18,846 \\
\hline First Stage F-Stat & 911 & 807 & 85 \\
\hline AR Wald F-Test p-value & 0.010 & 0.016 & 0.000 \\
\hline Panel C: First Stage & \multicolumn{3}{|c|}{ Immigration $_{d}^{t}$} \\
\hline Immigration Shock $\left(\hat{I}_{d}^{t}\right)$ & $\begin{array}{l}2.119^{* * *} \\
(0.070)\end{array}$ & $\begin{array}{l}2.124^{* * * *} \\
(0.075)\end{array}$ & $\begin{array}{c}1.610 * * * \\
(0.175)\end{array}$ \\
\hline $\mathrm{N}$ & 18,846 & 18,840 & 18,846 \\
\hline$R^{2}$ & 0.762 & 0.766 & 0.956 \\
\hline Geography FE & State & State & County \\
\hline Time FE & Yes & Yes & Yes \\
\hline State-Time FE & No & Yes & No \\
\hline
\end{tabular}

Notes: Panels A and B of this table reports the OLS and IV results, respectively, of the estimation of equation (1) where the dependent variable is the change in patenting per 100,000 people (population is based on baseline 1970 levels) in county $d$ in the five-year period ending in $t$ and the endogenous variable is non-European immigration $(1,000 \mathrm{~s})$ in $d$ and period $t$. Panel B reports the results for step 3 of instrument construction, or the coefficient estimates for the first-stage specification for non-European immigration $(1,000 \mathrm{~s})$ for the instrument described in equation (5). The table includes the first-stage F-statistic on the excluded instrument and the pvalue for the Anderson-Rubin Wald F test for each of the IV specifications. Standard errors are clustered by state for all specifications, and *,**, and *** denote statistical significance at the $10 \%, 5 \%$, and $1 \%$ levels, respectively. 
Table 4: Robustness - Relationship to Alternative Instruments for Immigration

5-Year Difference in Patenting per 100,000

(1)

(2)

(3)

$(4)$

\begin{tabular}{|c|c|c|c|c|}
\hline \multirow[t]{2}{*}{ Panel A } & \multicolumn{4}{|c|}{ Alternative Instrument Constructions } \\
\hline & $\begin{array}{l}\text { Leave-Out } \\
\text { Correlated Counties }\end{array}$ & $\begin{array}{c}\text { Leave-Out } \\
\text { Own Continent }\end{array}$ & $\begin{array}{l}\text { Ancestry in } \\
1975 \text { only }\end{array}$ & $\begin{array}{l}\text { Stop Push-Pull } \\
\text { in } 1960\end{array}$ \\
\hline Immigration $_{d}^{t}$ & $\begin{array}{l}0.102^{* *} \\
(0.041)\end{array}$ & $\begin{array}{c}0.107^{* * *} \\
(0.035)\end{array}$ & $\begin{array}{c}0.105^{* * *} \\
(0.035)\end{array}$ & $\begin{array}{c}0.078^{* * *} \\
(0.022)\end{array}$ \\
\hline $\mathrm{N}$ & 18,846 & 18,846 & 18,846 & 18,846 \\
\hline First Stage F-Stat & 127 & 830 & 1,171 & 1,750 \\
\hline $\begin{array}{l}\text { AR Wald F-Test p-value } \\
\text { Geography FE } \\
\text { Time FE }\end{array}$ & $\begin{array}{l}0.005 \\
\text { State } \\
\text { Yes }\end{array}$ & $\begin{array}{l}0.007 \\
\text { State } \\
\text { Yes }\end{array}$ & $\begin{array}{c}0.007 \\
\text { State } \\
\text { Yes }\end{array}$ & $\begin{array}{l}0.001 \\
\text { State } \\
\text { Yes }\end{array}$ \\
\hline Panel B & \multicolumn{4}{|c|}{ Alternative Instruments for Immigration } \\
\hline $\begin{array}{l}\text { Immigration }_{d}^{t} \\
\text { Sequeira et al. Instrument }\end{array}$ & $\begin{array}{c}0.114^{* * *} \\
(0.039) \\
169.483^{* * *} \\
(60.667)\end{array}$ & $\begin{array}{c}0.115^{* * *} \\
(0.040)\end{array}$ & $\begin{array}{c}0.113^{* * *} \\
(0.039) \\
169.487^{* * *} \\
(60.668)\end{array}$ & $\begin{array}{c}0.112^{* * *} \\
(0.024) \\
\text { (dropped) }\end{array}$ \\
\hline Hunt and Gauthier-Loiselle Instrument & & $\begin{array}{c}-80.993 \\
(113.029)\end{array}$ & $\begin{array}{c}-81.067 \\
(113.030)\end{array}$ & $\begin{array}{l}-81.168 \\
(113.770)\end{array}$ \\
\hline $\mathrm{N}$ & 18,666 & 18,666 & 18,666 & 18,666 \\
\hline First Stage F-Stat & 892 & 892 & 892 & 90 \\
\hline $\begin{array}{l}\text { AR Wald F-Test p-value } \\
\text { Geography FE } \\
\text { Time FE }\end{array}$ & $\begin{array}{c}0.010 \\
\text { State } \\
\text { Yes }\end{array}$ & $\begin{array}{c}0.010 \\
\text { State } \\
\text { Yes }\end{array}$ & $\begin{array}{c}0.010 \\
\text { State } \\
\text { Yes }\end{array}$ & $\begin{array}{l}0.000 \\
\text { County } \\
\text { Yes }\end{array}$ \\
\hline
\end{tabular}

Notes: This table displays the results of estimating equation (1), where the dependent variable is the change in patenting per 100,000 people (population is based on baseline 1970 levels) and the endogenous variable is nonEuropean immigration $(1,000 \mathrm{~s})$ to $d$ in $t$. In Panel $\mathrm{A}$, each column utilizes the same approach for instrument construction as the main instrument but with one adjustment. Column 1 takes the sum over push-pull interaction up to the year 1960 only in Step 1 to create an instrument for ancestry. Column 2 replaces predicted ancestry in $t-1$ with predicted ancestry in 1975 for all periods. Column 3 uses an alternative leave-out strategy in Step 1: the push factor excludes all destination counties whose overall time series of immigration flows are correlated with those of $d$ (as opposed to excluding counties in the same census division $(r(d))$ as $d$ ). Column 4 replaces the economic pull factor in Step 1 with the share of all migrants who settle in $d$ but excluding migrants from the same continent as $o$ (instead of using only European migrants). In Panel B, column 1 adds as a control the instrument of Sequeira et al. (2020), column 2 instead adds Hunt and Gauthier-Loiselle (2010), column 3 adds both instruments, and column 4 repeats the estimation in column 3 but with county fixed effects. The instrument of Hunt and Gauthier-Loiselle (2010) is for 10-year periods up to 2000 and so we assign the 1980 instrument to the 5-year period for 1980, the 1990 instrument to 1985 and 1990, and the 2000 instrument to 1995, 2000, 2005, and 2010. We report the first-stage $F$-statistic on the excluded instrument and the p-value for the Anderson-Rubin Wald $\mathrm{F}$ test for each specification. Standard errors are clustered by state for all specifications, and *, **, and *** denote statistical significance at the $10 \%, 5 \%$, and $1 \%$ levels, respectively. 
Table 5: Robustness - Alternative Share-Based Instruments and Rejection Rates

\begin{tabular}{|c|c|c|c|c|}
\hline \multirow{3}{*}{ Specification: } & \multicolumn{4}{|c|}{ 5-Year Difference in Patenting per 100,000 People Post 1980} \\
\hline & $\begin{array}{c}\text { Predicted Ancestry } \\
\text { Shares } \\
\text { (Baseline) }\end{array}$ & $\begin{array}{c}\text { Realized Immigration } \\
\text { Shares } \\
\text { (Card, 2001) }\end{array}$ & $\begin{array}{l}\text { Realized Ancestry } \\
\text { Shares }\end{array}$ & $\begin{array}{l}\text { Realized Ancestry } \\
\text { Shares } \\
\text { With Leave-Out }\end{array}$ \\
\hline & $(1)$ & $(2)$ & (3) & $(4)$ \\
\hline $\begin{array}{l}\text { Adão et al (2019) First Stage } \\
\text { False Rejection Rate (\%): }\end{array}$ & 3.8 & $\begin{array}{c}27.4 \\
\text { Overreject }\end{array}$ & $\begin{array}{c}26.8 \\
\text { Overreject }\end{array}$ & $\begin{array}{c}26.8 \\
\text { Overreject }\end{array}$ \\
\hline Immigration $_{d}^{t}$ & $\begin{array}{c}0.218^{* *} \\
(0.102)\end{array}$ & $\begin{array}{l}0.155 \\
(0.075)\end{array}$ & $\begin{array}{c}0.156 \\
(0.068)\end{array}$ & $\begin{array}{l}0.196 \\
(0.090)\end{array}$ \\
\hline $\mathrm{N}$ & 18,846 & 18,846 & 18,846 & 18,846 \\
\hline First Stage F-Stat & 656 & 695 & 361 & 498 \\
\hline $\begin{array}{l}\text { Instrument Functional Form: } \\
\text { Instrumented Ancestry } \\
\text { Push Factor Leave-Out } \\
\text { Controls: }\end{array}$ & $\begin{array}{l}\text { Yes } \\
\text { Yes }\end{array}$ & $\begin{array}{l}\text { No } \\
\text { Yes }\end{array}$ & $\begin{array}{l}\text { No } \\
\text { No }\end{array}$ & $\begin{array}{l}\text { No } \\
\text { No }\end{array}$ \\
\hline $\begin{array}{l}\text { Geography FE } \\
\text { Time FE }\end{array}$ & $\begin{array}{c}\text { State } \\
\text { Yes }\end{array}$ & $\begin{array}{l}\text { State } \\
\text { Yes }\end{array}$ & $\begin{array}{l}\text { State } \\
\text { Yes }\end{array}$ & $\begin{array}{l}\text { State } \\
\text { Yes }\end{array}$ \\
\hline
\end{tabular}

Notes: This table displays the results of estimating equation (1), where the dependent variable is the change in patenting per 100,000 people (population is based on baseline 1970 levels) and the endogenous variable is non-European immigration $(1,000 \mathrm{~s})$ to county $d$ at time $t$. Column 1 uses our baseline instrument but with predicted ancestry shares, as opposed to predicted ancestry in levels. Column 2 is an instrument based on Card (2001) that utilizes realized immigration shares. Column 3 replaces the realized immigration shares in column 2 with realized ancestry shares. Column 4 utilizes the same instrument as column 3 but adds the leave-out structure to the push factor. We report the first-stage $F$-statistic on the excluded instrument for each specification. For each instrument, we report the false rejection rate in the first-stage regression for a robustness test that follows the method proposed by Adão et al. (2019). See Appendix Table 3 for details. Standard errors are clustered by state for all specifications, and *, **, and *** denote statistical significance at the $10 \%, 5 \%$, and $1 \%$ levels, respectively. 
Table 6: Robustness - The Effect of Immigration on Long Differences in Innovation

Difference in Patenting per 100,000 People

$\Delta P a t_{t-2}^{t-1} \quad \Delta P a t_{t-1}^{t} \quad \Delta P a t_{t-1}^{t+1} \quad \Delta P a t_{t-1}^{t+2}$

(1)

$(2)$

$(3)$

\begin{tabular}{lcccc}
\hline Immigration $_{d}^{t}$ & -0.104 & $0.116^{* * *}$ & $0.414^{* * *}$ & $0.448^{* *}$ \\
& $(0.064)$ & $(0.026)$ & $(0.128)$ & $(0.216)$ \\
$\mathrm{N}$ & 15,705 & 18,846 & 15,705 & 12,564 \\
First Stage F-Stat & 80 & 85 & 11 & 7 \\
AR Wald F-Test p-value & 0.061 & 0.000 & 0.002 & 0.004 \\
\hline Geography FE & County & County & County & County \\
Time FE & Yes & Yes & Yes & Yes \\
\hline
\end{tabular}

Notes: This table reports the results of our IV specification, described in equation (1), for changes in patenting per 100,000 people with nonEuropean immigration to $d$ in $t$ as the endogenous variable. Column 1 uses the one-period lag of the dependent variable. Column 2 repeats the standard specification (5-year change in patenting). Columns 3 and 4 then utilize the two-period (10-year) and three-period (15-year) change in patenting as the dependent variable, respectively. We report the firststage $F$-statistic on the excluded instrument and the p-value for the Anderson-Rubin Wald F test for each specification. Standard errors are clustered by state for all specifications, and *, **, and *** denote statistical significance at the $10 \%, 5 \%$, and $1 \%$ levels, respectively. 
TABle 7: Immigration AND Wages

\begin{tabular}{|c|c|c|c|c|}
\hline & \multicolumn{2}{|c|}{ 5-Year Difference } & \multicolumn{2}{|c|}{$\begin{array}{l}\text { 10-Year Difference } \\
\text { Avg. Annual Wage }\end{array}$} \\
\hline & $\begin{array}{l}\text { Aver } \\
\text { Annual } \\
\text { (1) }\end{array}$ & $\begin{array}{l}\text { age } \\
\text { Wage } \\
(2)\end{array}$ & $\begin{array}{l}\text { Native } \\
\text { (3) }\end{array}$ & $\begin{array}{c}\text { Native } \\
\text { Non-Mover } \\
(4)\end{array}$ \\
\hline $\operatorname{Immigration}_{d}^{t}$ & $\begin{array}{c}0.155^{* * *} \\
(0.034)\end{array}$ & $\begin{array}{l}0.290^{*} \\
(0.159)\end{array}$ & $\begin{array}{c}0.088^{* * *} \\
(0.028)\end{array}$ & $\begin{array}{c}0.102^{* * *} \\
(0.036)\end{array}$ \\
\hline $\mathrm{N}$ & 21,978 & 21,978 & 9,411 & 6,274 \\
\hline First Stage F-Stat & 903 & 37 & 619 & 936 \\
\hline AR Wald F-Test p-value & 0.000 & 0.049 & 0.007 & 0.012 \\
\hline $\begin{array}{l}\text { Geography FE } \\
\text { Time FE }\end{array}$ & $\begin{array}{l}\text { State } \\
\text { Yes }\end{array}$ & $\begin{array}{l}\text { County } \\
\text { Yes }\end{array}$ & $\begin{array}{l}\text { State } \\
\text { Yes }\end{array}$ & $\begin{array}{l}\text { State } \\
\text { Yes }\end{array}$ \\
\hline
\end{tabular}

Notes: This table reports the results of our IV specification, described in equation (1), for each of our dependent variables with non-European immigration for those aged $25+(1,000 \mathrm{~s})$ to $d$ in $t$ as the endogenous variable. Column 1 reports the results of our IV regression where the dependent variable is the change in the average annual real wage $(\$ 100$ s, at 2010 prices) over the five-year period ending in $t$. Column 2 repeats the specification of column 1 but adds county fixed effects. Columns 2 and 3 report results where the dependent variable is the change in the average annual real wage $(\$ 100$ s, at 2010 prices) for natives (birthplace listed as US state or Washington DC) and native non-movers over the 10-year period ending in $t$ on instrumented non-European immigration for the 10-year period ending in $t$. We report the first-stage $F$-statistic on the excluded instrument and the p-value for the Anderson-Rubin Wald $\mathrm{F}$ test for each specification. Standard errors are clustered by state for all specifications, and $*, * *$, and $* * *$ denote statistical significance at the $10 \%, 5 \%$, and $1 \%$ levels, respectively. 
TABle 8: SpILlovers ANALysis

\begin{tabular}{|c|c|c|c|c|}
\hline & (1) & $(2)$ & $(3)$ & (4) \\
\hline Panel A & \multicolumn{4}{|c|}{$\begin{array}{c}\text { 5-Year Difference in Patenting per 100,000 } \\
\text { People Post } 1980\end{array}$} \\
\hline Immigration $_{d}^{t}$ & $\begin{array}{c}0.149^{* * *} \\
(0.050)\end{array}$ & $\begin{array}{c}0.122^{* * *} \\
(0.044)\end{array}$ & $\begin{array}{l}0.080^{*} \\
(0.041)\end{array}$ & $\begin{array}{l}0.090^{*} \\
(0.046)\end{array}$ \\
\hline Immigration $_{\text {State }}^{t}$ & & $\begin{array}{c}0.002^{* * *} \\
(0.000)\end{array}$ & & \\
\hline Neighbors' Immigration ${ }_{d}^{t}$ (Inverse Distance Weight) & & & $\begin{array}{c}7.863^{* * *} \\
(1.870)\end{array}$ & \\
\hline Immigration $_{100 \mathrm{~km}}^{t}$ & & & & $\begin{array}{c}0.066^{* * *} \\
(0.020)\end{array}$ \\
\hline Immigration $_{250 k m}^{t}$ & & & & $\begin{array}{c}0.017^{* * *} \\
(0.006)\end{array}$ \\
\hline Immigration $_{500 \mathrm{~km}}^{t}$ & & & & $\begin{array}{c}0.007 \\
(0.005)\end{array}$ \\
\hline $\mathrm{N}$ & 18,846 & 18,846 & 18,846 & 18,846 \\
\hline First Stage F-Stat (first coefficient) & 876 & 1,792 & 2,175 & 6,065 \\
\hline First Stage F-Stat (second coefficient) & & 470 & 162 & 383 \\
\hline First Stage F-Stat (third coefficient) & & & & 150 \\
\hline First Stage F-Stat (fourth coefficient) & & & & 66 \\
\hline AR Wald F-Test p-value & 0.008 & 0.000 & 0.000 & 0.000 \\
\hline Panel B & \multicolumn{4}{|c|}{$\begin{array}{l}\text { 5-Year Difference in Average Annual Wage } \\
\text { (\$100s) Post } 1975\end{array}$} \\
\hline $\operatorname{Immigration}_{d}^{t}$ & $\begin{array}{c}0.176^{* * *} \\
(0.039)\end{array}$ & $\begin{array}{c}0.172^{* * *} \\
(0.047)\end{array}$ & $\begin{array}{c}0.090^{* * *} \\
(0.023)\end{array}$ & $\begin{array}{c}0.102^{* * *} \\
(0.032)\end{array}$ \\
\hline Immigration $_{\text {State }}^{t}$ & & $\begin{array}{c}0.000 \\
(0.001)\end{array}$ & & \\
\hline Neighbors' Immigration ${ }_{d}^{t}$ (Inverse Distance Weight) & & & $\begin{array}{c}10.061^{* * *} \\
(3.418)\end{array}$ & \\
\hline Immigration $_{100 k m}^{t}$ & & & & $\begin{array}{c}0.105^{* * *} \\
(0.038)\end{array}$ \\
\hline Immigration $_{250 k m}^{t}$ & & & & $\begin{array}{l}-0.011 \\
(0.020)\end{array}$ \\
\hline Immigration $_{500 \mathrm{~km}}^{t}$ & & & & $\begin{array}{l}-0.002 \\
(0.015)\end{array}$ \\
\hline $\mathrm{N}$ & 21,978 & 21,978 & 21,978 & 21,978 \\
\hline First Stage F-Stat (first coefficient) & 873 & 1,742 & 3,050 & 7,030 \\
\hline First Stage F-Stat (second coefficient) & & 469 & 174 & 435 \\
\hline First Stage F-Stat (third coefficient) & & & & 159 \\
\hline First Stage F-Stat (fourth coefficient) & & & & 66 \\
\hline AR Wald F-Test p-value & 0.000 & 0.000 & 0.000 & 0.000 \\
\hline $\begin{array}{l}\text { Geography FE } \\
\text { Time FE }\end{array}$ & $\begin{array}{l}\text { Division } \\
\text { Yes }\end{array}$ & $\begin{array}{l}\text { Division } \\
\text { Yes }\end{array}$ & $\begin{array}{l}\text { Division } \\
\text { Yes }\end{array}$ & $\begin{array}{l}\text { Division } \\
\text { Yes }\end{array}$ \\
\hline
\end{tabular}

Notes: This table reports the results of our IV specification (1) for the change in patenting per 100,000 people (population is based on baseline 1970 levels) (Panel A) and the change in the real average annual wage (\$100s, at 2010 prices) (Panel B) with non-European immigration (Panel A) and immigration limited to those aged $25+$ (Panel B) (1,000s) to $d$ in $t$ as the endogenous variable. The first column repeats our baseline specification but with census division fixed effects. Column 2 adds as a second endogenous variable: total non-European immigration to the state in which $d$ is located, excluding own-immigration to $d$, in period $\mathrm{t}$ and a comparable instrument. Column 3 adds as a second endogenous variable the inverse-distance-weighted sum of non-European immigration to all counties in the US, excluding own-immigration, and an instrument constructed analogously. Column 4 includes variables, and appropriate instruments, for non-European immigration to counties within $100 \mathrm{~km}$ (excluding $d$ ), $100 \mathrm{~km}$ to $250 \mathrm{~km}$, and $250 \mathrm{~km}$ to $500 \mathrm{~km}$ of county $d$. For each specification we report the first-stage $F$-statistic(s), utilizing the $F$-statistic described in Angrist and Pischke (2009, p. 217-218) in the case of multiple endogenous variables. We report the p-value for the AndersonRubin Wald F test for each specification. Standard errors are clustered by state for all specifications, and $*, * *$, and $* * *$ denote statistical significance at the $10 \%, 5 \%$, and $1 \%$ levels, respectively. 
Table 9: Education Analysis

\begin{tabular}{|c|c|c|c|c|c|}
\hline & $(1)$ & $(2)$ & $(3)$ & $(4)$ & $(5)$ \\
\hline Panel A & \multicolumn{5}{|c|}{ 5-Year Difference in Patenting per 100,000 People } \\
\hline Immigration $_{d}^{t}$ & $\begin{array}{c}0.239^{* *} \\
(0.093)\end{array}$ & $\begin{array}{c}0.257^{* * *} \\
(0.094)\end{array}$ & $\begin{array}{c}0.433^{* * *} \\
(0.155)\end{array}$ & \multirow{2}{*}{\multicolumn{2}{|c|}{$\begin{array}{c}0.457^{* * *} \\
(0.101)\end{array}$}} \\
\hline Average Years Education ${ }_{d}^{t} \times \operatorname{Immigration}_{d}^{t}$ & & $\begin{array}{l}0.235^{*} \\
(0.129)\end{array}$ & $\begin{array}{c}0.217^{* * *} \\
(0.066)\end{array}$ & & \\
\hline Average Years College ${ }_{d}^{t} \times$ Immigration $_{d}^{t}$ & & & & \multicolumn{2}{|l|}{$\begin{array}{c}0.822^{* * *} \\
(0.249)\end{array}$} \\
\hline $1\{$ Low Avg. Years Education $\} \times$ Immigration $_{d}^{t}$ & & & & & $\begin{array}{l}2.023 \\
(3.628)\end{array}$ \\
\hline $1\{$ Medium Avg. Years Education $\} \times$ Immigration $_{d}^{t}$ & & & & & $\begin{array}{l}0.141^{*} \\
(0.081)\end{array}$ \\
\hline $\mathbf{1}\{$ High Avg. Years Education $\} \times$ Immigration $_{d}^{t}$ & & & & & $\begin{array}{l}1.180^{*} \\
(0.695)\end{array}$ \\
\hline $\mathrm{N}$ & 18,846 & 18,846 & 18,846 & 18,846 & 18,846 \\
\hline Montiel-Pflueger Effective F-Stats & 31 & $28 ; 21$ & $15 ; 15$ & $26 ; 9$ & $4 ; 34 ; 6$ \\
\hline AR Wald F-Test p-value & 0.000 & 0.000 & 0.000 & 0.000 & 0.000 \\
\hline Panel B & \multicolumn{5}{|c|}{ 5-year Difference in Average Annual Wage (\$100s) } \\
\hline Immigration $_{d}^{t}$ & $\begin{array}{c}0.240 * * * \\
(0.084)\end{array}$ & $\begin{array}{c}0.269^{* * *} \\
(0.048)\end{array}$ & $\begin{array}{l}0.757^{*} \\
(0.403)\end{array}$ & $\begin{array}{c}0.390^{* * *} \\
(0.055)\end{array}$ & \\
\hline Average Years Education ${ }_{d}^{t} \times \operatorname{Immigration}_{d}^{t}$ & & $\begin{array}{c}0.199^{* * *} \\
(0.045)\end{array}$ & $\begin{array}{c}0.180^{* *} \\
(0.079)\end{array}$ & & \\
\hline Average Years College ${ }_{d}^{t} \times$ Immigration $_{d}^{t}$ & & & & $\begin{array}{c}0.554^{* * *} \\
(0.111)\end{array}$ & \\
\hline $1\{$ Low Avg. Years Education $\} \times$ Immigration $_{d}^{t}$ & & & & & $\begin{array}{l}-0.184 \\
(0.242)\end{array}$ \\
\hline $1\{$ Medium Avg. Years Education $\} \times$ Immigration $_{d}^{t}$ & & & & & $\begin{array}{r}0.181^{* * * *} \\
(0.055)\end{array}$ \\
\hline $\mathbf{1}\{$ High Avg. Years Education $\} \times$ Immigration $_{d}^{t}$ & & & & & $\begin{array}{c}1.161^{* * *} \\
(0.425)\end{array}$ \\
\hline $\mathrm{N}$ & 21,978 & 21,978 & 21,978 & 21,978 & 21,978 \\
\hline Montiel-Pflueger Effective F-Stats & 34 & $31 ; 19$ & $12 ; 17$ & $27 ; 7$ & $44 ; 25 ; 5$ \\
\hline AR Wald F-Test p-value & 0.000 & 0.000 & 0.000 & 0.000 & 0.000 \\
\hline Geogrpahy FE & State & State & County & State & State \\
\hline Time FE & Yes & Yes & Yes & Yes & Yes \\
\hline
\end{tabular}

Notes: The table reports the results of our IV specification (1) for the change in patenting per 100,000 people (population is based on baseline 1970 levels) in Panel A and the 5-year difference in county-level average real annual wages (\$100s, at 2010 prices) in Panel B. Column 1 repeats our main specification but adjusting the migrant pool to those aged $25+(1,000 \mathrm{~s})$. Columns 2 and 3 then add a second endogenous variable for the interaction of immigration with the (demeaned) average years of education of the migrants arriving in the destination county, whereas column 4 adds (demeaned) average years of college education of those migrants. Repeating the regression in column 2 of the second panel for the 10-year difference in average annual wages (\$100s, at 2010 prices) of native non-movers (US-born working individuals who have not moved outside of the county within the past 5 years) on 10-year migration and corresponding education results in coefficients of $0.246(0.057)$ and $0.142(0.040)$ on immigration and average years of education times immigration, respectively. Column 5 uses as endogenous variables adult immigration interacted with indicators for the terciles of average years of education of migrants across counties in period $t$. In all specifications, for instrumentation, we exploit the fact that in our initial instrument construction we created quasi-exogenous immigration shocks for each origin country- $o \times$ destination county- $d$ pair in each time period $t$; each specification utilizes the predicted immigration shocks for each of the the top 20 origin nations as a joint set of instruments. For each regression we report the Montiel Olea and Pflueger (2013) effective $F$-statistic. In regressions with multiple endogenous variables we use the orthogonalizaiton method described in Angrist and Pischke (2009, p. 217-218). See the main text for details. We report the p-value for the Anderson-Rubin Wald $\mathrm{F}$ test for each specification. Standard errors are clustered by state for all specifications, and $*, * *$, and $* * *$ denote statistical significance at the $10 \%, 5 \%$, and $1 \%$ levels, respectively. 
Table 10: Parameters and Model Fit

\begin{tabular}{|c|c|c|}
\hline Panel A: Moments & Data & Model \\
\hline IV coeff., patenting ${ }_{d, t}$ on immigration $I_{d, t}$ & $\begin{array}{c}1.723 \\
(0.111)\end{array}$ & 1.734 \\
\hline Std. deviation, $o$ immigration $I_{o, t}$ & $\begin{array}{c}0.406 \\
(0.029)\end{array}$ & 0.391 \\
\hline Std. deviation $d$ immigration $I_{d, t}$ & $\begin{array}{c}0.179 \\
(0.011)\end{array}$ & 0.161 \\
\hline Std. deviation, $o-d$ immigration $I_{o, d, t}$ & $\begin{array}{c}0.072 \\
(0.012)\end{array}$ & 0.111 \\
\hline Autocorrelation, output per capita $Y_{d, t} / L_{d, t}$ & $\begin{array}{c}0.954 \\
(0.007)\end{array}$ & 0.945 \\
\hline Autocorrelation, patenting $_{d, t}$ & $\begin{array}{c}0.894 \\
(0.009)\end{array}$ & 0.909 \\
\hline Panel B: Estimated Parameters & Symbol & Value \\
\hline Elasticity, patenting to labor & $\gamma$ & $\begin{array}{c}0.859 \\
(0.020)\end{array}$ \\
\hline Autocorrelation, county TFP & $\rho$ & $\begin{array}{c}0.905 \\
(0.009)\end{array}$ \\
\hline Std. deviation, county TFP shocks & $\sigma_{\epsilon}$ & $\begin{array}{c}0.032 \\
(0.044)\end{array}$ \\
\hline Std. deviation, immigration push shocks & $\sigma_{\nu}$ & $\begin{array}{c}0.594 \\
(0.006)\end{array}$ \\
\hline Std. deviation, bilateral immigration shocks & $\sigma_{\tau}$ & $\begin{array}{c}0.552 \\
(0.043)\end{array}$ \\
\hline
\end{tabular}

Notes: The top Panel A reports targeted data moments vs simulated model moments. The bottom Panel B reports the estimated parameters. The standard errors, in parentheses beneath moments and estimates, are clustered by state. 


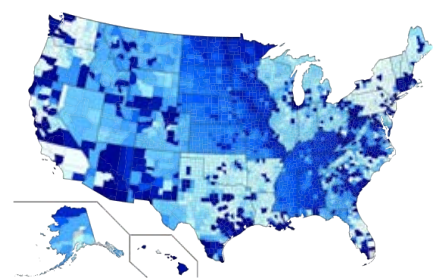

$1975-1980$

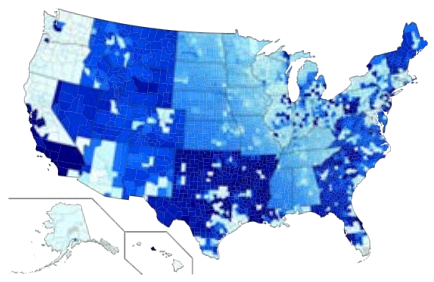

$1990-1995$

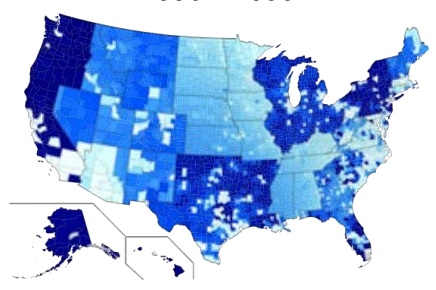

2005 - 2010

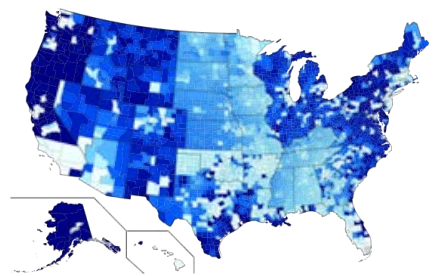

$1980-1985$

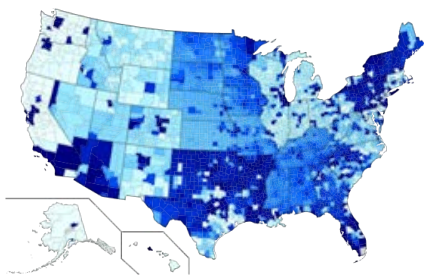

$1995-2000$

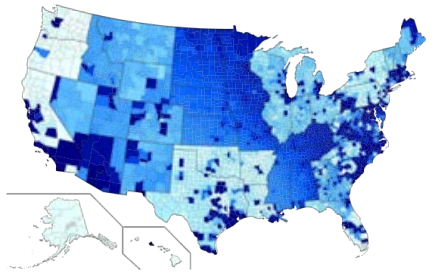

$1985-1990$

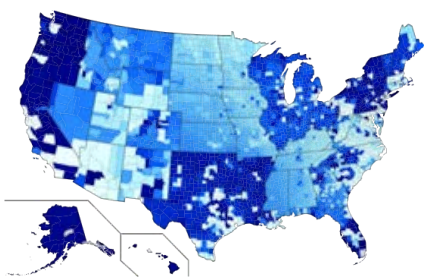

$2000-2005$

Figure 1: Immigration Shock Conditional on County and Time FE

Notes: This figure maps the instrumented non-European immigration flows into US counties by 5 -year periods. We regress the instrument for immigration into US county $d$ at time $t$ on county and state-year fixed effects, and calculate the residuals. This figure provides a visualization for the immigration shocks used as in instrument in the regression shown in column 3 of Table 3. The map's color coding depicts the 200 quantiles of the residuals across counties and within census periods. Darker colors indicate a higher quantile. 

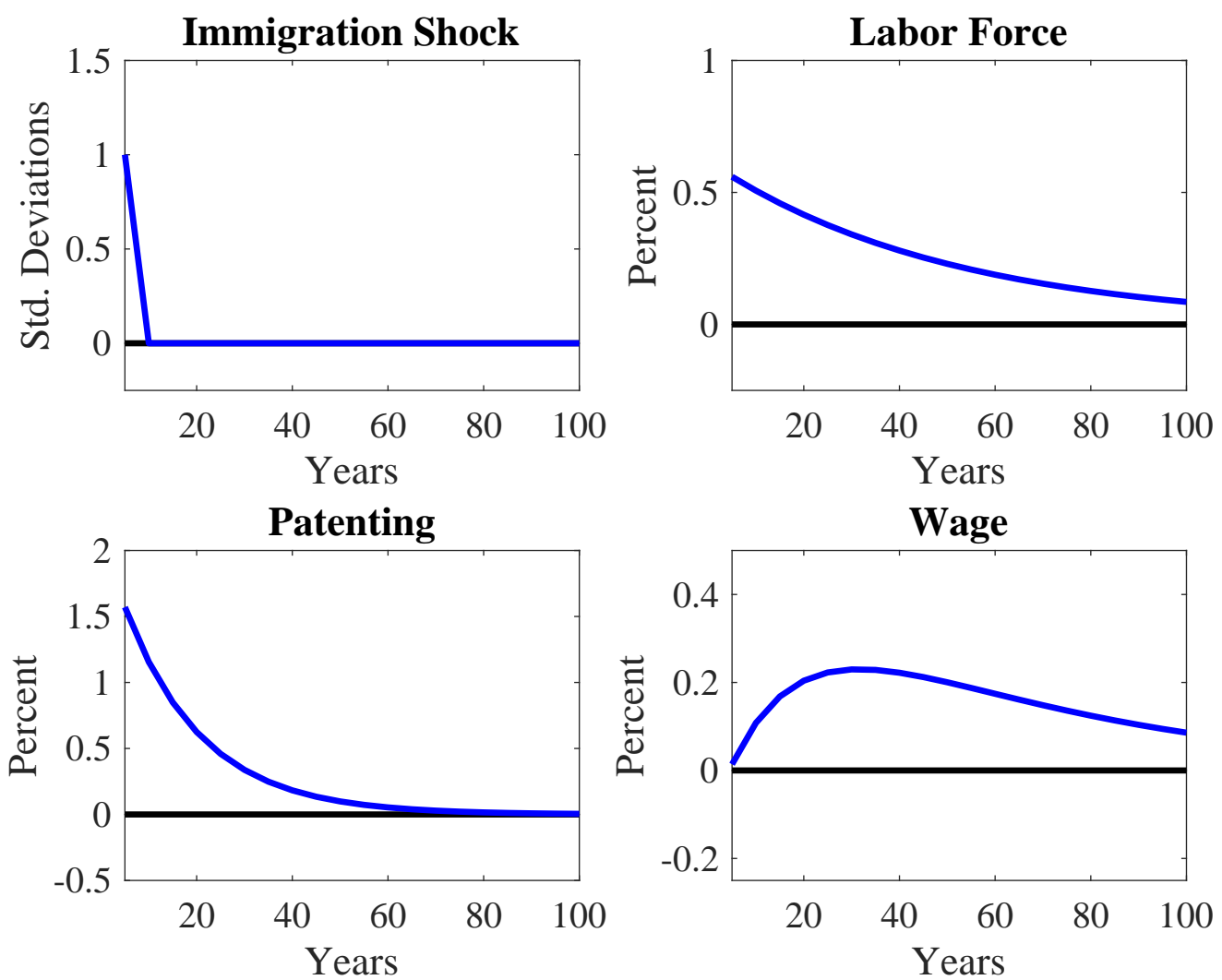

Figure 2: The Impact of an Immigration Shock

Notes: The figure plots impulse response functions to a one-standard deviation immigration shock in period 1. The top left plots the immigration shock $\nu_{o, t}$. The top right plots the labor force $l_{d, t}$. The bottom left panel plots patenting $m_{d, t}$. The bottom right panel plots the response of the wage $w_{d, t}$. The immigration shock is from a single origin $o$, and the responses of the labor force, patenting, and the wage are local responses for a county $d$. The labor force, patenting, and wage responses are in percentage point deviations from the balanced growth path. 

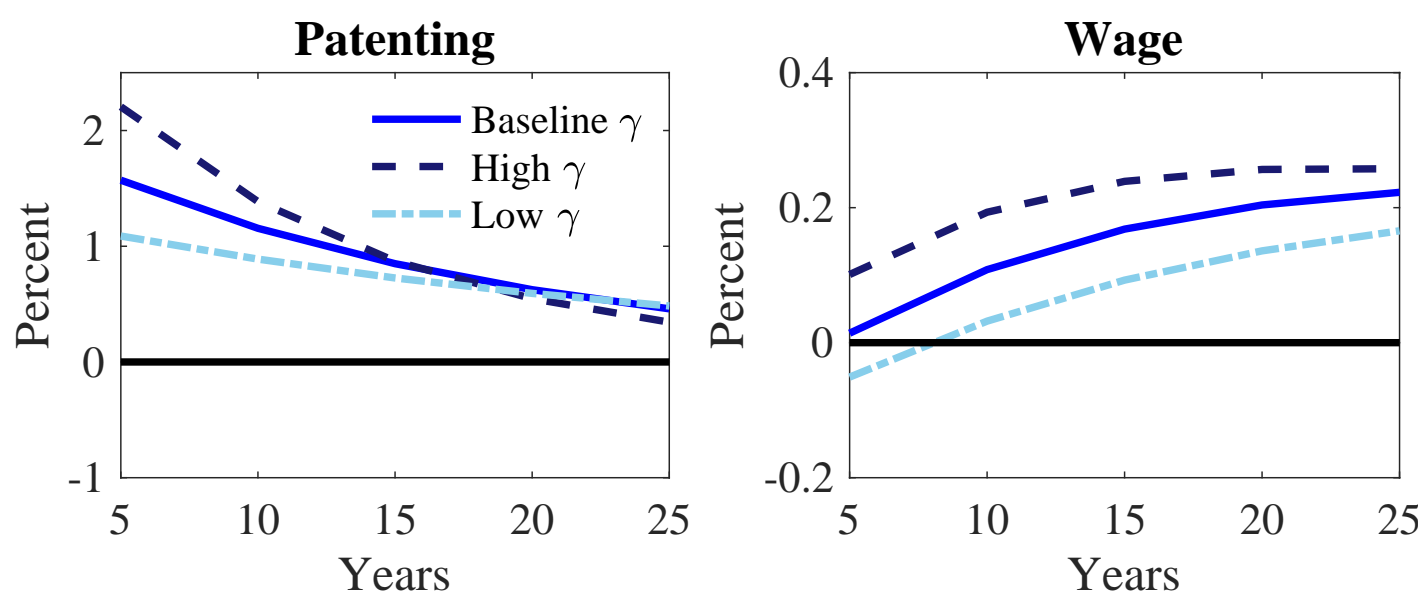

Figure 3: Innovation, Wages, and the Elasticity of Patenting to Labor

Notes: The figure plots impulse response functions to a one-standard deviation immigration shock in period 1 . The left panel plots patenting $m_{d, t}$. The right panel plots the response of the wage $w_{d, t}$. The immigration shock is from a single origin $o$, and the responses of the labor force, patenting, and the wage are local responses for a county $d$. The solid blue line labelled Baseline $\gamma$ is based on the calibrated parameters with $\gamma=0.86$. The dashed dark blue line labelled High $\gamma$ uses $\gamma=0.95$. The dash-dot light blue line labelled Low $\gamma$ uses $\gamma=0.75$. The responses are in percentage point deviations from the balanced growth path. 

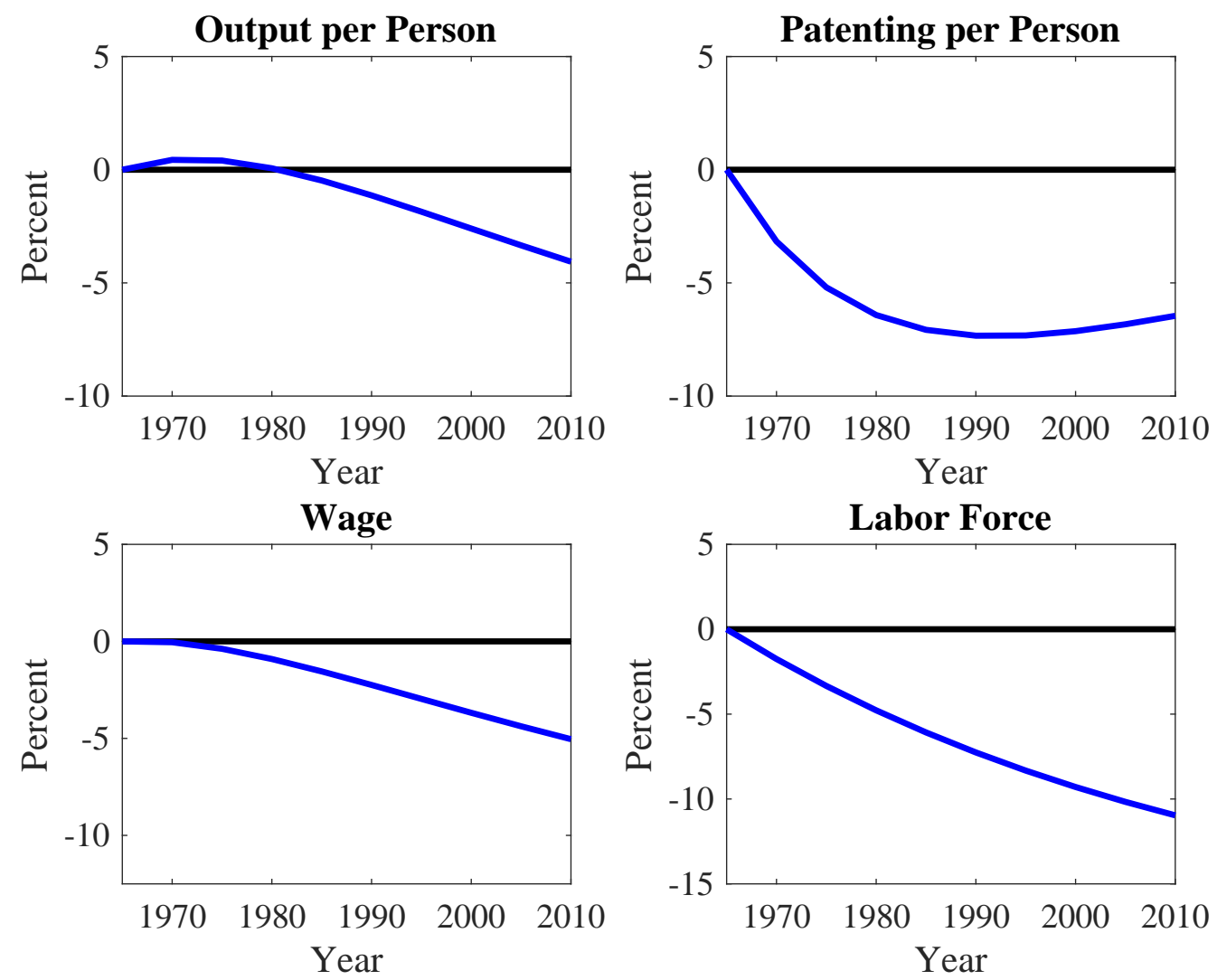

Figure 4: Removing the Post-INA Immigration Increase

Notes: The figure plots the simulated counterfactual impact to US economic outcomes from removing the increase in US population growth due to the foreign born empirically observed after the Immigration and Nationality Act of 1965 (INA). Each panel plots the percent deviation of the indicated outcome from the path of the economy without removal of the post-INA immigration contributions. 

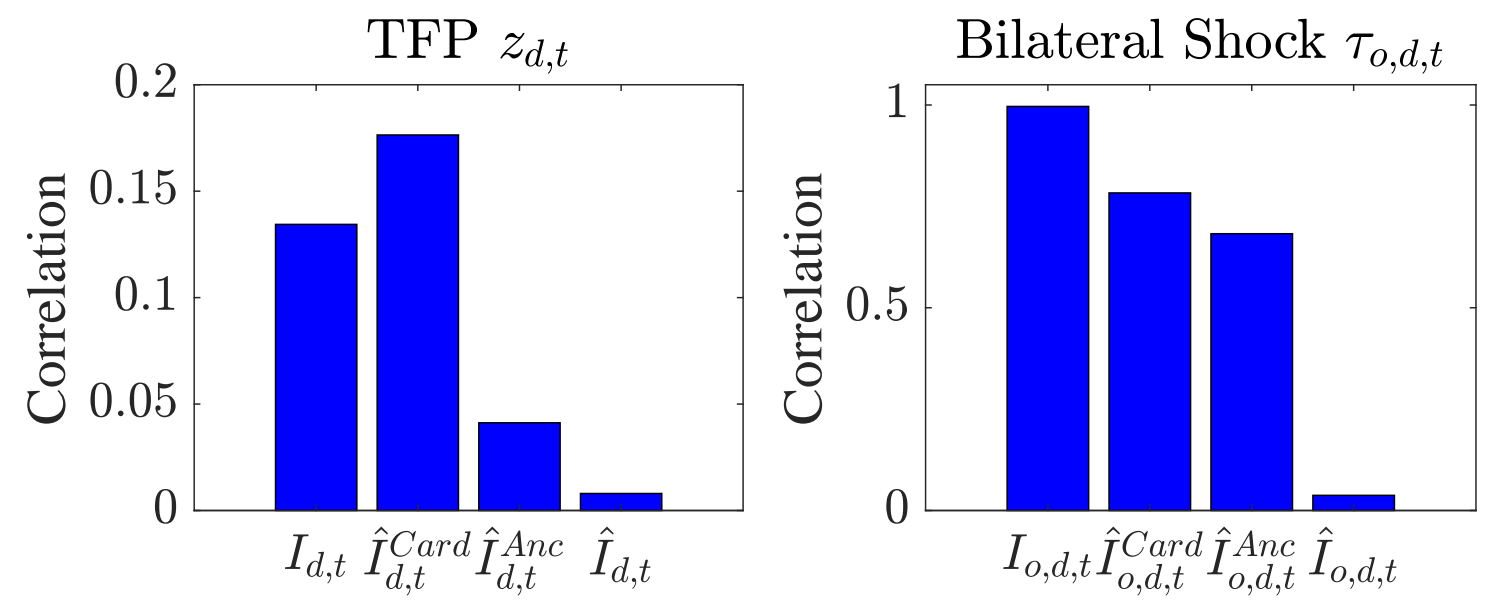

Figure 5: TFP, Bilateral Shocks, and Instrumental Variables

Notes: The figure reports correlations in simulated model data linking observable outcomes of interest to underlying model shock processes. In each panel, the observable data is given by the inverse hyperbolic sine of total immigration $I$, the Card IV $\hat{I}^{C a r d}$, a version of our baseline IV with realized rather than predicted ancestry shares $\hat{I}^{A n c}$, and our baseline IV $\hat{I}$. The left panel reports correlations from data aggregated to the destination county $d$ by time $t$ level with the log county-level TFP shock $z_{d, t}$. The right panel reports correlations from data disaggregated to the origin country $o$ by destination county $d$ by time $t$ level with (minus) the bilateral immigration shock $-\tau_{o, d, t}$. 


\section{Online Appendix}

\section{"Immigration, Innovation, and Growth" \\ Konrad B. Burchardi \\ Thomas Chaney \\ Tarek A. Hassan \\ Lisa Tarquinio \\ Stephen J. Terry}

\section{A Data Appendix}

\section{A.1 Details on the construction of migration and ethnicity data}

To construct county-level data on migration, ancestry, and ethnicity, we follow the approach of Burchardi et al. (2019). We utilize data from each available IPUMS wave from 1880 to 2010. Specifically, we use the $10 \%$ sample of the 1880 Census, the $5 \%$ sample of the 1900 Census, the $1 \%$ sample of the 1910 Census, the $1 \%$ sample of the 1920 Census, the $5 \%$ sample of the 1930 Census, 1\% Form 1 Metro sample of the 1970 Census, 5\% State sample of the 1980 Census, 5\% State sample of the 1990 Census, 5\% sample of the 2000 Census, and the American Community Service 5-Year sample of the 2010 Census. The following section summarizes this approach, highlighting any difference in data construction made in this paper.

\section{Construction of post-1880 immigration flows}

We start the construction of our immigration variable by identifying the number of individuals located in a given US geography $d$ at the time of each census who immigrated to the US since the prior census and were born in a historic origin country o (based on the detailed birthplace variable). For each census wave, we then separate this immigration count into (roughly) fiveyear periods based on the year in which each migrant arrived to the US. For the 1970, 1980, and 1990 censuses, the exact year of arrival for immigrants is not provided, and instead the year of arrival is provided in bins (e.g., a person who arrived in 1964 has a year of arrival of 1960-1964). For these years, we use as our five-year periods the bins that are reported in each census: 1925-34, 1935-44, 1945-49, 1950-54, 1955-59, 1960-64, 1965-70, 1970-74, 1975-80, 
1980-84, and 1985-90. We then follow the approach outlined in Burchardi et al. (2019) to transform foreign origin countries, given as birthplaces, to 1990 foreign countries and non-1990 counties and county groups into 1990 counties. Because some foreign birthplaces do not refer to any modern (1990) country, we use population-based weights for transitioning birthplaces to countries (for more details on the weighting scheme, see Burchardi et al. (2019)).

\section{Construction of pre-1880 immigration stock}

From the 1880 census, we count all individuals who were born in a foreign origin country $o$ and reside in a historic US geography $d$, regardless of the date of arrival to the US. We then add to this count all individuals residing in $d$ who were born in the US but whose parents were born in origin country $o$ (if an individual's parents were born in different countries, the individual is assigned a count of one half for each parent's origin country o). We then transform the given birthplace to 1990 foreign countries and the pre-1880 US geography to 1990 US counties following the transition method outlined in Burchardi et al. (2019).

\section{Construction of ancestry stock}

For the years 1980, 1990, 2000, and 2010, we take from the respective census all individuals in a US county or county group that list as their primary ancestry a foreign nationality or area. We then estimate the ancestry stock in each midyear $(1975,1985,1995$, and 2005) by taking the individuals identified in each census year as belonging to a given ancestry and removing all individuals who either were born or migrated to the US after the midyear. Ideally, we would also remove all individuals who moved to the county after the midyear, but data is not available for all census years; thus, for consistency, we do not remove these individuals. Again, we follow Burchardi et al. (2019) in transforming ancestries to 1990 countries and US geographies to 1990 US counties. As with the data on foreign birthplaces, some ancestries do not correspond directly to a modern (1990) country; again, we follow the weighting scheme outlined in Burchardi et al. (2019) for transitioning stated ancestries to 1990 foreign countries.

\section{Construction of education data for migrants}

For the five-year migration periods from 1975 to 2010, whose construction is previously described, we also identify the total number of years of education for each set of immigrants. Specifically, we take the set of individuals that make up each five-year immigration flow and limit to those individuals who are aged 25 years or older at the time of each respective census. For each 1990 US county $d$, we then sum the number of years each individual is reported to have 
over all immigrants in this set, assigning the midpoint when a range of years of education is provided instead of an exact number of years. We then generate the average years of education for immigrants to county $d$ in each period $t$ and demean these values. Finally, we take the demeaned average years of education and multiply by the count of immigrants aged 25 or older to generate the (demeaned) total years of education. We construct this variable for total years of education as well as for years of college education.

We also utilize information on education from the census to construct county-level demographic controls for the share of the county's population that has a specified level of education in a baseline year, 1970. Using data from the 1970 census, we calculate the share of all individuals, regardless of birthplace, residing in a historic US county $d$ who report having at least a Grade 12 education (share of high-school educated) and those who report having at least four years of college education (share of college educated). These values are then transformed from 1970 US counties to 1990 US counties, again using the transition matrices described by Burchardi et al. (2019).

\section{A.2 Construction of population data}

For the period 1970 to 2010, we collect county-level population data in each census year and intercensal year. The population counts for 2010 were taken directly from the US Census Bureau (the American Community Survey 5-year estimates). All other population counts are taken from the NBER's Census U.S. Intercensal County Population Data, 1970-2014. For each period, data are transformed from the given US counties to 1990 US counties using the transition matrices described by Burchardi et al. (2019).

\section{A.3 Construction of patenting data}

We utilize data on corporate utility patents with a US assignee from the the US Patent and Trademark Office microdata for the period 1975 to 2010. We translate the location of patents from assignee (or inventor) location to 2010 US counties and then transition to 1990 counties using area weights as in Burchardi et al. (2019) to estimate the number of patents granted to assignees in each county and year. For our main measure of patenting, we utilize unweighted patent counts with locations based on assignee, but we also consider location based on inventors and weighted patent counts as in Hall et al. (2001). We then construct a variable for the total number of patents filed in each five-year period ending in $t$, for each measure of patenting, and divide by the 1970 population (100,000 people) to get "per-capita patenting" in $t$. We then 
winsorize the variables at the $1 \%$ and $99 \%$ levels. The main patenting outcome variable is then the difference in this per-capita-patenting variable between $t-1$ and $t$.

\section{A.4 Construction of native wages data}

We construct variables for native wages in each census year from 1970 to 2010 using data from the 1970 1\% Form 1 Metro sample, 1980 5\% State sample, 1990 5\% State sample, 2000 5\% Census sample, and 2010 American Community Service (ACS). In each year, we limit the sample to the pre-tax wage and salary income (incwage) for individuals born in the US who are employed (empstat is equal to 1), referred to here as natives. For the census years 1980 to 2000, we also generate a wage measure for the subset of natives who report that they lived in the same county five years prior to the census year, referred to as native non-movers. We use the Consumer Price Index provided in IPUMS USA (CPI99) to adjust wages to a common dollar year, 1999. We then follow the same method as that used in Burchardi et al. (2019) to transform wages for county groups into 1990 US counties. Finally, we determine average wages in each county using the person weight (PERWT) for the selected sample and generate a variable for wage growth in each county that is the 10-year difference in average annual wages for natives (or native non-movers).

\section{A.5 Construction of business dynamism data}

In this section, we explain the construction of variables used to measure business dynamism. In each case, we take the five-year difference in the dynamism or wage variable.

Wages. The county-level average annual wage for every five years from 1975 to 2010 is taken from the Quarterly Census of Employment and Wages. The data for each period are then transformed from the US counties for that period to 1990 US counties using the transition matrices developed in Burchardi et al. (2019) and then converted to 2010 US dollars using the Personal Consumption Expenditures Price Index from the Bureau of Economic Analysis. We generate this county-level average annual wage for all industries as well as manufacturing (SIC 20-39 and NAICS 31-33) and services (SIC 60-67 and NAICS 52-53).

Growth Rate Skewness. The growth rate skewness variable for 2010 US counties for each five years from 1995 to 2010 is estimated using data from the Longitudinal Business Database. We compute the Kelly Skewness of employment growth rates across 4-digit sectors, and then 
transition this measure from 2010 to 1990 US counties.

Job Creation and Destruction Rates. Job creation and destruction data are taken from the Business Dynamics Statistics for metropolitan statistical areas (MSAs) and transitioned to 1990 US counties based on weights derived from 1990 population data. 
Appendix Table 1: Immigration and Economic Dynamism

\begin{tabular}{lccc}
\hline & \multicolumn{3}{c}{ 5-Year Difference } \\
\cline { 2 - 4 } & Job & Job & Job Growth \\
& Creation & Destruction & Rate \\
& $0.176^{* * *}$ & $0.152^{* * *}$ & $0.019^{* * *}$ \\
& $(0.033)$ & $(0.035)$ & $(0.004)$ \\
Immigration $_{d}^{t}$ & 6,600 & 6,600 & 12,564 \\
N & 951 & 951 & 151 \\
First Stage F-Stat & 0.000 & 0.000 & 0.000 \\
AR Wald F-Test p-value & State & State & State \\
\hline Geography FE & Yes & Yes & Yes \\
Time FE & & & Skewness \\
\hline
\end{tabular}

Notes: This table reports the results of our IV specification, described in equation (1), for each of our dependent variables with non-European immigration $(1,000 \mathrm{~s})$ to $d$ in $t$ as the endogenous variable. Columns 1 and 2 report the results with the job creation rate and job destruction rate as the dependent variable, respectively. Column 3 then provides results for job growth rate skewness as the dependent variable. We report the first-stage $F$-statistic on the excluded instrument and the p-value for the Anderson-Rubin Wald $\mathrm{F}$ test for each specification. Standard errors are clustered by state for all specifications, and *, **, and *** denote statistical significance at the $10 \%, 5 \%$, and $1 \%$ levels, respectively. 
Appendix Table 2: Assignment of States to Census Divisions

\begin{tabular}{l|l}
\hline \hline Census Region & State Names \\
\hline New England & Connecticut, Maine, Massachusetts, New Hampshire, Rhode Island, Vermont \\
\hline Middle Atlantic & New Jersey, New York, Pennsylvania \\
\hline East North Central & Illinois, Indiana, Michigan, Ohio, Wisconsin \\
\hline West North Central & Iowa, Kansas, Minnesota, Missouri, Nebraska, North Dakota, South Dakota \\
\hline South Atlantic & $\begin{array}{l}\text { Delaware, District Of Columbia, Florida, Georgia, Maryland, North Carolina, } \\
\text { South Carolina, Virginia, West Virginia }\end{array}$ \\
\hline East South Central & Alabama, Kentucky, Mississippi, Tennessee \\
\hline West South Central & Arkansas, Louisiana, Oklahoma, Texas \\
\hline Mountain & Arizona, Colorado, Idaho, Montana, Nevada, New Mexico, Utah, Wyoming \\
\hline Pacific & Alaska, California, Hawaii, Oregon, Washington \\
\hline \hline
\end{tabular}


Appendix Table 3: Results from Placebo Analysis Based on Adão et al

$(2019)$

\begin{tabular}{|c|c|c|c|c|}
\hline & $(1)$ & $(2)$ & $(3)$ & (4) \\
\hline & \multicolumn{2}{|c|}{ Coefficient } & Standard Error & Rejection \\
\hline & $($ Mean $)$ & (St. Dev.) & (Median) & Rate $(\%)$ \\
\hline \multicolumn{5}{|c|}{ Panel A: Realized Immigration Shares (Card, 2001) } \\
\hline First Stage & -0.007038 & 0.2338 & 0.1139 & 27.4 \\
\hline Reduced Form & 0.004835 & 0.0758 & 0.0455 & 20.2 \\
\hline \multicolumn{5}{|c|}{ Panel B: Realized Ancestry Shares } \\
\hline First Stage & -0.002579 & 0.3162 & 0.1510 & 26.8 \\
\hline Reduced Form & 0.005187 & 0.1066 & 0.0586 & 24.7 \\
\hline \multicolumn{5}{|c|}{ Panel C: Predicted Ancestry Shares (Baseline Instrument) } \\
\hline First Stage & -0.001602 & 0.0397 & 0.0249 & 3.8 \\
\hline Reduced Form & 0.001228 & 0.1230 & 0.1072 & 7.6 \\
\hline
\end{tabular}

Notes: Following Adão et al. (2019), we randomly generate immigration shocks (for each $\{o, r, t\}$ country-region-time triplet), and construct placebo instruments by interacting these random shocks with realized immigration shares (as in Card (2001)), realized ancestry shares, and our predicted baseline ancestry shares (as in the ancestry-share version of our baseline instrument). We then run 1,000 placebo regressions of the endogenous immigration variabale on the placebo variables for the Card (2001) instrument (Panel A), the Card-style instrument that uses ancestry shares (Panel B), and our ancestry-share instrument (Panel $\mathrm{C})$; we also run the comparable reduced-form regressions where the dependent variable is our primary measure of patenting, the five-year difference in patenting flows per 100,000 people. Column 1 reports the mean value of the coefficient over all placebo regressions, whereas column 2 reports the standard deviation. Column 3 then reports the median standard error for the coefficient of interest over all placebo regressions, and column 4 reports the fraction of placebo regressions for which we reject the null hypothesis of no effect at the $5 \%$ statistical significance threshold. As shown, the traditional shift-share instrument suffers from the over-rejection identified in Adão et al. (2019) with false rejection rates of $28.2 \%$ in the first stage and $18.8 \%$ in the reduced-form specification. The ancestry-share version of our baseline instrument has false rejection rates of $4.5 \%$ (first stage) and $8.2 \%$ (reduced form). The latter is similar to the false rejection rates reported in Adão et al. (2019) when using their proposed standard error correction (labelled "AKM"). 
Appendix Table 4: Panel Regression of 5-Year Difference in Patenting Per 100,000 People on Immigration using Alternative Patent Counts

\begin{tabular}{lcccc}
\hline & \multicolumn{2}{c}{ Difference in Patenting per } & 100,000 People Post 1980 \\
& Assignee & Assignee & Inventors & Inventors \\
& $($ Unweighted) & (Cite Weight) & (Unweighted) & (Cite Weight) \\
\cline { 2 - 5 } & $(1)$ & $(2)$ & $(3)$ & $(4)$ \\
\hline Immigration $_{d}^{t}$ & $\left(0.115^{* * *}\right.$ & $0.188^{* * *}$ & $0.306^{* * *}$ & $0.570^{* * *}$ \\
$\mathrm{~N}$ & 18,846 & $(0.054)$ & $(0.113)$ & $(0.180)$ \\
First Stage F-Stat & 911 & 18,846 & 18,846 & 18,846 \\
AR Wald F-Test p-value & 0.010 & 911 & 911 & 911 \\
\hline Geography FE & State & 0.003 & 0.015 & 0.005 \\
Time FE & Yes & State & State & State \\
\hline
\end{tabular}

Notes: This table reports the results of our second-stage specification, described in equation (1), for the change in patenting per 100,000 people (population is based on baseline 1970 levels) with non-European immigration (1,000s) to $d$ in $t$ as the endogenous variable. Column 1 repeats our main specification where patent location is based on assignees and raw patent counts are used. Column 2 also uses the assignee for patent location but uses citation-weighted patent counts. Columns 3 and 4 then provide results when inventors are used for identifying patent location where patent counts are unweighted and citationweighted, respectively. We report the first-stage $F$-statistic on the excluded instrument and the p-value for the Anderson-Rubin Wald F test for each specification. Standard errors are clustered by state for all specifications, and $*, * *$, and $* * *$ denote statistical significance at the $10 \%, 5 \%$, and $1 \%$ levels, respectively. 
Appendix Table 5: Permutation Tests for Main Specification

\begin{tabular}{|c|c|c|c|c|}
\hline & (1) & $(2)$ & $(3)$ & (4) \\
\hline & \multicolumn{2}{|c|}{ Coefficient } & Standard Error & RHS Rejection \\
\hline & (Mean) & (St. Dev.) & (Mean) & Rate (\%) \\
\hline \multicolumn{5}{|c|}{ Panel A: First Stage } \\
\hline Placebo1 & 0.0007 & 0.018 & 0.008 & 0.40 \\
\hline Placebo2 & -0.0006 & 0.013 & 0.008 & 0.10 \\
\hline Placebo3 & -0.0127 & 0.031 & 0.021 & 1.90 \\
\hline \multicolumn{5}{|c|}{ Panel B: Reduced Form } \\
\hline Placebo1 & -0.0025 & 0.086 & 0.059 & 1.10 \\
\hline Placebo2 & 0.0033 & 0.079 & 0.055 & 0.90 \\
\hline Placebo3 & -0.0043 & 0.100 & 0.059 & 5.80 \\
\hline
\end{tabular}

Notes: This table reports the results of three different placebo tests on our standard specification, corresponding to column 2 of Table 3. For each of the placebo tests, we randomly reassign the instrument across observations: in the first version, we randomly reassign within the entire sample (Placebo 1); in the second version, we randomly reassign within the same period $t$ (Placebo 2 ); and in the third version, we reassign within the same period $t$ and census division $r(d)$ (Placebo 3). For each version, we perform 1000 placebo runs. We present summary statistics on the first stage (Panel A) and reduced form (Panel B) coefficients of interest across placebo runs. Columns 1 and 2 report the average and standard deviation for the coefficient of interest, column 3 reports the mean standard errors, and columns 4 reports the percentage of runs for which we reject that the coefficient of interest is different from 0 at the $5 \%$ level on the right-hand side. The standard errors are clustered by state in our standard specification and hence all placebo runs. 
Appendix Table 6: County-Level Panel Regressions of Difference in Patenting on Population GrowTH

\begin{tabular}{|c|c|c|c|}
\hline & (1) & $(2)$ & (3) \\
\hline \multicolumn{4}{|l|}{ Panel A: OLS } \\
\hline$\Delta$ Population $_{d}^{t}$ & $\begin{array}{c}0.279^{* * *} \\
(0.083)\end{array}$ & $\begin{array}{c}0.275^{* * *} \\
(0.081)\end{array}$ & $\begin{array}{c}0.197^{*} \\
(0.108)\end{array}$ \\
\hline $\mathrm{N}$ & 18,846 & 18,840 & 18,846 \\
\hline$R^{2}$ & 0.030 & 0.050 & 0.155 \\
\hline \multicolumn{4}{|l|}{ Panel B: IV } \\
\hline$\Delta$ Population $_{d}^{t}$ & $\begin{array}{c}0.129^{* * * *} \\
(0.039)\end{array}$ & $\begin{array}{c}0.125^{* * *} \\
(0.041)\end{array}$ & $\begin{array}{c}0.090^{* * * *} \\
(0.020)\end{array}$ \\
\hline $\mathrm{N}$ & 18,846 & 18,840 & 18,846 \\
\hline First Stage F-Stat & 110 & 103 & 63 \\
\hline AR Wald F-Test p-value & 0.010 & 0.016 & 0.000 \\
\hline Panel C: First Stage & \multicolumn{3}{|c|}{$\Delta$ Population $_{d}^{t}$} \\
\hline Immigration Shock $\left(\hat{I}_{d}^{t}\right)$ & $\begin{array}{c}1.896^{* * *} \\
(0.181)\end{array}$ & $\begin{array}{c}1.887^{* * *} \\
(0.186)\end{array}$ & $\begin{array}{c}2.080^{* * * *} \\
(0.262)\end{array}$ \\
\hline $\mathrm{N}$ & 18,846 & 18,840 & 18,846 \\
\hline$R^{2}$ & 0.324 & 0.340 & 0.805 \\
\hline Geography FE & State & State & County \\
\hline Time FE & Yes & Yes & Yes \\
\hline State-Time FE & No & Yes & No \\
\hline
\end{tabular}

Notes: Panels A and B of this table report the OLS and IV results, respectively, of the estimation of equation (1) where the dependent variable is the change in patenting per 100,000 people (population is based on baseline 1970 levels) in county $d$ in the five-year period ending in $t$ and the endogenous variable is population growth $(1,000 \mathrm{~s})$ in $d$ and period $t$. Panel $\mathrm{C}$ reports the results for step 3 of instrument construction, or the coefficient estimates for the first-stage specification for population change $(1,000 \mathrm{~s})$ for the instrument described in equation (5). The table includes the first-stage F-statistic on the excluded instrument and the p-value for the AndersonRubin Wald F test for each of the IV specifications. Standard errors are clustered by state for all specifications, and *, **, and ${ }^{* * *}$ denote statistical significance at the $10 \%, 5 \%$, and $1 \%$ levels, respectively. 
Appendix Table 7: Robustness - Additional Controls from Baseline Year (1970)

\begin{tabular}{|c|c|c|c|c|c|}
\hline & \multicolumn{5}{|c|}{$\begin{array}{c}\text { 5-Year Difference in Patents per 100,000 } \\
\text { People for } 1980 \text { to } 2010\end{array}$} \\
\hline & (1) & $(2)$ & $(3)$ & $(4)$ & $(5)$ \\
\hline $\operatorname{Immigration}_{d}^{t}$ & $\begin{array}{l}0.115^{* * *} \\
(0.040)\end{array}$ & $\begin{array}{c}0.117^{* * * *} \\
(0.042)\end{array}$ & $\begin{array}{c}0.114^{* * *} \\
(0.040)\end{array}$ & $\begin{array}{c}0.105^{* * *} \\
(0.038)\end{array}$ & $\begin{array}{c}0.093^{* * *} \\
(0.035)\end{array}$ \\
\hline Population Density (1970) & & $\begin{array}{l}-0.002 \\
(0.003)\end{array}$ & & & \\
\hline Patents per 1,000 People (1975) & & & $\begin{array}{c}0.169 * * \\
(0.063)\end{array}$ & & \\
\hline Share High School Education (1970) & & & & $\begin{array}{c}33.941^{* * *} \\
(12.236)\end{array}$ & \\
\hline Share $4+$ Years College (1970) & & & & & $\begin{array}{c}124.163^{* * *} \\
(33.694)\end{array}$ \\
\hline $\mathrm{N}$ & 18,846 & 18,840 & 18,840 & 18,846 & 18,846 \\
\hline First Stage F-Stat & 911 & 1,661 & 911 & 945 & 1,017 \\
\hline AR Wald F-Test p-value & 0.010 & 0.011 & 0.010 & 0.013 & 0.015 \\
\hline Geography FE & State & State & State & State & State \\
\hline Time FE & Yes & Yes & Yes & Yes & Yes \\
\hline
\end{tabular}

Notes: This table reports the results of our IV specification, described in equation (1), where the dependent variable is the change in patenting per 100,000 people (population is based on baseline 1970 levels) and the endogenous variable is non-European immigration (1,000s) to $d$ in $t$. Column 1 repeats our main specification, whereas columns 2-5 add as a control county d's population density in 1970, patents per 1,000 people in 1975 (1970 population is used to match the dependent variable), share of high school educated, and share of the population with $4+$ years of college, respectively. We report the first-stage $F$-statistic on the excluded instrument and the p-value for the Anderson-Rubin Wald F test for each specification. Standard errors are clustered by state for all specifications, and $*, * *$, and $* * *$ denote statistical significance at the $10 \%, 5 \%$, and $1 \%$ levels, respectively. 
Appendix Table 8: Robustness - Alternative Samples

\begin{tabular}{|c|c|c|c|c|c|}
\hline & \multicolumn{5}{|c|}{ Difference in Patenting per 100,000 People Post 1980} \\
\hline & Мехiсо & China & India & Philippines & Vietnam \\
\hline & $(1)$ & $(2)$ & (3) & (4) & $(5)$ \\
\hline \multicolumn{6}{|c|}{ Panel A: Excluding Given Country } \\
\hline Immigration $_{d}^{t}$ & $\begin{array}{c}0.093^{* * *} \\
(0.031)\end{array}$ & $\begin{array}{c}0.116^{* * *} \\
(0.041)\end{array}$ & $\begin{array}{c}0.115^{* * *} \\
(0.040)\end{array}$ & $\begin{array}{c}0.115^{* * *} \\
(0.040)\end{array}$ & $\begin{array}{c}0.115^{* * *} \\
(0.040)\end{array}$ \\
\hline $\mathrm{N}$ & 18,846 & 18,846 & 18,846 & 18,846 & 18,846 \\
\hline First Stage F-Stat & 666 & 1,576 & 1,267 & 1,261 & 1,179 \\
\hline AR Wald F-Test p-value & 0.006 & 0.011 & 0.010 & 0.010 & 0.010 \\
\hline \multicolumn{6}{|c|}{ Panel B: Including Only Given Country } \\
\hline $\operatorname{Immigration}_{d}^{t}$ & $\begin{array}{c}0.117^{* * *} \\
(0.042)\end{array}$ & $\begin{array}{l}0.079 * * \\
(0.034)\end{array}$ & $\begin{array}{c}0.153^{* * *} \\
(0.042)\end{array}$ & $\begin{array}{l}0.154^{* *} \\
(0.064)\end{array}$ & $\begin{array}{l}0.140^{*} \\
(0.078)\end{array}$ \\
\hline $\mathrm{N}$ & 18,846 & 18,846 & 18,846 & 18,846 & 18,846 \\
\hline First Stage F-Stat & 2,094 & 535 & 318 & 22 & 2 \\
\hline AR Wald F-Test p-value & 0.011 & 0.027 & 0.001 & 0.001 & 0.050 \\
\hline $\begin{array}{l}\text { Geography FE } \\
\text { Time FE }\end{array}$ & $\begin{array}{l}\text { State } \\
\text { Yes }\end{array}$ & $\begin{array}{l}\text { State } \\
\text { Yes }\end{array}$ & $\begin{array}{l}\text { State } \\
\text { Yes }\end{array}$ & $\begin{array}{l}\text { State } \\
\text { Yes }\end{array}$ & $\begin{array}{l}\text { State } \\
\text { Yes }\end{array}$ \\
\hline \multicolumn{6}{|c|}{$\begin{array}{l}\text { Notes: This table reports the results of our IV specification, described in equation }(1) \text {, } \\
\text { run on alternative samples where the dependent variable is the change in patenting } \\
\text { per 100,000 people (population is based on baseline } 1970 \text { levels) and the endogenous } \\
\text { variable is non-European immigration }(1,000 \mathrm{~s}) \text { to } d \text { in } t \text {. In instrument construction, } \\
\text { each column either drops migrants from the given country (Panel A) or drops all other } \\
\text { migrants except those from the specified country (Panel B) from the sum in equation } \\
\text { (5) for each of the five largest sending countries post } 1975 \text { (Mexico, China, India, } \\
\text { Philippines, and Vietnam). We report the first-stage } F \text {-statistic on the excluded } \\
\text { instrument and the p-value for the Anderson-Rubin Wald F test for each specification, } \\
\text { and note the instrument constructed using only migrants from Vietnam does not } \\
\text { significantly predict non-European immigration. Standard errors are clustered by } \\
\text { state for all specifications, and *, **, and } * * * \text { denote statistical significance at the } \\
10 \%, 5 \% \text {, and } 1 \% \text { levels, respectively. }\end{array}$} \\
\hline
\end{tabular}


Appendix Table 9: Panel Regressions of Inflows of Native Migrants on Non-European ImmiGRATION

\begin{tabular}{lcc}
\hline & \multicolumn{2}{c}{$\begin{array}{c}\text { Inflows of } \\
\text { All }\end{array}$} \\
& Natives & $\begin{array}{c}\text { Non-Hispanic } \\
\text { White Natives }\end{array}$ \\
\cline { 2 - 3 } & $(1)$ & $(2)$ \\
\hline Immigration $_{d}^{t}$ & $3.675^{* * *}$ & $2.100^{* * *}$ \\
& $(0.616)$ & $(0.406)$ \\
$\mathrm{N}$ & 9,415 & 9,415 \\
First Stage F-Stat & 3,484 & 3,484 \\
AR Wald F-Test p-value & 0.000 & 0.000 \\
\hline Geography FE & State & State \\
Time FE & Yes & Yes \\
\hline
\end{tabular}

Notes: This table reports the results of our second-stage specification, described in equation (1), for the migration of natives $(1,000$ s) into county $d$ in period $t$ (for 1980, 1990, and 2000) with non-European immigration $(1,000 \mathrm{~s})$ to $d$ in $t$ as the endogenous variable. Note, migrants who moved into county $d$ from a foreign country are excluded. We report the first-stage $F$-statistic on the excluded instrument and the p-value for the Anderson-Rubin Wald F test for each specification. Standard errors are clustered by state for all specifications and $* * *$, and $* * *$ denote statistical significance at the $10 \%, 5 \%$, and $1 \%$ levels, respectively. 


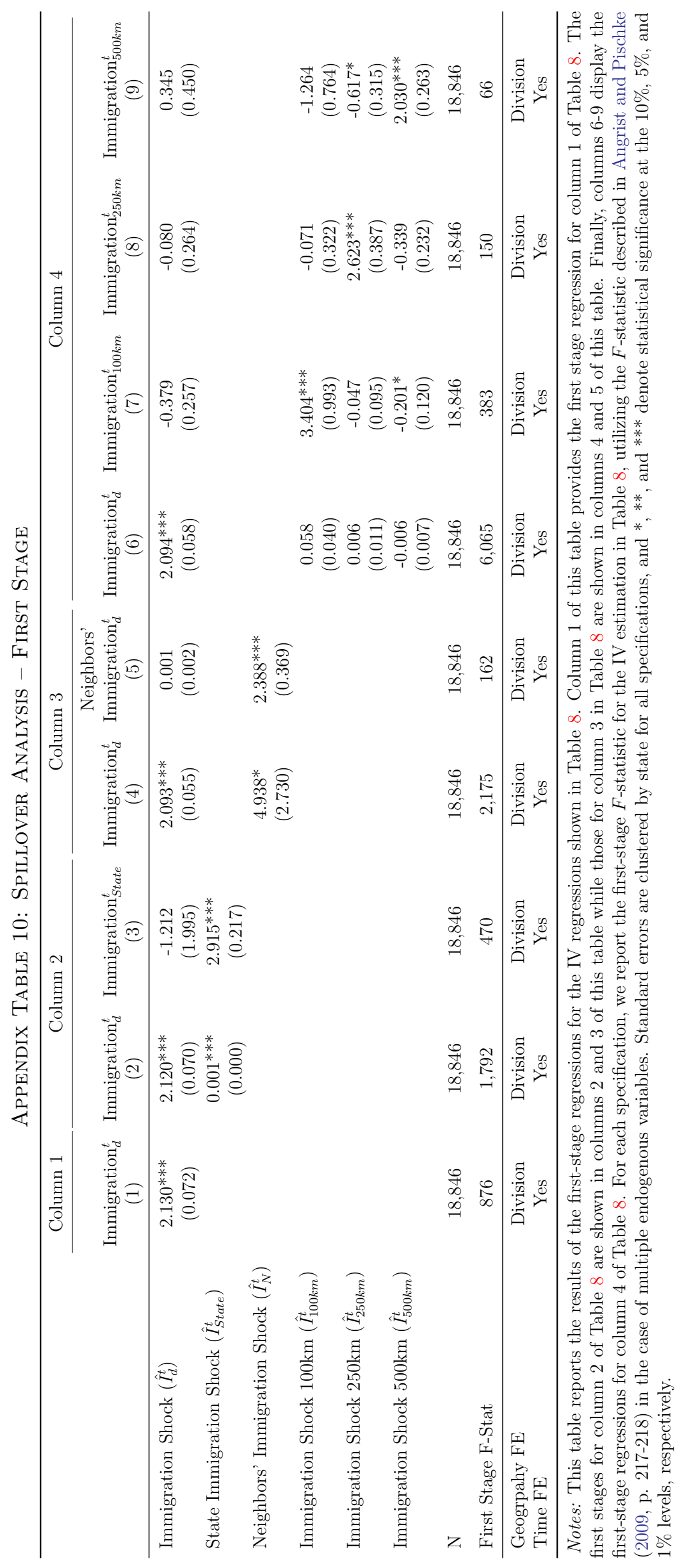


Appendix Table 11: Growth Models and Population Change

\begin{tabular}{|c|c|c|c|}
\hline & \multicolumn{2}{|c|}{$\begin{array}{c}\text { Difference in Patenting per } \\
100,000 \text { People Post } 1980\end{array}$} & \multirow{2}{*}{$\begin{array}{c}\text { IHS of Patenting } \\
\text { Post } 1975 \\
(3)\end{array}$} \\
\hline & (1) & $(2)$ & \\
\hline Immigration $_{d}^{t}$ & $\begin{array}{c}0.115^{* * *} \\
(0.040)\end{array}$ & $\begin{array}{c}0.598^{* * *} \\
(0.105)\end{array}$ & \\
\hline $\mathrm{sq}\left(\operatorname{Immigration}_{d}^{t}\right)$ & & $\begin{array}{c}-0.001^{* * *} \\
(0.000)\end{array}$ & \\
\hline IHS(Immigration $_{d}^{t}$ ) & & & $\begin{array}{c}1.723^{* * *} \\
(0.111)\end{array}$ \\
\hline $\mathrm{N}$ & 18,846 & 18,846 & 21,987 \\
\hline First Stage F-Stat (first coefficient) & 911 & 95 & 94 \\
\hline First Stage F-Stat (second coefficient) & & 11231.347 & \\
\hline AR Wald F-Test p-value & 0.010 & 0.000 & 0.000 \\
\hline Geography FE & State & State & State \\
\hline Time FE & Yes & Yes & Yes \\
\hline
\end{tabular}

Notes: This table reports the results of our IV specification, described in equation (1), for changes in patenting per 100,000 people (columns 1 and 2) and the inverse hyperbolic sine (IHS) of patenting (column 3), where patenting is defined as the number of patents filed in the five-year period. Column 1 repeats our main specification while column 2 adds as a second endogenous variable the square of non-European immigration $(1,000 \mathrm{~s})$ to $d$ in $t$. Column 3 includes as endogenous variable the IHS of non-European immigration $(1,000 \mathrm{~s})$ in $d$ at $t$, respectively. For each specification, we report the first-stage $F$-statistic(s), utilizing the $F$-statistic described in Angrist and Pischke (2009, p. 217-218) in the case of multiple endogenous variables. We also provide the p-value for the Anderson-Rubin Wald $\mathrm{F}$ test for each specification. Standard errors are clustered by state for all specifications, and *, **, and ${ }^{* * *}$ denote statistical significance at the $10 \%, 5 \%$, and $1 \%$ levels, respectively. 
MEXICO

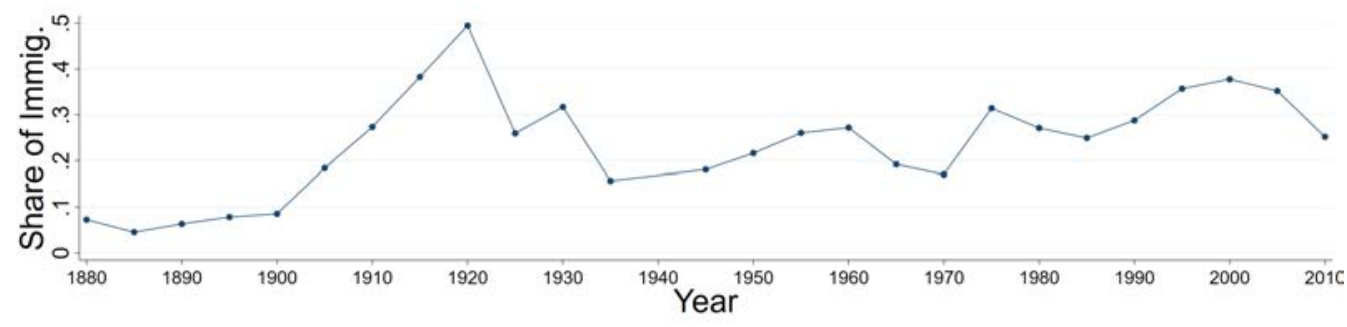

CHina

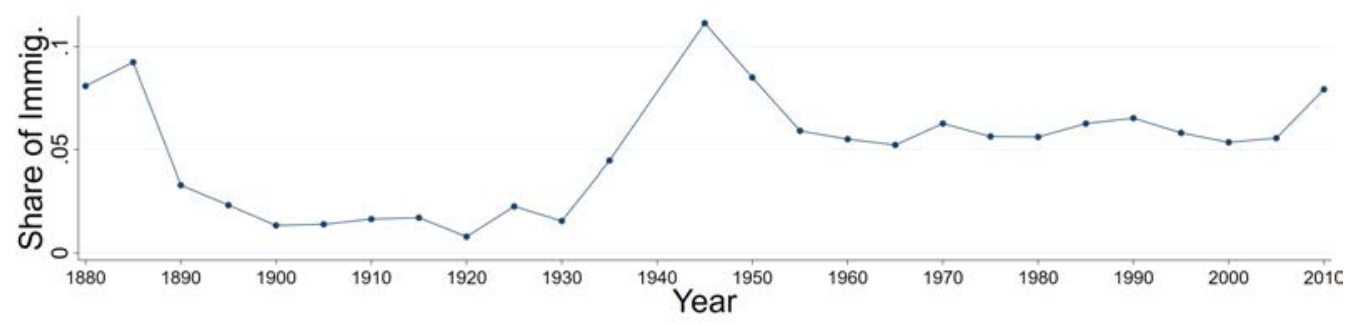

INDIA

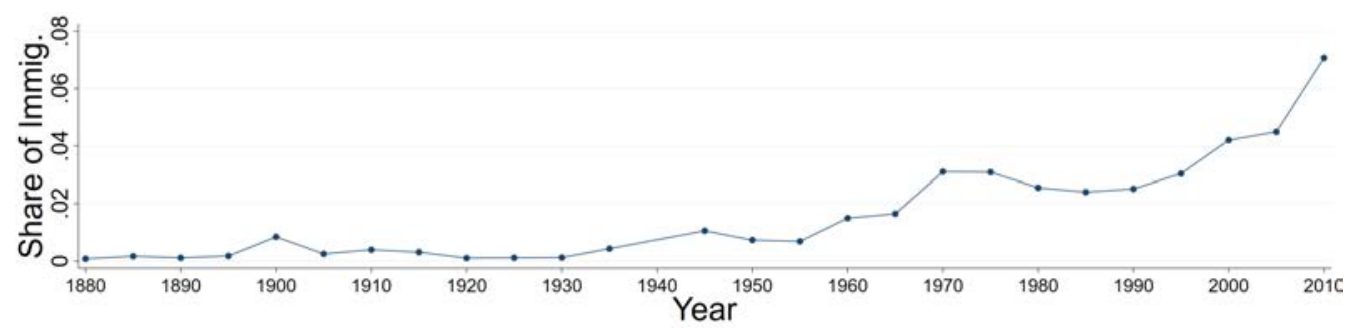

Philippines

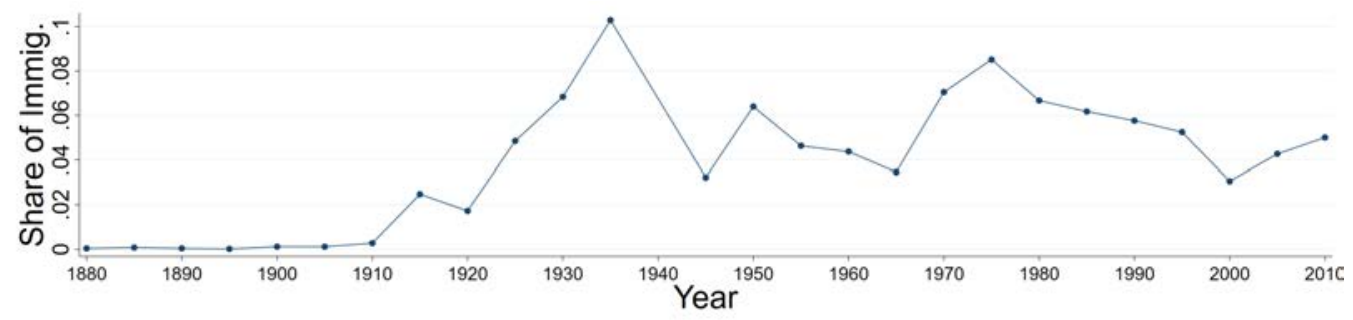

VIETNAM

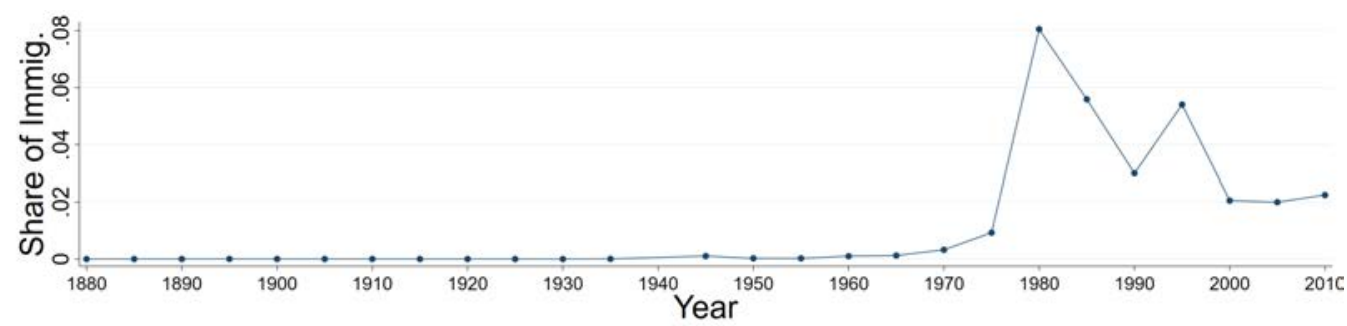

Appendix Figure 1: Share Non-European Immigrants to the US By Origin COUNTRY

Notes: This figure plots the share of non-European immigration into the US from the 5 non-European origin nations with the largest cumulative immigration to the US: Mexico, China, India, Philippines, and Vietnam. The figure highlights variation in the push factor, showing how the number of migrants from a given origin country $o$ varies over time. 

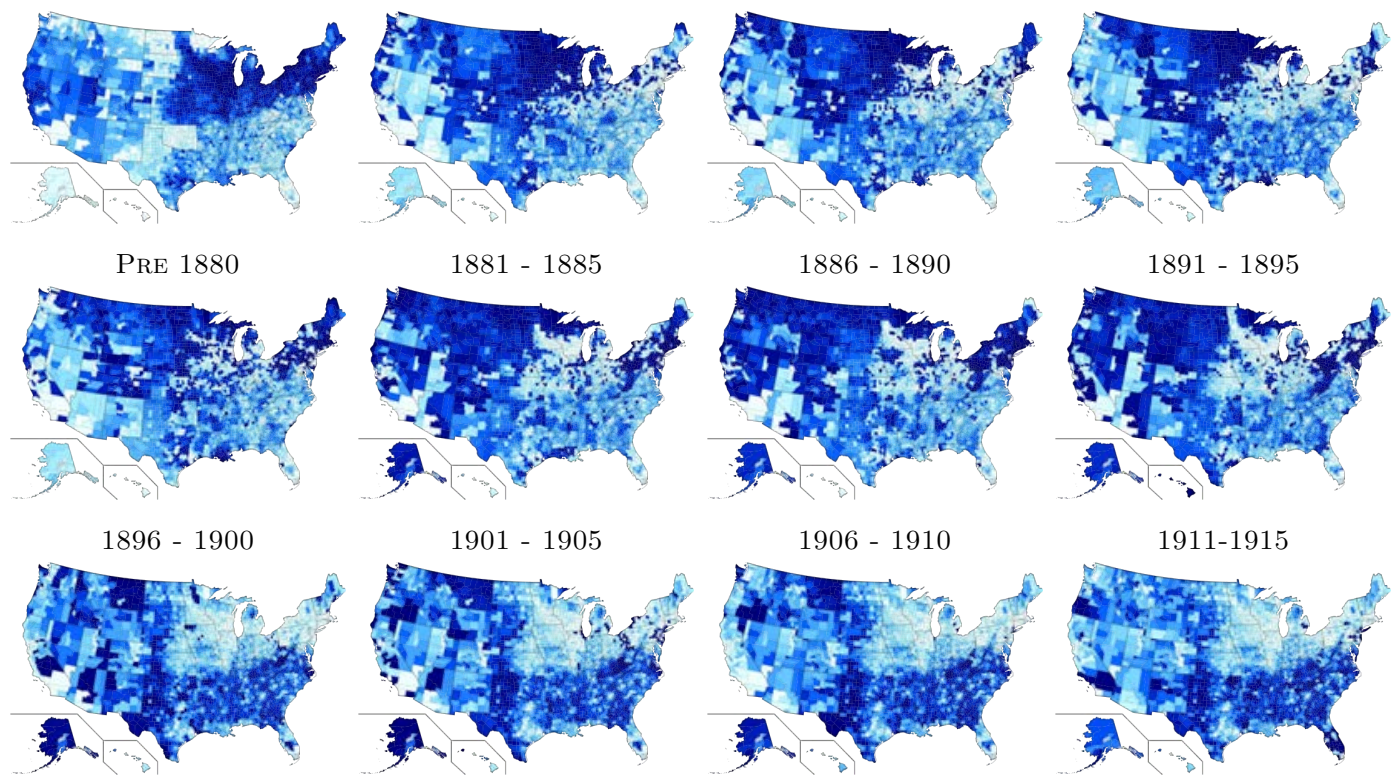

1911-1915

1916-1920

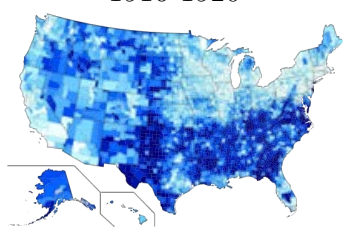

$1921-1925$

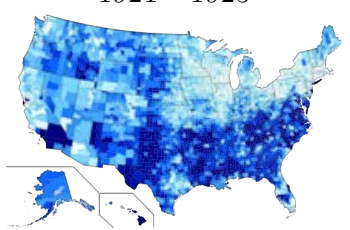

$1926-1930$

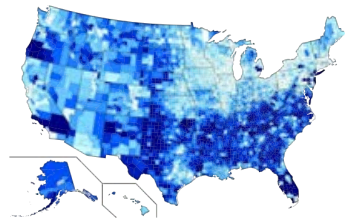

1935 - 1944

$1945-1949$

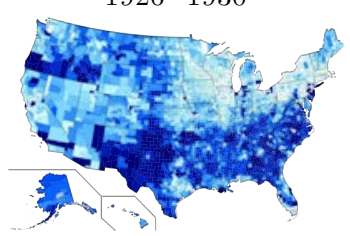

$1925-1934$
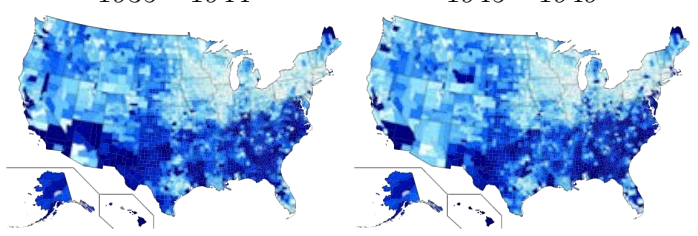

1950 - 1954
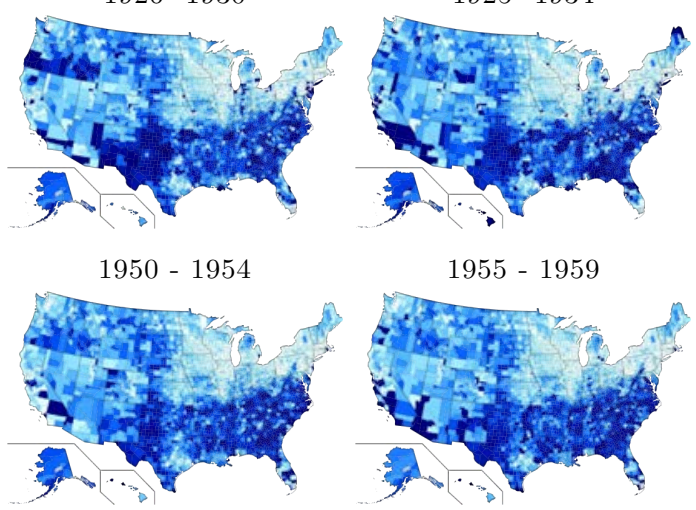

$1955-1959$
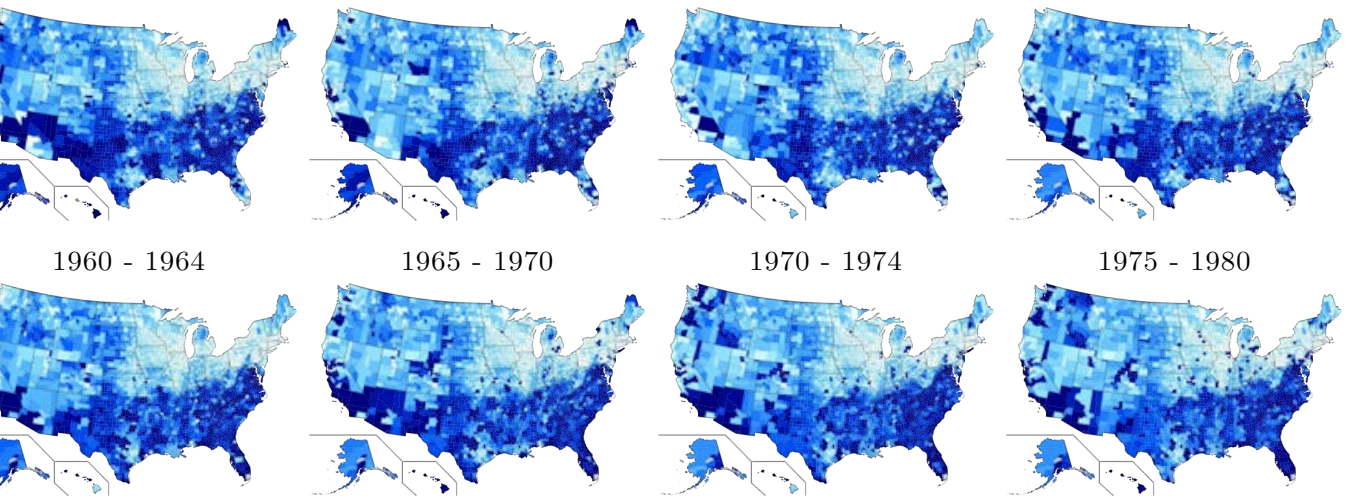

$1980-1984$

$1985-1990$

$1991-1995$

$1996-2000$
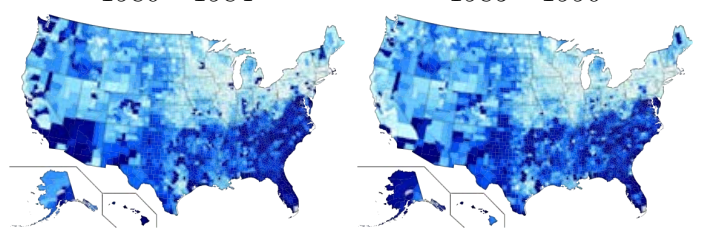

$2006-2010$

$2001-2005$

Appendix Figure 2: Destinations of European Immigrants to the US

Notes: This figure maps immigration flows into US counties by 5-year periods (except between 1930 and 1950). We regress the number of European immigrants into US county $d$ at time $t, I_{d}^{t}$, on destination county $d$ and year $t$ fixed effects, and calculate the residuals. The map's color coding depicts the 20 quantiles of the residuals across counties and within census periods. Darker colors indicate a higher quantile. 


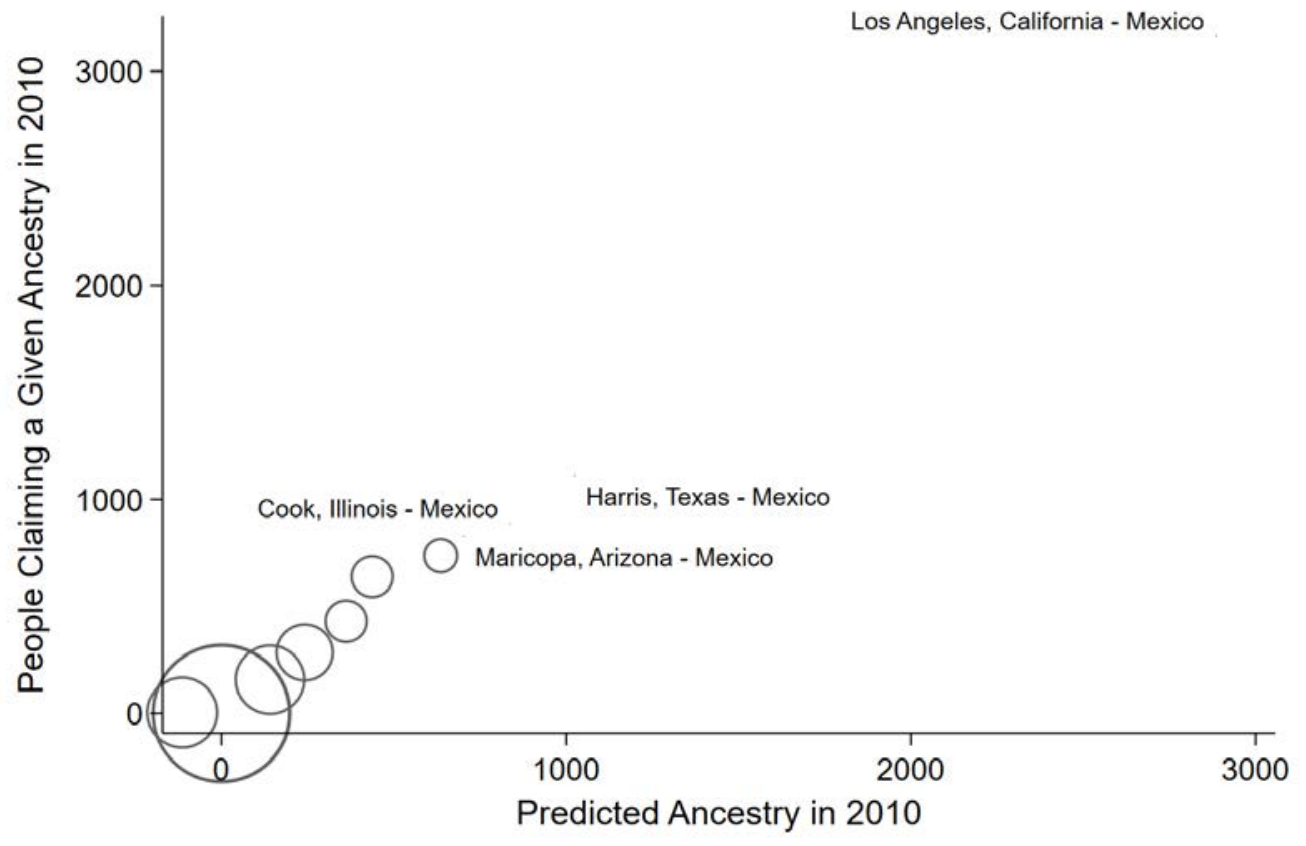

Appendix Figure 3: Step 1 - Predicting Ancestry (2010)

Notes: This figure plots actual ancestry in 2010 against predicted ancestry, as given in equation (3), with the size of each circle indicating the log number of observations in a given bin of predicted ancestry. The labeled counties are those with the highest number of individuals declaring a given ancestry in 2010. The corresponding regression of $A_{o, d}^{2010}$ on $\hat{A}_{o, d}^{2010}$, as defined in equation (3), yields an $R^{2}$ of $74.9 \%$. 


\section{B Model Appendix}

This appendix provides an equilibrium definition and balanced growth path analysis of the quantitative equilibrium regional endogenous growth model. This appendix also provides information on the solution and simulation of the model away from the balanced growth path, together with details of the structural estimation procedure.

\section{B.1 Environment}

There are $d=1, \ldots, D$ destination regions. There are $o=1, \ldots, O$ origin nations. Time $t$ is discrete.

\section{B.1.1 Final Goods Production}

A final good is produced by a firm in $d$ with the technology

$$
Y_{t}=Z_{d, t} Q_{d, t} L_{Y, d, t}^{\alpha}
$$

where $Q_{d, t}$ is the number of ideas used by the firm in $d$ at time $t$ and $L_{Y, d, t}$ is labor used for production purposes by the firm in region $d$ at time $t$. The elasticity of output to labor satisfies $0<\alpha<1$. The stationary exogenous shock $Z_{d, t}$ to production efficiency satisfies

$$
\ln Z_{d, t}=\rho \ln Z_{d, t-1}+\epsilon_{d, t}
$$

where the autocorrelation of the shock satisfies $0<\rho<1$. We have positive variance with $\epsilon_{d, t} \sim \mathcal{N}\left(0, \sigma_{\epsilon}^{2}\right)$, where $\sigma_{\epsilon}>0$.

\section{B.1.2 Idea Production}

A mass $M_{d, t}$ of new ideas is produced each period by a research firm with an innovation or idea production technology given by

$$
M_{d, t}=L_{M, d, t}^{\gamma} \bar{Q}_{d, t-1}^{1-\gamma},
$$

where the elasticity of innovation to researchers satisfies $0<\gamma<1$. There are positive externalities in the growth process, through which past ideas aid in the production of new ideas. $\bar{Q}_{d, t-1}$ is a weighted average of varieties invented across regions at time $t-1$ described further below. Note that we have that the mass of varieties invented in region $d$ evolves according to

$$
Q_{d, t}=M_{d, t}+Q_{d, t-1}
$$




\section{B.1.3 Regional Idea Aggregates \& Spillovers}

The mass of ideas useful to researchers in region $d$ at time is given by

$$
\bar{Q}_{d, t}=\prod_{f=1}^{D} Q_{f t}^{\alpha(d, f)} .
$$

The elasticity of region $d$ 's research-effective ideas to region $f$ 's invented ideas, is $\alpha(d, f)$. The elasticities sum to 1 for each region $d$, i.e.,

$$
\sum_{f} \alpha(d, f)=1
$$

and the elasticities are proportional to a term declining in the physical distance $\tilde{d}(d, f)$ between $d$ and $f$ with

$$
\alpha(d, f) \propto 1-\delta \tilde{d}(d, f)
$$

for some value $\delta \geq 0$. Note that two extreme cases are nested: no idea spillovers $(\delta=\infty)$ and full idea spillovers $(\delta=0)$. The baseline model described in the text imposes no spillovers with $\delta=\infty$, in which case $\bar{Q}_{d, t}=Q_{d, t}$.

\section{B.1.4 Population Structure: Residents, Immigrants, and Ancestry}

The population of region $d$ is made up of current residents and immigrants, all of whom are members of the labor force. Growth in the population comes only from immigrants, with accumulation of the labor force over time according to

$$
L_{d, t+1}=\sum_{o=1}^{O} I_{o, d, t}+L_{d, t} .
$$

Above, $I_{o, d, t}$ is the mass of immigrants from origin $o$ in destination $d$ at time $t$. The sum of migrants across all destinations $d$ from a given origin is

$$
I_{o, t}=\sum_{d} I_{o, d, t}
$$

and the sum of migrants across all origins $o$ in a given destination is

$$
I_{d, t}=\sum_{o} I_{o, d, t}
$$

The stock of residents in destination $d$ with ancestry from origin $o$ in time $t$ is given by $A_{o, d, t}$ which evolves over time according to $A_{o, d, t+1}=I_{o, d, t}+A_{o, d, t}$. Aggregates $A_{o, t}$ and $A_{d, t}$ are defined analogously to $I_{o, t}$ and $I_{d, t}$ above. 


\section{B.1.5 Immigrant Population Dynamics \& Destination Choices}

The supply of migrants exogenously grows at rate $n$ but is also subject to some stationary iid shocks, i.e.,

$$
I_{o, t}=(1+n)^{t} e^{\nu_{o, t}}
$$

where the shocks $\nu_{t}^{o}$ are normal with mean 0 and variance $\sigma_{\nu}^{2}$. Individual migrants from origin $o$ within the continuum of migrants $I_{o, t}$ statically optimize over destinations $d$ according to a discrete choice framework. A migrant $\mu$ 's realized (static) utility from migrating to destination $d$ in period $t$ is

$$
u_{o, d, t}(\mu)=W_{d, t}^{\lambda}\left(\frac{A_{o, d, t}}{A_{o, t}}\right)^{1-\lambda} e^{-\tau_{o, d, t}} \varepsilon_{d, t}(\mu)
$$

where $\varepsilon_{d, t}(\mu)$ are iid extreme-value distributed shocks across migrants $\mu$ with dispersion parameter $\theta, \tau_{o, d, t} \sim \mathcal{N}\left(0, \sigma_{\tau}^{2}\right)$ are iid normal shocks representing bilateral costs, and the relative weight on wages versus ancestry composition satisfies $0<\lambda<1$.

\section{B.1.6 Resident Labor Supply}

Each resident in the continuum of mass $L_{d, t}$ in destination $d$ and time $t$ supplies one unit of labor inelastically to only its local labor market and can choose whether to allocate this labor to the output sector " $Y$ " or the innovation sector " $M$," resulting in the following identity: $L_{Y, d, t}+L_{M, d, t}=L_{d, t}$.

\section{B.2 Equilibrium Definition}

An equilibrium in this economy is a sequence of local wages $\left\{W_{d, t}\right\}_{d}$, patent prices $\left\{p_{d, t}\right\}_{d}$, immigration flows $\left\{I_{o, d, t}\right\}_{o, d},\left\{I_{d, t}\right\}_{d},\left\{I_{o, t}\right\}_{o}$, ancestry levels $\left\{A_{o, d, t}\right\}_{o, d},\left\{A_{d, t}\right\}_{d},\left\{A_{o, t}\right\}_{o}$, labor force levels $\left\{L_{d, t}\right\}_{d}$, labor force allocations $\left\{L_{M, d, t}, L_{Y, d, t}\right\}_{d}$, output levels $\left\{Y_{d, t}\right\}_{d}$, patent flows $\left\{M_{d, t}\right\}_{d}$, local idea levels $\left\{Q_{d, t}\right\}_{d}$, research knowledge levels $\left\{\bar{Q}_{d, t}\right\}$, and productivity levels $\left\{Z_{d, t}\right\}_{d}$ such that the following conditions hold.

\section{B.2.1 Final Goods Producers Optimize}

Taken as given the numeraire price of the nationally traded output good, local wages $W_{d, t}$, patent prices $p_{d, t}$, local idea levels $Q_{d, t-1}$, and local productivity levels $Z_{d, t}$ as given, the competitive local final goods producer in region $d$ chooses patent demand $M_{d, t}$ and production labor 
demand $L_{Y, d, t}$ to maximize static profits

$$
\max _{M_{d, t}, L_{Y, d, t}} Z_{d, t}\left(M_{d, t}+Q_{d, t-1}\right) L_{Y, d, t}^{\alpha}-W_{d, t} L_{Y, d, t}-p_{d, t} M_{d, t}
$$

This optimization leads to two input optimality conditions listed below.

\section{B.2.2 Research Firms Optimize}

Taking as given the price of new varieties or patents $p_{d, t}$ and the wage $W_{d, t}$, the research firm demands research labor $L_{M, d, t}$ to maximize flow profits according to

$$
\max _{L_{M, d, t}} p_{d, t} L_{M, d, t}^{\gamma} \bar{Q}_{d, t-1}^{1-\gamma}-W_{d, t} L_{M, d, t}
$$

Note that the underlying timing here requires that the research firm only be paid for a single period's use of their new ideas or varieties, which are assumed to become freely available to all local firms after one period. This optimization leads to two input optimality conditions listed below, which we emphasize represent a static research choice given our assumption on the timing of expiration of protection of new ideas.

\section{B.2.3 Immigrants Optimize}

Taking as given wages $\left\{W_{d, t}\right\}_{d}$ in all regions, as well as ancestry levels $\left\{A_{o, d, t}\right\}_{o, d}$ and $\left\{A_{o, t}\right\}$, an individual immigrant from origin $o$ in period $t$ optimally chooses their destination $d$ to maximize their static utility

$$
u_{o, d, t}(\mu)=W_{d, t}^{\lambda}\left(\frac{A_{o, d, t}}{A_{o, t}}\right)^{1-\lambda} e^{-\tau_{o, d, t}} \varepsilon_{d, t}(\mu) .
$$

As usual, this structure together with the distributional assumption on $\varepsilon_{d, t}(\mu)$ leads via a discrete-choice law of large numbers across migrants to immigration shares given by

$$
I_{o, d, t}=I_{o, t}\left(\frac{W_{d, t}^{\lambda \theta}\left(\frac{A_{o, d, t}}{A_{o, t}}\right)^{(1-\lambda) \theta} e^{-\theta \tau_{o, d, t}}}{\sum_{k=1}^{D} W_{k t}^{\lambda \theta}\left(\frac{A_{o, k, t}}{A_{o, t}}\right)^{(1-\lambda) \theta} e^{-\theta \tau_{o, k, t}}}\right)
$$

\section{B.2.4 Residents Optimize}

Individual residents from the labor force of mass $L_{d, t}$ optimally choose whether to supply labor in the ideas sector or output sector in their local region. This optimization requires, if labor used in both sectors is positive in equilibrium, that the workers be indifferent across sectors and face a common wage $W_{d, t}$ in both final goods and idea production. 
Note that the assumptions we have made, which constrain all profit maximization problems by firms and labor decisions by immigrants and residents to be static, do not require us to specify further the nature of household preferences, the details of the nationally traded goods market, nor the intertemporal prices of any assets or savings. To characterize the joint equilibrium dynamics of innovation, immigration, wages, and output, these supplemental details can remain unrestricted.

\section{B.2.5 Labor Markets Clear}

The total labor demanded in final goods and ideas production in region $d$ equals the labor force $L_{Y, d, t}+L_{M, d, t}=L_{d, t}$, and the labor force evolves dynamically according to the optimal location decisions of immigrants $L_{d, t+1}=I_{o, t}+L_{d, t}$.

\section{B.2.6 Ideas Markets Clear}

The patent or variety flows demanded by the final goods firm in region $d$ equal the patent or varieties produced by the research firms in region $d$ at the value $M_{d, t}$.

\section{B.2.7 Productivity Levels Evolve Exogenously}

Productivity $Z_{d, t}$ in region $d$ evolves stochastically and exogenously according to

$$
\ln Z_{d, t}=\rho \ln Z_{d, t-1}+\epsilon_{d, t}
$$

where shocks are iid according to $\epsilon_{d, t} \sim \mathcal{N}\left(0, \sigma_{d}^{2}\right)$.

\section{B.3 Equilibrium Conditions}

The equilibrium of the economy can be summarized as a system of $2 O+D \times(2 O+10)$ nonlinear equations in $2 O+D \times(2 O+10)$ endogenous and exogenous variables. These equations are listed below.

- $O$ equations characterizing the immigration push process $I_{o, t}$ from origin $o$ to all destinations at time $t$

$$
I_{o, t}=(1+n)^{t} e^{\nu_{o, t}}, \quad \nu_{o t} \sim N\left(0, \sigma_{\nu}^{2}\right)
$$

- $O \times D$ equations characterizing $I_{o, d, t}$, the immigration flows from origin $o$ to destination $d$ at time $t$ 


$$
\begin{gathered}
I_{o, d, t}=I_{o, t}\left(\frac{W_{d, t}^{\lambda \theta}\left(\frac{A_{o, d, t}}{A_{o, t}}\right)^{(1-\lambda) \theta} e^{-\theta \tau_{o, d, t}}}{\sum_{k=1}^{D} W_{k t}^{\lambda \theta}\left(\frac{A_{o, k, t}}{A_{o, t}}\right)^{(1-\lambda) \theta} e^{-\theta \tau_{o, k, t}}}\right) . \\
\tau_{o k t} \sim \mathcal{N}\left(0, \sigma_{\tau}^{2}\right)
\end{gathered}
$$

Note that $I_{o, t}=\sum_{d=1}^{D} I_{o, d, t}$ is redundant based on the equations above.

- $O \times D$ equations linking ancestry shares to immigration flows

$$
A_{o, d, t+1}=A_{o, d, t}+I_{o, d, t}
$$

- $O$ equations linking total ancestry stocks to regional ancestry stocks

$$
A_{o, t}=\sum_{d=1}^{D} A_{o, d, t}
$$

- $D$ equations linking population dynamics to immigration.

$$
L_{d, t+1}=L_{d, t}+\sum_{o=1}^{O} I_{o, d, t}
$$

- $D$ equations with the final goods production function for $Y_{d, t}$

$$
Y_{d, t}=Z_{d, t} Q_{d, t} L_{Y, d, t}^{\alpha}
$$

- $D$ equations characterizing exogenous local productivity dynamics

$$
\ln Z_{d, t}=\rho \ln Z_{d, t-1}+\epsilon_{d, t}, \quad \epsilon_{d, t} \sim \mathcal{N}\left(0, \sigma_{d}^{2}\right)
$$

- $D$ equations with the idea production function for the mass of new ideas $M_{d, t}$

$$
M_{d, t}=L_{M, d, t}^{\gamma} \bar{Q}_{d, t-1}^{1-\gamma}
$$

- $D$ equations characterizing idea dynamics in each region

$$
Q_{d, t}=M_{d, t}+Q_{d, t-1}
$$

- $D$ equations summarizing spillovers through the effective ideas available to researchers in $d$ at time $t, \bar{Q}_{d, t}$ :

$$
\bar{Q}_{d, t}=\prod_{f=1}^{D} Q_{f t}^{\alpha(d, f)}
$$


- $D$ equations linking labor used in production $L_{Y, d, t}$ inversely to the wage

$$
\alpha Z_{d, t} Q_{d, t} L_{Y, d, t}^{\alpha-1}=W_{d, t}
$$

- $D$ equations linking labor used in research $L_{M, d, t}$ inversely to the wage

$$
\gamma p_{d, t} L_{M, d, t}^{\gamma-1} \bar{Q}_{d, t-1}^{1-\gamma}=W_{d, t}
$$

- $D$ equations linking the price of new ideas positively to the local productivity shock and labor used in production.

$$
Z_{d, t} L_{Y, d, t}^{\alpha}=p_{d, t} .
$$

- $D$ equations for labor market clearing

$$
L_{M, d, t}+L_{Y, d, t}=L_{d, t}
$$

\section{B.4 Balanced Growth Path Growth Rates}

We say that variable $X$ grows at rate $g_{X}$ if $X_{t}=\left(1+g_{X}\right) X_{t-1}$ or equivalently if $X_{t} \propto\left(1+g_{X}\right)^{t}$. We guess and verify that the equilibrium conditions are satisfied with a symmetric balanced growth path (BGP) structure. Assume that all shocks are equal to 0 , i.e., $\tau_{o, d, t}=0, \epsilon_{d, t}=0$, and $\nu_{o, t}=0$. Note that if $g_{Q}$ is the growth rate of $Q_{d, t}$ for each region, then $\bar{Q}_{d, t}$ also trivially grows at rate $g_{Q}$, since $\sum_{f} \alpha(d, f)=1$ for all $d$. Then, note that the growth rate of new ideas in each region is given by

$$
\frac{M_{d, t}}{Q_{d, t-1}}=\left(\frac{L_{M, d, t}}{Q_{d, t-1}}\right)^{\gamma}\left(\frac{\bar{Q}_{d, t-1}}{Q_{d, t-1}}\right)^{1-\gamma}
$$

On a balanced growth path we have

$$
\begin{gathered}
g_{Q}=\frac{M_{d, t}}{Q_{d, t-1}} \\
g_{Q}=\left(\frac{L_{M, d, t}}{Q_{d, t-1}}\right)^{\gamma}\left(\frac{\bar{Q}_{d, t-1}}{Q_{d, t-1}}\right)^{1-\gamma} \\
g_{Q} \propto\left(\frac{L_{M, d, t}}{Q_{d, t-1}}\right)^{\gamma}
\end{gathered}
$$

which implies that

$$
L_{M, d, t} \propto Q_{d, t-1} \propto Q_{d, t} .
$$

In other words, $L_{M}$ and $Q$ and $\bar{Q}$ grow at the same rate in each region with

$$
g_{Q}=g_{\bar{Q}}=g_{L_{M}} .
$$


Intuitively, this means that in the long run, only increased research labor input drives growth, a direct implication of the fact that this model falls into the class of semi-endogenous growth models highlighted by Jones (1995). We also immediately have from the optimality condition for research labor input demand that

$$
\gamma p_{d, t}\left(\frac{L_{M, d, t}}{\bar{Q}_{d, t-1}}\right)^{\gamma-1}=W_{d, t}
$$

Given that $L_{M, d, t} \propto \bar{Q}_{d, t-1}$, we have that

$$
p_{d, t} \propto W_{d, t} \rightarrow g_{p}=g_{W}
$$

or in other words both the wage and the price of new ideas grow at the same rate. But recall the final goods input demand optimality conditions

$$
\begin{gathered}
\alpha Z_{d, t} Q_{d, t} L_{Y, d, t}^{\alpha-1}=W_{d, t} \\
Z_{d, t} L_{Y, d, t}^{\alpha}=p_{d, t} .
\end{gathered}
$$

These conditions imply that $1+g_{p}=1+g_{W}=\left(1+g_{L_{Y}}\right)^{\alpha}$. Also, since $p_{d, t} \propto W_{d, t}$ and since $Z_{d, t}$ is stationary and equal to 1 in steady state, we have that

$$
\begin{gathered}
\alpha Z_{d, t} Q_{d, t} L_{Y, d, t}^{\alpha-1} \propto Z_{d, t} L_{Y, d, t}^{\alpha} \\
Q_{d, t} L_{Y, d, t}^{\alpha-1} \propto L_{Y, d, t}^{\alpha} \\
Q_{d, t} \propto L_{Y, d, t} \rightarrow g_{Q}=g_{L_{Y}} .
\end{gathered}
$$

But then we see immediately that since $g_{L_{M}}=g_{Q}=g_{L_{Y}}$, production and research labor must be proportional to one another with

$$
L_{Y, d, t} \propto L_{M, d, t} \propto L_{d, t} \rightarrow g_{L}=g_{L_{M}}=g_{L_{Y}}=n
$$

In other words, on a balanced growth path, labor is allocated in fixed proportions to research and production purposes. Here, for the last equality we are also guessing (and later will verify through the immigration block) that total labor grows at the rate $n$. Now recall the final goods production function

$$
Y_{d, t}=Z_{d, t} Q_{d, t} L_{Y, d, t}^{\alpha}
$$

We see immediately, again since $Z_{d, t}$ is stationary and equal to 1 in steady state, that output growth rates $g_{Y}$ satisfy

$$
\left(1+g_{Y}\right)=\left(1+g_{Q}\right)\left(1+g_{L}\right)^{\alpha}=(1+n)^{1+\alpha}
$$


Also, per-capita output is given by

$$
\frac{Y_{d, t}}{P_{d, t}}=\frac{Z_{d, t} Q_{d, t} L_{Y, d, t}^{\alpha}}{P_{d, t}}
$$

so we have that per-capita output growth rates satisfy

$$
\left(1+g_{Y / P}\right)=\frac{\left(1+g_{Q}\right)\left(1+g_{L}\right)^{\alpha}}{(1+n)}=(1+n)^{\alpha},
$$

where we have used that $g_{Q}=g_{L}=n$. Note that above we guessed above that total labor grew at the gross rate $1+n$. We now show that is consistent with the immigration block. Note that on the BGP we have

$$
I_{o, t}=(1+n)^{t},
$$

and we also have that

$$
I_{o, d, t}=(1+n)^{t}\left(\frac{\left(\frac{W_{d, t}}{(1+n)^{\alpha t}}\right)^{\lambda \theta}\left(\frac{\frac{A_{o, d, t}}{(1+)^{t}}}{\frac{A_{o, t}}{(1+n)^{t}}}\right)^{(1-\lambda) \theta}}{\sum_{k=1}^{D}\left(\frac{W_{k t}}{(1+n)^{\alpha t}}\right)^{\lambda \theta}\left(\frac{\frac{A_{o, k, t}}{\left(\frac{(1+n)^{t}}{A_{o, t}}\right.}}{(1+n)^{t}}\right)^{(1-\lambda) \theta}}\right),
$$

which is consistent with $g_{I_{o}}=g_{I_{o, d}}=g_{A_{o}}=g_{A_{o, d}}=n$.

\section{B.4.1 Balanced Growth Path Equilibrium Conditions}

Given the derivations above of BGP growth rates, we can scale or detrend the variables and equations above to express them in stationary form away from the BGP. The number of variables is again $2 O+D \times(2 O+10)$, denoted with lowercase labels:

1. $i_{o, t}=\frac{I_{o, t}}{(1+n)^{t}}, O$ immigration supply shocks

2. $i_{o, d, t}=\frac{I_{o, d, t}}{(1+n)^{t}}, O \times D$ immigration flows to region $d$ from $o$ at time $t$

3. $a_{o, d, t}=\frac{A_{o, d, t}}{(1+n)^{t}}, O \times D$ ancestry stocks from $o$ in region $d$ in time $t$

4. $a_{o, t}=\frac{A_{o, t}}{(1+n)^{t}}, O$ ancestry stocks from $o$ in total in time $t$

5. $l_{d, t}=\frac{L_{d, t}}{(1+n)^{t}}, D$ total labor stocks

6. $l_{M, d, t}=\frac{L_{M, d, t}}{(1+n)^{t}}, D$ labor inputs used in innovation

7. $l_{Y, d, t}=\frac{L_{Y, d, t}}{(1+n)^{t}}, D$ labor inputs used in production

8. $y_{d, t}=\frac{Y_{d, t}}{(1+n)^{(1+\alpha) t}}, D$ outputs 
9. $D$ values of $z_{d, t}$, which is already stationary productivity $z_{d, t}=Z_{d, t}$

10. $m_{d, t}=\frac{M_{d, t}}{(1+n)^{t}}, D$ masses of new ideas

11. $q_{d, t}=\frac{Q_{d, t}}{(1+n)^{t}}, D$ masses of ideas invented locally

12. $\bar{q}_{d, t}=\frac{\bar{Q}_{d, t}}{(1+n)^{t}}, D$ aggregates of ideas useful for innovation locally

13. $w_{d, t}=\frac{W_{d, t}}{(1+n)^{\alpha t}}, D$ wages

14. $p_{d, t}=\frac{p_{d, t}}{(1+n)^{\alpha t}}, D$ prices of new ideas

These stationary variables are pinned down by the same number of nonlinear equations in stationary form, which are equivalent to the raw equilibrium conditions above but simply rescaled. The equations are:

1. Immigration push shock distributions

$$
i_{o, t}=e^{\nu_{o, t}}
$$

2. Endogenous immigration flows

$$
i_{o, d, t}=i_{o, t}\left(\frac{w_{d, t}^{\lambda \theta}\left(\frac{a_{o, d, t}}{a_{o, t}}\right)^{(1-\lambda) \theta} e^{-\theta \tau_{o, d, t}}}{\sum_{k=1}^{D} w_{k t}^{\lambda \theta}\left(\frac{a_{o, k, t}}{a_{o, t}}\right)^{(1-\lambda) \theta} e^{-\theta \tau_{o, k, t}}}\right) .
$$

3. Ancestry accumulation equations

$$
a_{o, d, t+1}=\frac{1}{1+n}\left(a_{o, d, t}+i_{o, d, t}\right)
$$

4. Ancestry across regions identity

$$
a_{o, t}=\sum_{d=1}^{D} a_{o, d, t}
$$

5. Labor force accumulation equations

$$
l_{d, t+1}=\frac{1}{1+n}\left(l_{d, t}+\sum_{o=1}^{O} i_{o, d, t}\right)
$$

6. Labor market clearing equations

$$
l_{d, t}=l_{Y, d, t}+l_{M, d, t}
$$


7. Output production functions

$$
y_{d, t}=z_{d, t} q_{d, t} l_{Y, d, t}^{\alpha}
$$

8. Regional productivity shocks stochastic processes

$$
\ln z_{d, t}=\rho \ln z_{d, t-1}+\epsilon_{d, t}
$$

9. Idea production functions

$$
m_{d, t}=l_{M, d, t}^{\gamma} \bar{q}_{d, t-1}^{1-\gamma}(1+n)^{\gamma-1}
$$

10. Idea accumulation equations

$$
q_{d, t}=m_{d, t}+\left(\frac{1}{1+n}\right) q_{d, t-1}
$$

11. Regional research knowledge aggregators

$$
\bar{q}_{d, t}=\prod_{f=1}^{D} q_{f t}^{\alpha(d, f)}
$$

12. Labor demand optimality for final goods producers

$$
w_{d, t}=\alpha z_{d, t} q_{d, t} l_{Y, d, t}^{\alpha-1}
$$

13. Labor demand optimality from research firms

$$
w_{d, t}=\gamma p_{d, t}(1+n)^{\gamma-1}\left(\frac{l_{M, d, t}}{\bar{q}_{d, t-1}}\right)^{\gamma-1}
$$

14. Idea demand optimality from final goods producers

$$
p_{d, t}=z_{d, t} l_{Y, d, t}^{\alpha}
$$

\section{B.5 Solution and Simulation}

We solve the stationary system of equations from section B.4.1 above using second-order perturbation around the nonstochastic BGP of the economy. This nonlinear solution approach is crucial for accounting for the nonlinear mapping from shocks to immigration supply $\nu_{o t}$ to immigration flows at the regional level which is state-dependent, varying with predetermined ancestry levels and current wages.

To simulate the model, we draw immigration supply shocks $\nu_{o t}$, regional productivity shocks $\epsilon_{d, t}$, and bilateral immigration cost shocks $\tau_{o, d, t}$ for a large number of periods $T=1000, O=10$ 
origins, and $D=9$ destination regions. Given a parametrization of the model, the exogenous shock draws together with the nonlinear policy functions obtained in our solution step allow for unconditional simulation of the model. This unconditionally simulated data can be processed to produce a range of moments for structural estimation of the model, which is detailed below.

We also can produce impulse response functions following the simulation approach to computing nonlinear generalized impulsed response functions from Koop et al. (1996). This involves simulating pairs of economies with and without a particular shock present, and comparing subsequent dynamics over a large number of simulations.

We implement all of these numerical model steps, i.e., solution, unconditional simulation, and impulse response calculations, using Dynare within a MATLAB environment. Given the smooth nature of our equilibrium conditions, the well behaved non-stochastic BGP, and the large number of equilibrium conditions, the Dynare package is a natural choice for numerical analysis in this context.

\section{B.6 Post-1970 Immigration Accounting Exercise}

We first extract overall population counts and counts of the population of the foreign born from decadal US Census tabulations in the 1860-2010 time period (US Census Bureau, 2014). Let the total population in Census year $t P_{t}$ be made up of native $N_{t}$ and foreign-born $F_{t}$ individuals

$$
P_{t}=N_{t}+F_{t}
$$

Total population change in a Census decade must equal the sum of the change of the foreignborn and native populations

$$
\Delta P_{t}=\Delta N_{t}+\Delta F_{t}
$$

implying that the shares of population growth accounted for by natives and the foreign born must sum to 1 , i.e.,

$$
1=\frac{\Delta N_{t}}{\Delta P_{t}}+\frac{\Delta F_{t}}{\Delta P_{t}}
$$

In the decades 1860-1960 before the Immigration and Nationality Act of 1965 (INA), the foreignborn share of population growth $\frac{\Delta F_{t}}{\Delta P_{t}}$ was around $5 \%$ on average, while from 1970-2010 this contribution increased $16 \%$ to a little over $20 \%$ on average.

To understand the rough quantitative implications of a shift in foreign-born population growth of the magnitude observed in the post-1970 US data, we compute the counterfactual evolution over time of macroeconomic aggregates in our model without the increased foreignborn share of population growth. In particular, we impose a string of negative exogenous 
shocks to immigration supply, symmetric across origins, which reduce population growth by $16 \%$ relative to the BGP growth rate. The resulting cumulative declines in per-capita aggregate output, patenting, and wages, together with the cumulative decline in the aggregate labor force, resulting from this experiment are plotted in the main text.

\section{B.7 Structural Estimation}

To parameterize our model, we first externally calibrate or fix the magnitudes of various parameters to values commonly employed in the literature. To match our empirical approach, we solve and simulate the model in five-year periods, and we choose the value $n$ of exogenous population growth $n$, equal to the BGP growth rate of knowledge or ideas in our economy, to be $2 \%$ on an annualized basis. We also choose a conventional value for the labor share $\alpha=0.67$ in final goods production. Finally, based on the analysis in Caliendo et al. (2019), we match an elasticity of immigration shares to local wages of 0.5 through the choices $\lambda=0.5$ and $\theta=1$.

\section{B.7.1 Estimated Parameters}

After external calibration of the parameters noted above, there are six remaining parameters in our model:

1. Elasticity of local innovation to researchers $\gamma$

2. Autocorrelation of regional productivity shocks $\rho$

3. Volatility of regional productivity shocks $\sigma_{\epsilon}$

4. Volatility of immigration supply shocks $\sigma_{\nu}$

5. Volatility of bilateral immigratioc cost shocks $\sigma_{\tau}$

6. Linear decline in research knowledge spillovers with distance $\delta$

We structurally estimate the values of the first five parameters above using an overidentified simulated method of moments (SMM) procedure outlined below. ${ }^{35}$ For the sixth parameter, related to idea spillovers, we explore the implications of varying the parameter to extreme values implying full, frictionless spillovers of ideas across regions $(\delta=0)$ versus no idea spillovers across idea-autarkic regions $(\delta=\infty$, our baseline described in the main text). For each of these

\footnotetext{
${ }^{35}$ Note that one of our target moments is an IV regression coefficient, leading us to sometimes interchangeably refer to this approach as an indirect inference procedure in the main text.
} 
alternative cases for idea spillovers, we implement the full SMM estimation procedure below conditional upon the appropriate value of $\delta$. Note also that the values we choose for $\delta, 0$ vs $\infty$, imply spillovers that are either non-existent or independent of distance, implying that we do not need to explicitly specify the geographic structure of the model.

\section{B.7.2 Target Moments}

To discipline the values of the five estimated parameters, we target the value of six related moments:

1. IV coefficient estimating the elasticity of patenting to immigration at the county $d$ level

2. Standard deviation of origin-level immigration flows at the origin $o$ level

3. Standard deviation of destination $d$-level immigration flows

4. Standard deviation of origin $o \times$ destination $d$-level immigration flows

5. Autocorrelation of output per capita at the county $d$ level

6. Autocorrelation of patenting at the county $d$ level

Moments 1-4 and 6 are directly computable within the 1975-2010 sample used for the main reduced-form empirical results in the paper. We compute the fifth moment based on the BEA's county level GDP estimates for five-year periods within the available 2001-19 window.

Although the mapping from parameters to moments in our model is nonlinear and joint in nature, there are certain parameters particularly influential for determining the value of individual moments in our simulation. These links are intuitive, and Appendix Figure 4 plots comparative statics of the values of the moments within our model simulation as we vary some related parameters. In particular, the IV-estimated elasticity of patenting to immigration moves directly in the model with the underlying local elasticity of innovation to researchers $\gamma$. The volatilities of origin-, destination-, and origin $\times$ destination-level immigration flows depend upon the volatilities of origin-, destination-, and origin $\times$ destination-level exogenous shocks $\sigma_{\nu}, \sigma_{\epsilon}$, and $\sigma_{\tau}$, respectively. The autocorrelations of per-capita output and patenting increase with the autocorrelation of underlying regional productivity shocks $\rho$. 


\section{B.7.3 SMM Objective and Standard Errors}

First, we collect the five estimated parameters into the vector $\theta=\left(\gamma, \rho, \sigma_{\epsilon}, \sigma_{\nu}, \sigma_{\tau}\right)^{\prime}$. We similarly collect the values of the six target moments $m$ into vectors, denoting by $m(X)$ the value of these moments in the empirical data $X$, denoting by $m^{S}(\theta)$ the values of these moments based on our unconditionally simulated data in the model, and denoting by $m(\theta)$ the population values of these moments. Our SMM estimation procedure generates point estimates $\hat{\theta}$ as the solution to the minimization problem

$$
\min _{\theta}\left(m(X)-m^{S}(\theta)\right)^{\prime} W\left(m(X)-m^{S}(\theta)\right)
$$

where $W$ is a symmetric weighting matrix for the simulated moment deviations. If the moment vector behaves in an asymptotically normal fashion according to

$$
\sqrt{N}(m(X)-m(\theta)) \rightarrow_{d} \mathcal{N}(0, V)
$$

then standard SMM derivations yield asymptotic normality for the parameter estimates

$$
\sqrt{N}(\hat{\theta}-\theta) \rightarrow_{d} \mathcal{N}(0, \Sigma)
$$

where the asymptotic variance $\Sigma$ is given by the sandwich formula

$$
\Sigma=\left(1+\frac{1}{S}\right)\left(\frac{\partial m^{\prime}}{\partial \theta} W \frac{\partial m}{\partial \theta}\right)^{-1} \frac{\partial m^{\prime}}{\partial \theta} W V W \frac{\partial m}{\partial \theta}\left(\frac{\partial m^{\prime}}{\partial \theta} W \frac{\partial m}{\partial \theta}\right)^{-1}
$$

Above, $\frac{\partial m}{\partial \theta}$ is the Jacobian of model moments to parameters and $S$ is the ratio of the simulated to empirical sample sizes.

Some practical decisions must be made to compute point estimates $\hat{\theta}$ as well as a feasible estimate $\hat{\Sigma}$ of the asymptotic variance above. First, we use the identity weighting matrix $W=I$. We compute the Jacobian numerically using finite differences relative to our point estimates. To compute an estimate of the moment covariance matrix $\hat{V}$, we first impose diagonality across the moments which all differ by aggregation level and sample size. We then compute asymptotic variances for each moment using a combination of standard analytic formulas, clustering by state, and the Delta method. The resulting standard errors reported are given by $\left(\frac{\operatorname{diag} \hat{\Sigma}}{N}\right)^{0.5}$. The main text's Table 10 reports parameter estimates, standard errors, and model vs data moments for our baseline case with no idea spillovers, and Table 12 reports the same information for the alternative case with full idea spillovers. 


\section{B.8 Efficiency Units of Labor \& Education}

The empirical results in Section 5 suggest that immigration flows with higher levels of schooling cause larger increases in innovation and wages. This pattern is compatible with a simple generalization of our model differentiating between quantities and efficiency units of labor. In particular, allow for the total efficiency units of labor in a region to be given by

$$
H_{d, t}=L_{d, t} e^{\phi S_{d, t}}
$$

where $L_{d, t}$ is the size of the labor force in region $d$ in year $t, S_{d, t}$ is average years of schooling of that labor force, and $\phi>0$ is a Mincerian coefficient linking education to efficiency units of labor. This formulation of a human capital or efficiency units specification is common in the cross-country income accounting literature, e.g., Hall and Jones (1999).

To very crudely quantify $\phi$ in the context of our empirics, note that column (3) of Table 9 implies that the impact of immigrants on wage growth is $(0.757 \times 3.7+0.180) / 0.180 \approx$ 1.8797 times larger for immigrants with one standard deviation (3.7 years) more education than for immigrants with the average years of schooling. Very roughly matching this ratio to the efficiency units formulation above implies that $e^{\phi 3.7} \approx 1.8797$, so that $\phi \approx 0.17$.

Because the efficiency units structure changes effective labor supply magnitudes but does not change the rest of the structure of our model, we can very roughly and approximately gauge the importance of this potential educational heterogeneity for the impact of immigration flows in our model in a straightforward fashion. We compute the local impulse response of county-level patenting and wages to a one-standard deviation shock to immigration in three cases: 1) our baseline estimated model, 2) an extremely high education case in which immigration flows cause an increase in the average schooling level in an entire county by 1 year, and 3) an extremely low education case in which immigration flows cause a decline in the average schooling level in an entire county by 1 year. Given the average magnitude of immigration flows relative to the size of a county's local labor force, we emphasize that these are extreme, even if transparent, cases. Appendix Figure 5 shows that the peak impact of the immigration shock on patenting ranges from around 1.3 to 1.8 percent growth across these cases, while the peak impact on wages varies from around 0.19 to 0.27 percent growth, all relative to the balanced growth path or steady state case. Clearly, even considering extreme cases in which immigration flows cause relatively large shifts in average local schooling levels for a given county, these back of the envelope checks provide reassurance that the impact of immigration on local growth is robustly positive and quantitatively meaningful. 

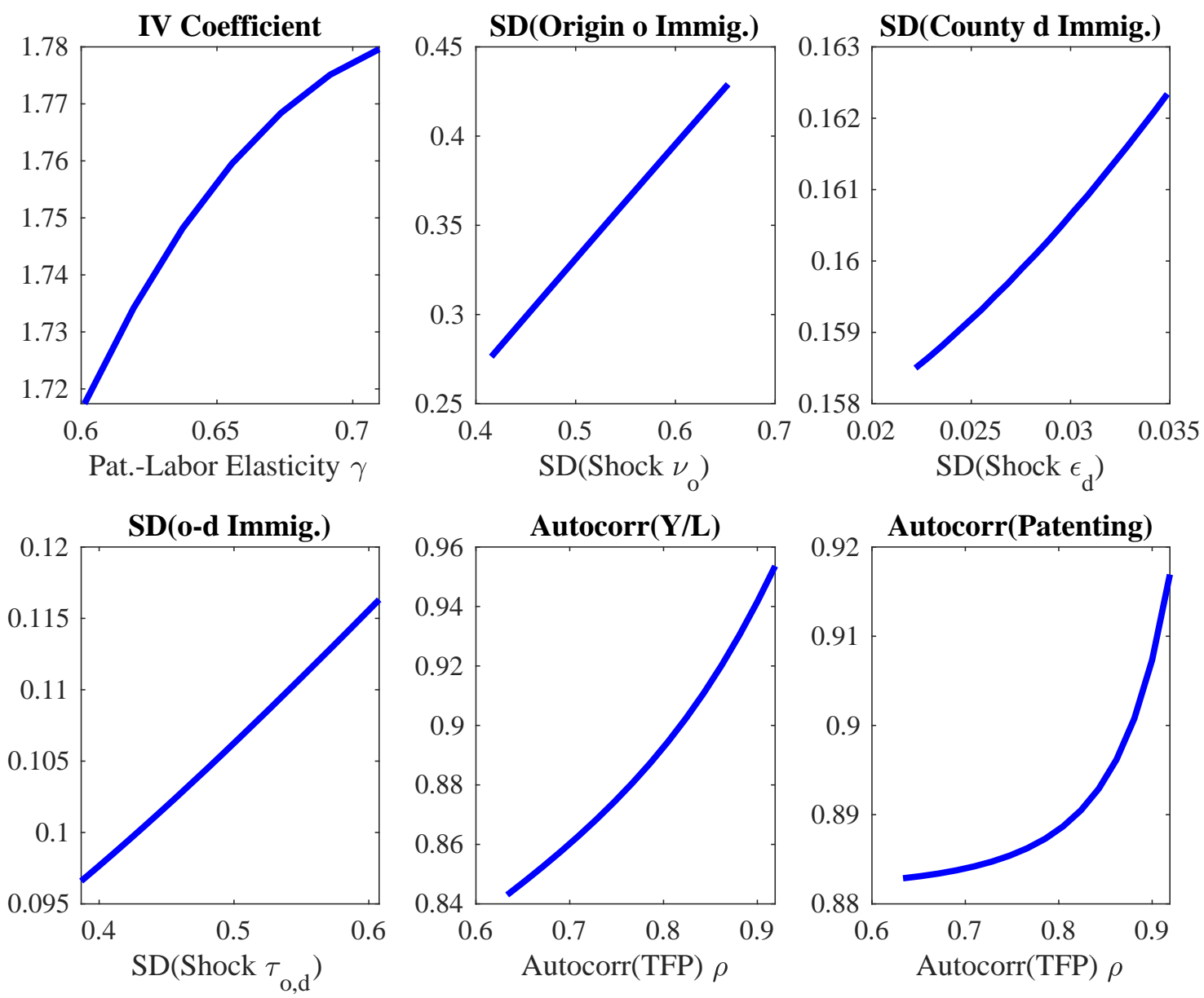

Appendix Figure 4: Moments and Parameters in the Model

Notes: Each panel in the figure plots a simulated moment targeted in the calibration of the model as a function of a single parameter. The title of each panel indicates the targeted moment and the horizontal axis indicates the parameter. The values are computed near the Baseline calibrated parameters of the model. 

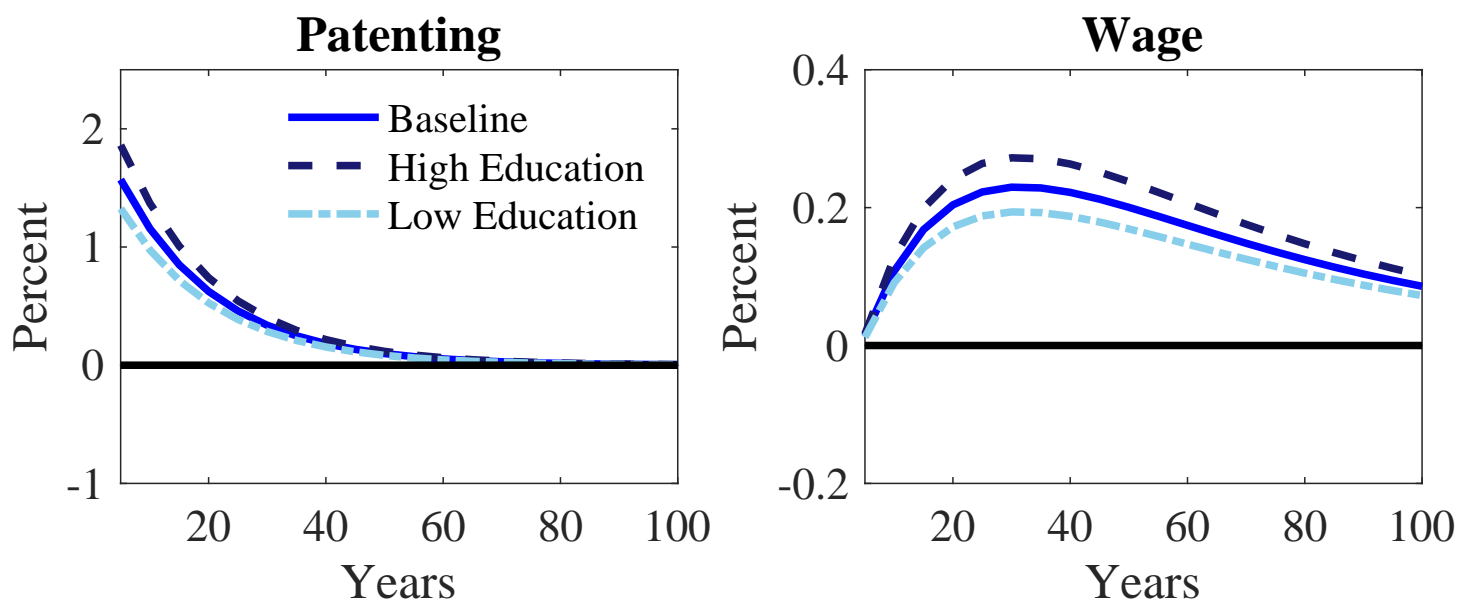

Appendix Figure 5: Moments and Parameters in the Model

Notes: The figure plots impulse response functions to a one-standard deviation immigration shock in period 1 . The left panel plots patenting $m_{d, t}$. The right panel plots the response of the wage $w_{d, t}$. The immigration shock is from a single origin $o$, and the responses of the labor force, patenting, and the wage are local responses for a county $d$. The solid blue line labelled Baseline traces the impact of an immigration shock of average education. The dashed dark blue line labelled High Education reports the impact of an immigration shock increasing local education levels by one year on average. The dashdot light blue line labelled Low Education reports the impact of an immigration shock decreasing local education levels by one year on average. The responses are in percentage point deviations from the balanced growth path. 
Appendix Table 12: Parameters and Model Fit, Full Idea Spillovers

\begin{tabular}{|c|c|c|}
\hline Panel A: Moments & Data & Model \\
\hline IV coeff., patenting ${ }_{d, t}$ on immigration $I_{d, t}$ & $\begin{array}{c}1.723 \\
(0.111)\end{array}$ & 1.720 \\
\hline Std. deviation, $o$ immigration $I_{o, t}$ & $\begin{array}{c}0.406 \\
(0.029)\end{array}$ & 0.383 \\
\hline Std. deviation $d$ immigration $I_{d, t}$ & $\begin{array}{c}0.179 \\
(0.011)\end{array}$ & 0.152 \\
\hline Std. deviation, o- $d$ immigration $I_{o, d, t}$ & $\begin{array}{c}0.072 \\
(0.012)\end{array}$ & 0.106 \\
\hline Autocorrelation, output per capita $Y_{d, t} / L_{d, t}$ & $\begin{array}{c}0.954 \\
(0.007)\end{array}$ & 0.951 \\
\hline Autocorrelation, patenting $_{d, t}$ & $\begin{array}{c}0.894 \\
(0.009)\end{array}$ & 0.910 \\
\hline Panel B: Estimated Parameters & Symbol & Value \\
\hline Elasticity, patenting to labor & $\gamma$ & $\begin{array}{c}0.837 \\
(0.029)\end{array}$ \\
\hline Autocorrelation, county TFP & $\rho$ & $\begin{array}{c}0.918 \\
(0.009)\end{array}$ \\
\hline Std. deviation, county TFP shocks & $\sigma_{\epsilon}$ & $\begin{array}{c}0.026 \\
(0.044)\end{array}$ \\
\hline Std. deviation, immigration push shocks & $\sigma_{\nu}$ & $\begin{array}{c}0.580 \\
(0.005)\end{array}$ \\
\hline Std. deviation, bilateral immigration shocks & $\sigma_{\tau}$ & $\begin{array}{c}0.526 \\
(0.043)\end{array}$ \\
\hline
\end{tabular}

Notes: The table reports the model fit and estimated parameters in the alternative model with full idea spillovers across counties. The top Panel A reports targeted data moments vs simulated model moments. The bottom Panel B reports the estimated parameters. The standard errors, in parentheses beneath momentsand estimates, are clustered by state. 